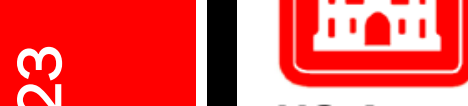

US Army Corps

of Engineers ${ }_{\circledast}$

Engineer Research and

Development Center

Environmental Security Technology Certification Program (ESTCP)

\title{
Demonstration of Subsurface Passive Acoustic Monitoring (SPAM) to Survey for and Estimate Populations of Imperiled Underwater-calling Frogs
}

Patrick J. Wolff, Brett A. DeGregorio, and Aaron N. Rice

November 2021

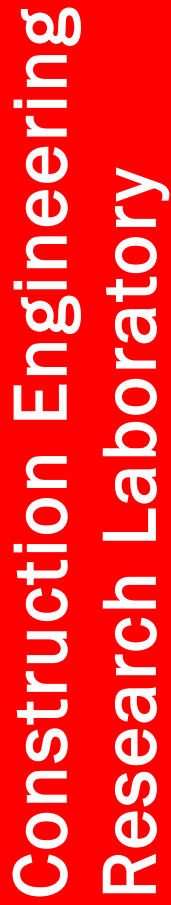
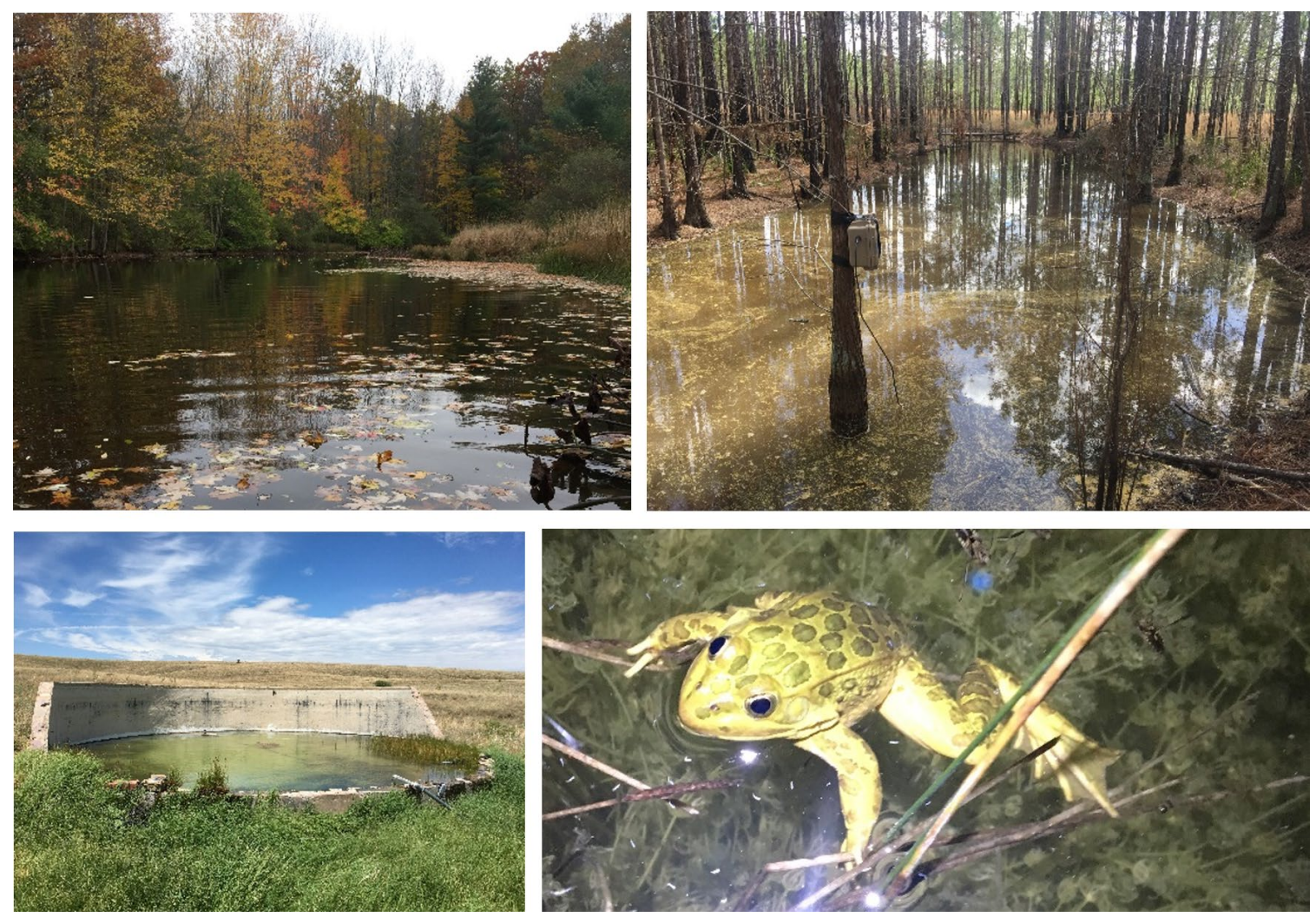
The U.S. Army Engineer Research and Development Center (ERDC) solves the nation's toughest engineering and environmental challenges. ERDC develops innovative solutions in civil and military engineering, geospatial sciences, water resources, and environmental sciences for the Army, the Department of Defense, civilian agencies, and our nation's public good. Find out more at www.erdc.usace.army.mil.

To search for other technical reports published by ERDC, visit the ERDC online library at https://erdclibrary.on.worldcat.org/discovery. 


\section{Demonstration of Subsurface Passive Acoustic Monitoring (SPAM) to Survey for and Estimate Populations of Imperiled Underwater-calling Frogs}

Patrick J. Wolff, Brett A. DeGregorio, and Aaron N. Rice

U.S. Army Engineer Research and Development Center (ERDC)

Construction Engineering Research Laboratory (CERL)

2902 Newmark Dr.

Champaign, IL 61822

Final Technical Report (TR)

Approved for public release; distribution is unlimited.

Prepared for Strategic Environmental Research and Development Program (SERDP)/

Environmental Security Technology Certification Program (ESTCP)

Alexandria, VA 22350-3605 


\section{Abstract}

The management and recovery of threatened and endangered amphibians on Department of Defense (DoD) lands relies on an understanding of their distribution and abundance. Fortunately, most anuran species can be surveyed acoustically using vocalizations during the breeding season. This work demonstrated the use of subsurface passive acoustic monitoring (SPAM) to survey for rare underwater-calling, at-risk anuran species on DoD installations. We evaluated the performance of SPAM relative to traditional passive acoustic monitoring (PAM) (microphone) and human manual calling survey (MCS) methods. Results showed that SPAM outperformed PAM and MCS in validation experiments where calls were generated underwater; SPAM was less successful than PAM and MCS in the field demonstration. Most leopard frog calls were apparently produced in air despite previous reports of extensive underwater-calling behavior. This project highlights how acoustic information can help address a data gap in the ecology of at-risk species, which can help refine future survey methodology and management efforts. Ultimately, the utility of SPAM for underwater-calling species will depend on the focal species, the landscape where it occurs, and technological considerations available to the surveyor. SPAM is more expensive than traditional methods but, in some situations, may be the only way to effectively detect species.

DISCLAIMER: The contents of this report are not to be used for advertising, publication, or promotional purposes. Citation of trade names does not constitute an official endorsement or approval of the use of such commercial products. All product names and trademarks cited are the property of their respective owners. The findings of this report are not to be construed as an official Department of the Army position unless so designated by other authorized documents.

DESTROY THIS REPORT WHEN NO LONGER NEEDED. DO NOT RETURN IT TO THE ORIGINATOR. 


\section{Contents}

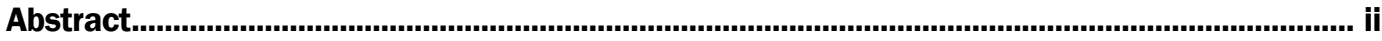

Figures and Tables......................................................................................................................................

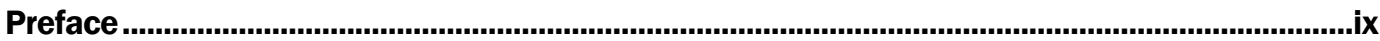

Executive Summary ..........................................................................................................................

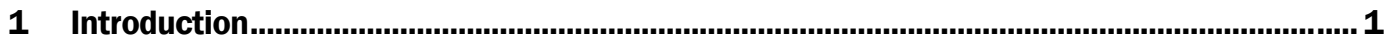

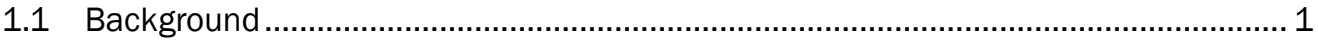

1.2 Objective of the demonstration ........................................................................ 3

1.3 Regulatory drivers .................................................................................... 4

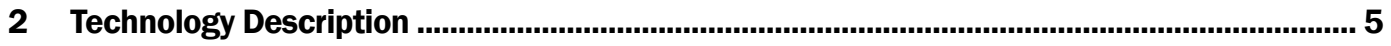

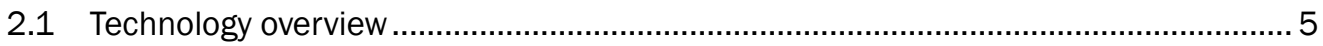

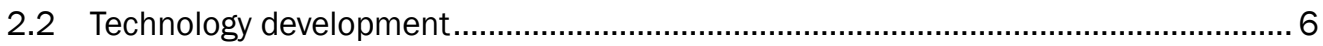

2.3 Advantages and limitations of the technology ................................................ 6

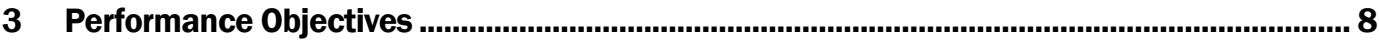

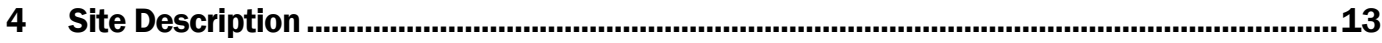

4.1 Cornell Lab of Ornithology, Ithaca, New York ................................................... 13

4.2 Fort Stewart, Georgia............................................................................... 14

4.3 Coronado National Forest, Arizona ............................................................. 15

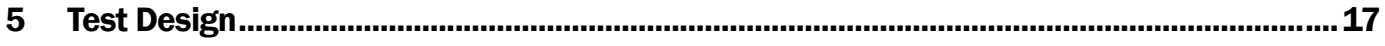

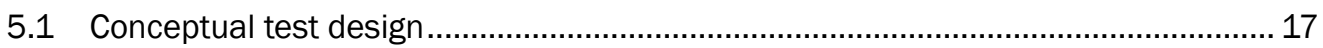

5.2 Baseline characterization and preparation .........................................................20

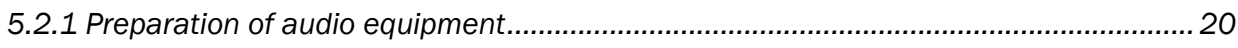

5.2.2 Statuses of focal species at demonstration sites.......................................................... 20

5.3 Design and layout of technology components ..................................................... 21

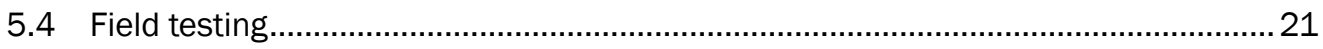

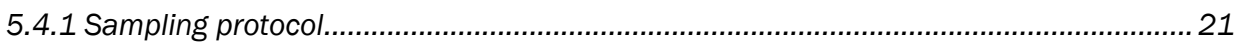

5.4.2 Validation experiment 1: Factors influencing detection range ......................................22

5.4.3 Validation experiment 2: Confirming the efficacy of SPAM ...........................................26

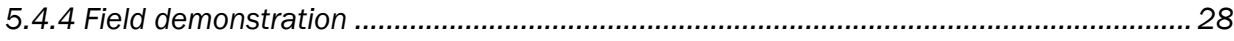

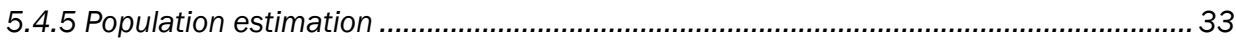

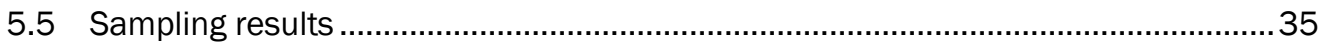

5.5.1 Validation experiment 1: Factors influencing detection range......................................35

5.5.2 Validation experiment 2: Confirming the efficacy of SPAM......................................... 37

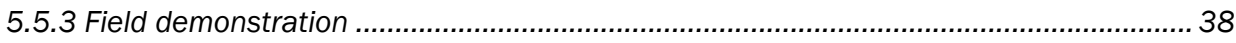

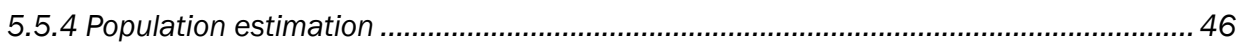




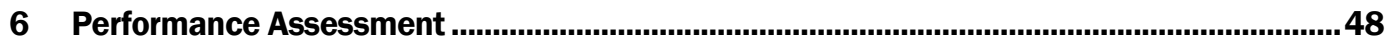

6.1 Performance Objective 1: Examine the influence of environmental factors on acoustic detectability.

6.2 Performance Objective 2: Validate the ability of SPAM to detect calls generated below the water's surface

6.3 Performance Objective 3: Demonstrate the effectiveness of SPAM data for population estimation through direct counts of distinct individuals in recordings

6.4 Performance Objective 4: Compare costs associated with SPAM relative to

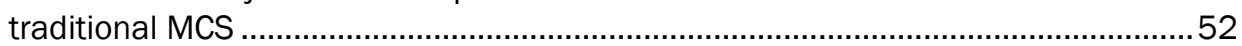

7 Cost Assessment.............................................................................................................. 53

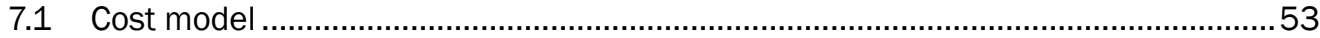

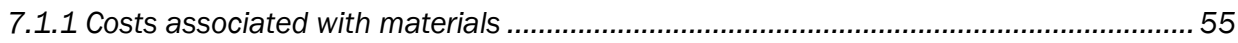

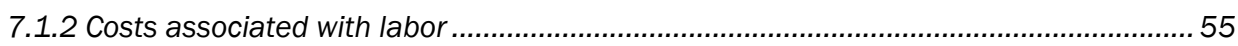

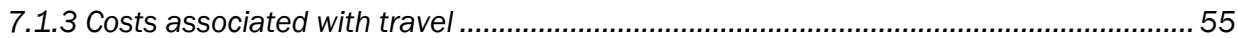

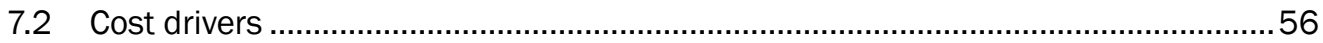

7.3 Cost analysis and comparison .......................................................................56

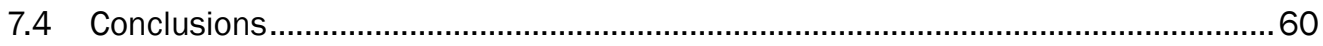

8 Implementation Issues .................................................................................................61

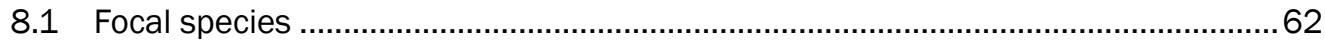

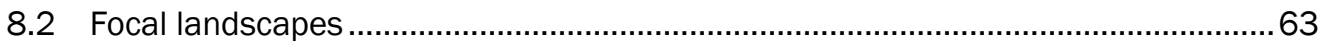

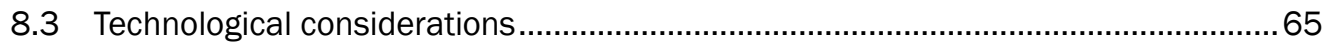

References...................................................................................................................................................67

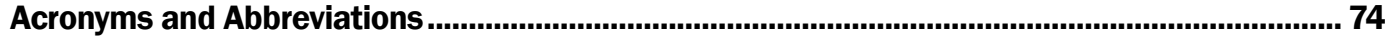

Appendix A: Points of Contact........................................................................................................ 75

Appendix B: Suitability of Anuran Species Found on DoD Lands for Detection via Subsurface Passive Acoustic Monitoring......................................................................... 76

Report Documentation Page (SF 298) ................................................................................80 


\section{Figures and Tables}

\section{Figures}

1 Schematic of SPAM workflow, showing steps from data collection through data analysis, resulting in spatial occurrence and activity patterns of different species

2 Locations of wetlands (A-E) in Sapsucker Woods at the Cornell Lab of Ornithology, NY, where validation experiments were conducted in 2017 to examine the influence of environmental variable on detection by SPAM and to compare SPAM to PAM and MCS

3 Locations of wetlands (A-E) on Fort Stewart, GA, where SPAM was deployed in 2018 and 2019

4 Locations of wetlands (A-G) in Coronado National Forest, AZ, where SPAM was deployed in 2018 and 2019.

5 Wetlands at the CLO used to evaluate the influence of wetland characteristics on the detection of underwater-generated frog calls by hydrophones

6 Representative playback sounds with (top) waveform and (bottom) spectrogram (FFT $=2048$ ) of the playback sequence used to evaluate underwater frog-call attenuation in wetlands of varying habitat characteristics. The playback sequence begins with six $0.5 \mathrm{sec}$ pure tones at $100,200,500,750,1000,1500$, and $2000 \mathrm{~Hz}$, followed by a sequence of gopher frog calls and a sequence of Chiricahua leopard frog calls.

7 Configuration of validation experiment 2, from the perspective of the human observer. Although only two speakers emitted frog calls in any given trial, dummy stakes were placed at different distances in the wetland, so the observer did not know the distances from which calls were emitted

8 Five wetlands at which SPAM and PAM were deployed to search for breeding gopher frogs (Lithobates capito) from February through May 2018. Three recording units were redeployed at wetland D in February 2019

9 Swift recording unit equipped with microphone (PAM) and hydrophone (SPAM) at wetland $D$ at Fort Stewart, GA, in 2018. This wetland was resampled in 2019 based on gopher frog detection in 2018.

SPAM and PAM were deployed at four wetlands to search for breeding Chiricahua leopard frogs (Lithobates chiricahuensis) from June through August 2018. Leopard frogs are known to occur at a variety of wetlands, from naturally occurring ponds $(A)$ and seeps $(B)$ to manmade, concretelined pools $(C)$. Wetland $D$, not pictured, was similar to wetland $C$

11 Wetland $\mathrm{E}$, a former cattle tank now used for Chiricahua leopard frog restoration, and wetland G, a natural, ephemeral wetland, where Swift recording units were deployed at Coronado National Forest, AZ, in 2019. Wetland $\mathrm{F}$, not pictured, was similar to wetland $\mathrm{E}$. 
12 Effects of the number of submerged obstacles $(A)$ and water depth $(B)$ on detection probability of underwater frog calls by a hydrophone (SPAM). Black line $=$ model-predicted estimate; gray shading $=95 \%$ confidence interval..

13 Spectrogram visualization of frog call attenuation during validation experiment 1 at the Cornell Lab of Ornithology, NY. Detection of the playback sequence decreased with increasing distance between the speaker broadcasting playback and the hydrophone.

14 Percentage of broadcast gopher frog (Lithobates capito) and Chiricahua leopard frog (L. chircahuensis) calls detected by a hydrophone (SPAM), a microphone (PAM), and human observers (MCS).

15 Spectrograms showing the drumming of a woodpecker captured both by a microphone (top) and a hydrophone (center), and a spectrogram of an underwater-calling gopher frog (Lithobates capito) recorded by a hydrophone (bottom).

16 Spectrograms of a gopher frog (Lithobates capito) recorded with a microphone (top) and a hydrophone (bottom) at Fort Stewart, GA, in 2018.

17 Percentage of 5-min subsamples of long-term acoustic data in which Chiricahua leopard frogs (Lithobates chiricahuensis) were detected by the hydrophone (SPAM) and microphone (PAM) at wetlands A, C, and D in Coronado National Forest, AZ, in 2018. No frogs were detected at wetland $B$, so it is not shown. " $\star$ " indicates a significant difference between SPAM and PAM at $\alpha=0.05$

18 Representative recordings of Chiricahua leopard frogs (Lithobates chiricahuensis) on hydrophones $(A, B)$ and microphones $(C, D)$, shown as waveforms $(A, C)$ and spectrograms $(B, D)$. Substantially more ambient noise (e.g., insects, wind) was present on microphone recordings because the air-water interface limits above-surface noise from reaching hydrophones

19 Comparison of detection (mean \pm SE) of Chiricahua leopard frogs (Lithobates chiricahuensis) via hydrophone (SPAM), microphone (PAM), and human observer (MCS) over three nights of surveys at Coronado National Forest, AZ, in 2019. Due to an equipment malfunction, no data were available for PAM at wetland $F(X)$. The $y$-axis represents the proportion of frog calls detected by each method averaged across all surveys.

20 Percentage of 5-min subsamples of acoustic data in which Chiricahua leopard frogs (Lithobates chiricahuensis) were detected by hydrophones (SPAM) and microphones (PAM) at wetlands $E$ and $G$ in Coronado National Forest, AZ, in 2019. The microphone malfunctioned at wetland F, so a comparison was not possible. " $\star$ " indicates a significant difference between SPAM and PAM at $\alpha=0.05$

21 Many Chiricahua leopard frogs (Lithobates chiricahuensis) were observed above the water's surface, rather than below, at wetlands $E-G$ at Coronado National Forest, AZ, in 2019.

22 Waveform $(A)$ and spectrogram $(B)$ of hydrophone from wetland $E$ in Arizona showing the number of detected calling Chiricahua leopard frogs (Lithobates chiricahuensis). The same individuals are numbered in both panels. Recording is from 27 July 2019 at 20:00. 
23 Estimated total cost of SPAM and PAM deployments. The higher starting cost of SPAM is due to the cost of a hydrophone, then costs for both methods accrue at the same rate. Increases at 30 and 60 days are incurred by extra site visits needed to check and refresh memory cards and batteries.

24 Estimated cost per night of data generated by SPAM and PAM long-term deployments. The higher starting cost of SPAM is due to the cost of a hydrophone

25 A decision support tree for evaluating the suitability of the use of passive acoustic monitoring approaches for anuran species, taking into account calling behavior of the focal species, the calling environment, and reporting requirements. Gray boxes represent decision points, and white boxes represent recommendations. Dashed lines represent the next set of questions following a recommendation. Begin at the top-left.

\section{Tables}

1 Performance Objectives to evaluate subsurface passive acoustic monitoring (SPAM) technology ...

2 Overview of conceptual test design, outlining the experiments or assessments conducted to address each performance objective, and the locations of their methods in this report

3 Timeline for validation of SPAM at the Cornell Lab of Ornithology, Ithaca, New York, and demonstration of SPAM at Fort Stewart, Georgia, and Coronado National Forest, Arizona.

4 Frogs detected by SPAM or PAM recorders at Fort Stewart, GA, during the 2018 anuran breeding season

5 Variables evaluated for their influence on detection of frog calls by hydrophones and the direction of their relationship to detection probability. Statistically significant variables at $\alpha=0.05$ based on univariate binomial generalized linear mixed models are shaded in gray. Prerecorded frog calls of gopher frogs (GF) and Chiricahua leopard frogs (CLF) were emitted on underwater speakers at variable depths below the surface in validation experiment 1 (see Section 5.4.2 for methods)

6 Percentage of frog calls detected by SPAM, PAM, and MCS under controlled conditions in validation experiment 2

7 Variables evaluated for their influence on detection by SPAM, PAM, and MCS in a controlled experiment. Statistically significant variables at $\alpha=0.05$ based on univariate binomial generalized linear mixed models are shaded in gray. Prerecorded frog calls of gopher frogs (GF) and Chiricahua leopard frogs (CLF) were emitted on underwater speakers at variable distances and amplitudes in validation experiment 2 (see Section 5.4.3 for methods)

8 Cost model for a single-night anuran survey via SPAM, PAM, and MCS at a single site

9 Cost of MCS surveys at different levels of effort. The cost of MCS is a function of the number of sites surveyed in a night and their distance apart. One survey is a 5-min period during which a human observer listens and records the presence of focal species 
10 The cost of SPAM and PAM for deployments of varying lengths at a single site. One-time costs of materials, labor for travel for initial deployment, and labor to learn acoustic analysis software were added to recurring costs of subsequent site visits and labor for data analysis, depending on the length of deployment (survey length) ................................................................................58

B-1 Anuran species documented to occur on DoD lands in the United States...................... 77 


\section{Preface}

Funding for this demonstration was provided by the Strategic Environmental Research and Development Program (SERDP) and Environmental Security Technology Certification Program (ESTCP) under MIPR W74RDV93508403 under Resource Conservation and Resiliency (RC) Project RC-201706, "Demonstration of Subsurface Passive Acoustic Monitoring (SPAM) to Survey for and Estimate Populations of Imperiled Underwater-calling Frogs." The ESTCP program manager was Dr. Kurt Preston.

This work was conducted by the Ecological Processes Branch, of the Installations Division, of the Construction Engineering Research Laboratory (CERL), Engineer Research and Development Center (ERDC). Dr. Chris Rewerts was Chief of the Ecological Processes Branch, and Mr. Charles Schroeder was Acting Chief of the Installations Division. The associated Technical Director was Mr. Hany Zaghloul. The Acting Deputy Director of ERDC-CERL was Ms. Michelle Hanson and the Director was Dr. Andrew Nelson.

We thank the ESTCP for funding this project. We also thank the ESTCP staff, especially Dr. Kurt Preston, for support throughout this project. Roy King and Larry Carlisle of Fort Stewart were crucial to the planning and execution of the demonstration on Fort Stewart. John Kraft of the U.S. Forest Service provided indispensable knowledge, coordination, and access to study sites in Arizona. Similarly, field work in 2019 would not have been possible without the assistance of Cristina Francois of the National Audubon Society. The Beatty Family graciously provided access to their property to conduct surveys for Chiricahua leopard frogs. We thank Elliot Lassiter and Daniel Salisbury for their diligent analysis of acoustic data. We are grateful to David Prival, Kristin Hodge, Dylan O'Hearn, Valerie Buxton, Kerry Gendron, and the volunteers at the Cornell Lab of Ornithology for their assistance in the field.

COL Teresa A. Schlosser was Commander of ERDC, and Dr. David W. Pittman was the Director. 


\section{Executive Summary}

\section{Introduction}

The management and recovery of threatened and endangered amphibians on Department of Defense (DoD) lands necessarily rely on an understanding of their distribution and abundance. Fortunately, most anurans (frogs and toads) can be relatively easily surveyed because males make audible mating vocalizations during the breeding season that can be identified to the species level by trained observers. Currently, the most widely used method for monitoring vocalizing anurans is manual calling surveys (MCS), a method analogous to point count surveys conducted for breeding birds. However, this method has inherent limitations, and emerging research shows that some frog species primarily or even exclusively call while submerged underwater (Degenhardt, Painter, and Price 1996; Dorcas et al. 2009; Jensen, Palis, and Bailey 1995; Mactague and Northen 1993; Palis and Fischer 1997). MCS are unreliable for surveying for submerged species, many of which are at-risk and occur on numerous installations. PAM technology (consisting of a recording unit and microphone) has been increasingly used to detect anuran vocalizations and may be the only practical way to reliably detect species that have very short or unpredictable breeding seasons. Despite PAM's substantial improvements over MCS, it has the same limitations and simply may not be the proper tool for documenting anurans that vocalize primarily or exclusively underwater. Alternatively, subsurface PAM (hereafter SPAM) uses the same recording technology but substitutes hydrophones for microphones. This work demonstrated the use of SPAM to survey for cryptic or rare, underwatercalling, at-risk anuran species occurring on DoD installations and validated the utility of SPAM in direct comparison to MCS and PAM.

\section{Objectives of the demonstration}

The objective of this project was to demonstrate how SPAM can be used to document and monitor the occurrence and relative abundance of two atrisk, underwater-calling frogs on DoD installations. Specifically, we aimed to (1) examine the influence of environmental factors (e.g., water depth, temperature, substrate type, vegetation density) on acoustic detectability, (2) demonstrate and validate the ability of SPAM to detect frog calls generated below the water's surface, (3) demonstrate the effectiveness of SPAM 
data for estimating relative abundance, and (4) compare the cost-effectiveness of SPAM as a monitoring technology relative to traditional survey methods for amphibians on DoD installations.

\section{Technology description}

In its present form, SPAM has been a staple of the U.S. Navy and marine mammal monitoring for nearly two decades (e.g., Charif et al. 2014; Clark and Gagnon 2002; Fristrup, Hatch, and Clark 2003; Stafford, Fox, and Clark 1998). Increases in technological capability (memory size, battery life, and computer processing speed) have led to massive increases in the spatial and temporal scale addressed by acoustic surveys (Clark et al. 2011). Here, we transferred SPAM technology to freshwater systems to survey for two at-risk species: the Chiricahua leopard frog (Lithobates chiricahuensis), a federally threatened species, and the gopher frog (Lithobates capito), under review for federal listing.

We used archival acoustic recording units with two channels of audio input, modified from the Swift autonomous recording unit developed by the Center for Conservation Bioacoustics at Cornell University (https://www.birds.cornell.edu/ccb/swift/). One channel was connected to a hydrophone for recording underwater (SPAM component), and the other channel was connected to an airborne microphone for recording sounds in air (PAM component). The recorders stored data on secure digital extended capacity (SDXC) flash cards and were powered by 16 D-cell batteries, enabling continuous recording for up to three months.

\section{Performance assessment}

This project consisted of several steps to both validate and demonstrate SPAM technology. First, we conducted an extensive, controlled validation experiment to test the influence of environmental factors on the detectability of underwater-generated frog calls by SPAM. Second, we validated the ability of SPAM to detect anuran calls generated below the water's surface and compared the ability of SPAM to detect frog calls relative to PAM and MCS in controlled conditions. Third, we conducted long-term deployments of SPAM to record the calls of free-ranging gopher frogs and Chiricahua leopard frogs, species found on military installations in the southeastern and southwestern United States, respectively. Fourth, we compared the performance of SPAM relative to PAM and MCS for detecting Chiricahua leopard frogs in field conditions in nightly surveys. Fifth, we demonstrated 
how data generated from SPAM can be used to make population estimates. Finally, we compared the cost-effectiveness of SPAM to PAM and MCS.

To evaluate the influence of wetland characteristics on the detection of underwater-generated frog calls by hydrophones (Performance Objective 1), we conducted playback trials in a series of diverse wetlands and measured underwater sound propagation. We found substantial variation in detection range across wetlands. Overall, five variables significantly influenced detection (Table ES-1), but model ranking indicated that two variables-number of submerged obstacles and water depth-had the greatest influences on detection by the hydrophone $\left(\mathrm{AIC}_{\mathrm{c}}\right.$ weight $\left.=0.84\right)$; no other model was competitive $\left(\Delta \mathrm{AIC}_{\mathrm{c}}<2\right)$.

Table ES-1. Variables evaluated for their influence on detection of frog calls by hydrophones and the direction of their relationship to detection probability. Statistically significant variables at $\alpha=0.05$ based on univariate binomial generalized linear mixed models are shaded in gray. Prerecorded frog calls of gopher frogs (GF) and Chiricahua leopard frogs (CLF) were emitted on underwater speakers at variable depths below the surface.

\begin{tabular}{|c|c|c|}
\hline Variable & Relationship to detection & $P$-value \\
\hline $\begin{array}{l}\text { Number of submerged obstacles } \\
\text { between underwater speaker and } \\
\text { hydrophone }\end{array}$ & Negative & $<0.001$ \\
\hline Water depth & Positive & $<0.001$ \\
\hline $\begin{array}{l}\text { Distance between underwater speaker } \\
\text { and hydrophone }\end{array}$ & Negative & $<0.001$ \\
\hline Turbidity & Positive & $<0.01$ \\
\hline Substrate depth & Positive & 0.02 \\
\hline $\begin{array}{l}\text { Speaker depth (near-surface, mid-water } \\
\text { column, or bottom) }\end{array}$ & $\begin{array}{l}\text { Mid-water column }>\text { near-surface }>\text { bottom } \\
\text { (not significant) }\end{array}$ & $>0.38$ \\
\hline $\begin{array}{l}\text { Species of call emitted (gopher frog or } \\
\text { Chiricahua leopard frog) }\end{array}$ & $\begin{array}{l}\text { GF }>\text { CLF } \\
\text { (not significant) }\end{array}$ & $>0.37$ \\
\hline
\end{tabular}

Detection increased as the number of submerged obstacles between the speaker and hydrophone decreased, and no calls were detected when greater than two submerged obstacles were between the speaker and hydrophone (Figure ES-1A). Detection increased with increasing water depth (Figure ES1B). 
Figure ES-1. Effects of the number of submerged obstacles $(A)$ and water depth $(B)$ on detection probability of underwater frog calls by a hydrophone (SPAM). Black line $=$ modelpredicted estimate; gray shading $=95 \%$ confidence interval.
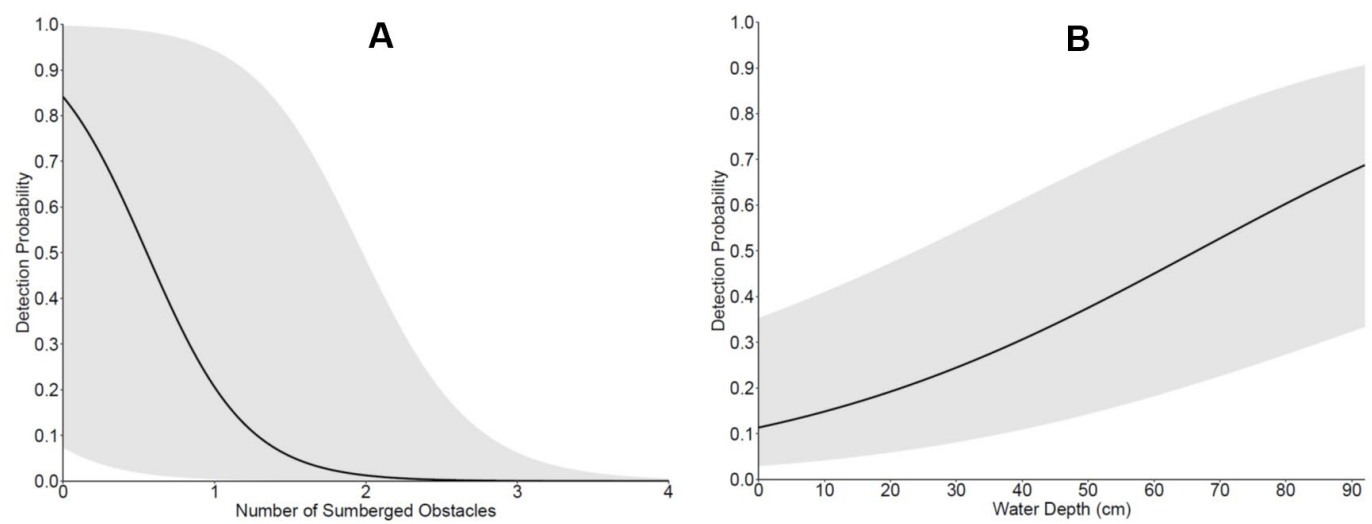

Our results indicate that SPAM is best suited for wetlands with deeper water and few underwater obstacles. Wetland characteristics will affect the number of hydrophones needed to ensure adequate site coverage, with larger wetlands requiring multiple hydrophones and smaller wetlands being easily surveyed using only one hydrophone. Given the diversity of anuran habitats across North America, further research is warranted to more extensively explore the effects of environmental characteristics on underwater sound propagation in freshwater systems.

To validate the ability of SPAM to detect anuran calls generated below the water's surface (Performance Objective 2), we first conducted an experiment to test the ability of SPAM to detect frog calls broadcast by underwater speakers and directly compared the detection of calls by SPAM, PAM, and MCS in a controlled environment. Overall, the survey method had a significant effect on the number of underwater calls detected $\left(F_{1,562}=53.78\right.$, $P<$ 0.001). SPAM detected $79 \%$ of calls, MCS detected $49 \%$, and PAM detected only $13 \%$ of calls. SPAM was 30 times more likely to detect underwater calls relative to PAM $(t=-9.92, \mathrm{df}=559, P=0.001, \beta=-3.42)$ and 8.5 times more likely relative to MCS $(t=-6.92, \mathrm{df}=559, P=0.001, \beta=-2.14)$.

Two variables influenced detection by the three survey methods (Table ES2): amplitude at which a speaker emitted calls (louder calls more frequently detected than quieter ones) and species of frog (gopher frog more frequently detected than Chiricahua leopard frog). 
Table ES-2. Variables evaluated for their influence on detection by SPAM, PAM, and MCS in a controlled experiment. Statistically significant variables at $\alpha=0.05$ based on univariate binomial generalized linear mixed models are shaded in gray. Prerecorded frog calls of gopher frogs (GF) and Chiricahua leopard frogs (CLF) were emitted on underwater speakers at variable distances and amplitudes.

\begin{tabular}{|l|l|l|}
\hline \multicolumn{1}{|c|}{ Variable } & \multicolumn{1}{|c|}{$\begin{array}{c}\text { Relationship to } \\
\text { detection }\end{array}$} & \multicolumn{1}{|c|}{$\boldsymbol{P \text { -value }}$} \\
\hline Frog call amplitude (high or low) & Positive & $<0.001$ \\
\hline Species of call emitted (gopher frog or Chiricahua leopard frog) & GF $>$ CLF & $<0.001$ \\
\hline $\begin{array}{l}\text { Distance between speaker and } \\
\text { hydrophone/microphone/human }(4,8,12, \text { or } 16 \mathrm{~m})\end{array}$ & $\begin{array}{l}\text { Positive } \\
\text { (not significant) }\end{array}$ & 0.73 \\
\hline
\end{tabular}

Second, we conducted long-term field deployments to compare SPAM and PAM at Fort Stewart and Coronado National Forest. At Fort Stewart, we recorded continuously for over three months in 2018 (five wetlands) and for 12 days in 2019 (one wetland), resulting in the detection of only two gopher frog calls: one detected by SPAM only, and one detected by both SPAM and PAM. Interestingly, we documented an additional seven anuran species on hydrophones not previously known to call underwater. We still know relatively little about how frequently frogs employ this interesting behavior, and there is no doubt that the list of frogs that call underwater will grow rapidly as biologists adopt and deploy SPAM. Further research is needed to explore the prevalence of underwater-calling behavior to better inform monitoring decisions using SPAM and PAM.

At Coronado National Forest, we recorded at four wetlands (two natural and two manmade) from June to August 2018. During this time, both SPAM and PAM recorded numerous calls of the Chiricahua leopard frog from three of the four wetlands. Detection varied widely between wetlands with different habitat characteristics and densities of frogs (Figure ES-2). At wetland A, a natural, deep, spring-fed pond with very few frogs, PAM detected significantly more leopard frog calls than SPAM $(z=-4.96, P$ $<0.0001)$. Leopard frogs were detected in $59 \%$ of microphone recordings compared to $5 \%$ of hydrophone recordings. In the two concrete-lined cattle tanks (wetlands $\mathrm{C}$ and D), detection was similar between methods (wetland C: $\mathrm{SPAM}=84 \%, \mathrm{PAM}=94 \% ; z=-1.59, P=0.06$; wetland D: $\mathrm{SPAM}=$ $100 \%$, PAM $=100 \%$ ). 
Figure ES-2. Percentage of 5-min subsamples of long-term acoustic data in which Chiricahua leopard frogs (Lithobates chiricahuensis) were detected by the hydrophone (SPAM) and microphone (PAM) at wetlands A, C, and D in Coronado National Forest, AZ, in 2018. No frogs were detected at wetland $B$, so it is not shown. * indicates a significant difference between SPAM and PAM at $\alpha=0.05$.

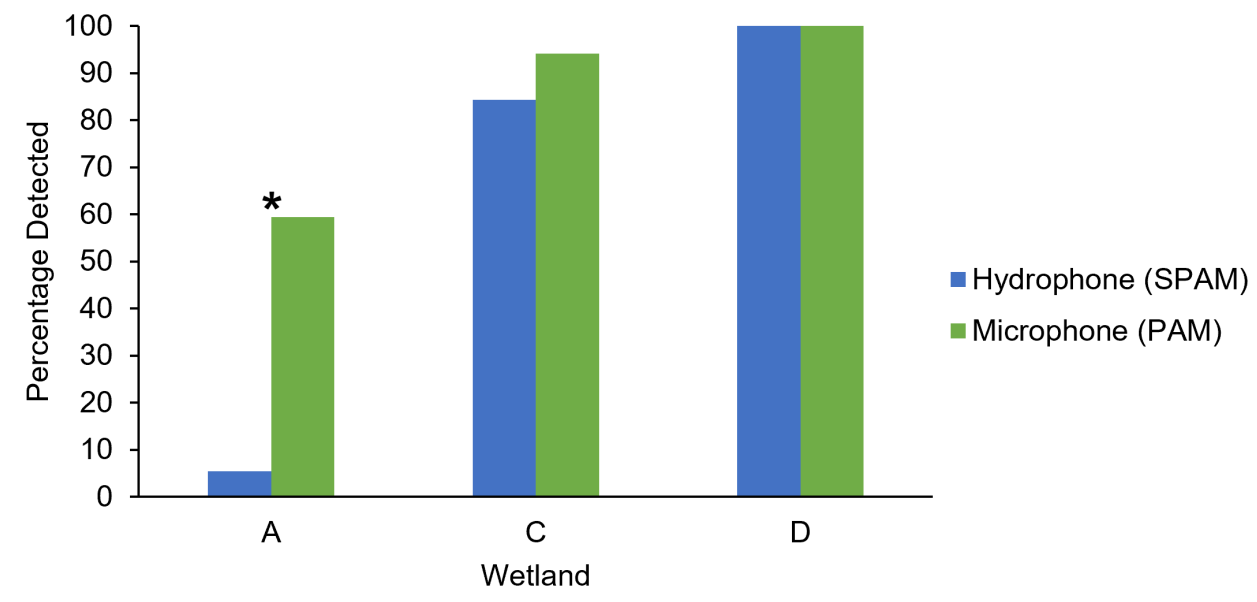

Third, we conducted a field experiment to compare detection of free-ranging Chiricahua leopard frogs by SPAM, PAM, and MCS in nightly surveys. Overall, PAM and MCS were similarly effective, and both outperformed SPAM (Figure ES-3). Hydrophones did not detect a single frog at the natural wetland site, which had relatively shallow water and abundant vegetation, characteristics found to limit underwater sound propagation in Performance Objective 1. Although SPAM did detect frogs in $50 \%$ and $75 \%$ of trials at the two artificial wetlands (cattle tanks), PAM and MCS detected frogs in $100 \%$ of surveys (Figure ES-3). We subsampled the continuous recordings produced during the three-night deployment and found that detection by microphones was greater than hydrophones at both sites evaluated (wetland $\mathrm{E}: z=-5.56, P<0.0001$; wetland $\mathrm{G}: z=-2.42, P=0.008$ ). 
Figure ES-3. Comparison of detection (mean \pm SE) of Chiricahua leopard frogs (Lithobates chiricahuensis) via hydrophone (SPAM), microphone (PAM), and human observer (MCS) over three nights of surveys at Coronado National Forest, AZ, in 2019. Due to an equipment malfunction, no data were available for PAM at wetland $F(X)$.

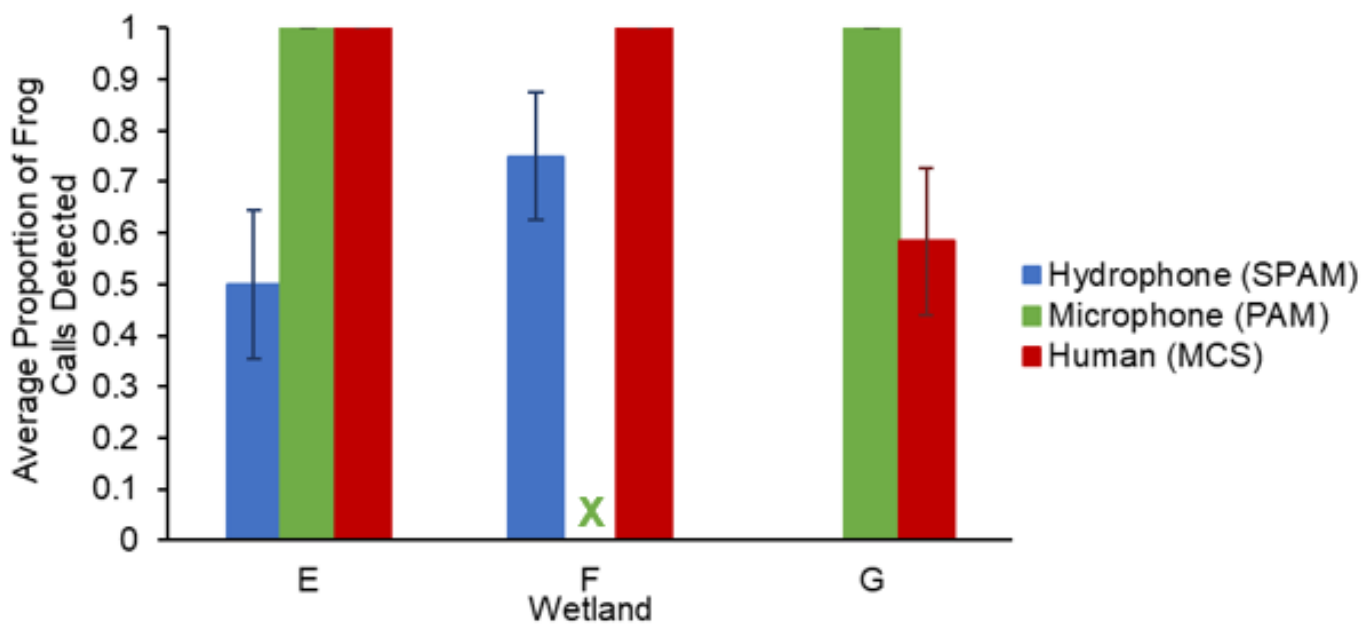

Our results from long-term deployment monitoring of Chiricahua leopard frogs suggest that this species likely vocalizes more rarely underwater than previously reported. Hence, even though underwater vocalizations can propagate long distances, calls produced in air would need to be near hydrophones for them to be detected via SPAM. For frogs primarily vocalizing above water, such as the Chiricahua leopard frog, microphones should be the preferred approach. In small wetlands (such as wetlands C and D), the high density of frogs in limited space makes either recording approach similarly effective, but in more natural conditions, microphones are expected to outperform hydrophones.

To demonstrate the effectiveness of SPAM data for population estimation (Performance Objective 3), we used recordings of Chiricahua leopard frogs collected at two artificial ponds in Coronado National Forest in 2019. These ponds presented an advantageous scenario from a survey perspective because they were considered closed populations (i.e., all individuals occurred within the monitoring location), and all calls detected were known to come from within the ponds being surveyed. Because we were able to record the entire population and had high detection probability for visually counting frogs to corroborate our acoustic estimates, we used direct counts in the acoustic data to estimate the number of calling individuals. We identified a maximum of eight distinct individuals at each of the two wetlands. We assumed a sex ratio of 1:1 (male [calling]:female [not calling]) to calculate population estimates of 16 individuals at each site. 
Compared to visual counts of 17 and 15 individuals, we deemed our acoustic estimate highly accurate. The field of acoustic population assessment is advancing rapidly, with new statistical models being developed. If population size estimation is a monitoring goal or requirement, future survey designs for calling frogs can incorporate these new approaches.

\section{Cost assessment}

To compare costs associated with SPAM relative to traditional PAM and MCS (Performance Objective 4), we quantified the cost of field data collection and data analysis for each of the three methods, including costs of materials, labor, and travel. However, before considering the cost of implementing these methods, the practitioner should first determine the suitability of each method for the survey goals. Then, and only then, should cost be a deciding factor. Ultimately, the utility of SPAM for underwater-calling species will depend on the focal species and the landscape where it occurs.

Because a distinct advantage of SPAM and PAM over MCS is continuous coverage of the study area for an extended period of time (which may be necessary to detect certain species), it is impractical for an investigator to conduct a SPAM or PAM survey for the short duration typical of MCS ( 5 min per site), making direct comparisons between methods difficult. Therefore, we evaluated the cost for each method at different levels of effort (i.e., survey durations) that represent realistic scenarios a biologist might use in practice (Table ES-3, Table ES-4).

Our analysis demonstrated that, after the substantial up-front costs related to materials and the time to learn to use acoustic software, in the long-term, costs for SPAM and PAM grow incrementally based on the steady accumulation of data. Overall costs of SPAM and PAM will always be substantially greater than those associated with MCS. However, a primary benefit of SPAM and PAM technologies is that they enable the user to drastically increase the temporal coverage of surveys. In some situations, it may make the most sense for the practitioner to simply choose the cheapest option. If a species is conspicuous, SPAM or PAM may not be necessary. MCS is a cheap and effective methodology when applied in the appropriate context. However, in other situations, SPAM may be the only way to effectively detect species. We must stress that SPAM may be critical to detecting underwater-calling species if their vocalizations are not detectable by terrestrial observers. In these situations, although PAM and MCS will be cheaper than SPAM, they may not accomplish the objective. 
Table ES-3. Estimated cost of MCS surveys at different levels of effort. The cost of MCS is a function of the number of sites surveyed in a night and their distance apart. One survey is a 5min period during which a human observer listens and records the presence of focal species.

\begin{tabular}{|l|l|l|l|l|l|}
\hline MCS per night & Survey hours & Data entry hours & Travel $\mathrm{km}(\mathrm{miles})$ & Total cost & Cost per survey \\
\hline 1 & 2.08 & 1 & $96(60)$ & $\$ 111.50$ & $\$ 111.50$ \\
\hline 5 & 3 & 1.25 & $113(70)$ & $\$ 146.50$ & $\$ 29.30$ \\
\hline 10 & 4 & 1.5 & $129(80)$ & $\$ 183.50$ & $\$ 18.35$ \\
\hline 15 & 5 & 1.75 & $145(90)$ & $\$ 220.50$ & $\$ 14.70$ \\
\hline 20 & 6 & 2 & $161(100)$ & $\$ 257.50$ & $\$ 12.88$ \\
\hline
\end{tabular}

Table ES-4. The cost of SPAM and PAM for deployments of varying lengths at a single site. One-time costs of materials, labor for travel for initial deployment, and labor to learn acoustic analysis software were added to recurring costs of subsequent site visits and labor for data analysis, depending on the length of deployment (survey length).

\begin{tabular}{|c|c|c|c|c|}
\hline Survey length & $\begin{array}{c}\text { Number of site } \\
\text { visits }^{*}\end{array}$ & $\begin{array}{c}\text { Data analysis hours } \\
\text { (1 hour per survey } \\
\text { night })^{\dagger}\end{array}$ & $\begin{array}{l}\text { SPAM total } \\
\text { cost }\end{array}$ & $\begin{array}{c}\text { PAM tota } \\
\text { cost }\end{array}$ \\
\hline 1 night & 1 & 1 & $\$ 3,370$ & $\$ 2,489$ \\
\hline 2 weeks (14 nights) & 2 & 14 & $\$ 3,796$ & $\$ 2,915$ \\
\hline 1 month (30 nights) & 2 & 30 & $\$ 4,196$ & $\$ 3,315$ \\
\hline 2 months (60 nights) & 3 & 60 & $\$ 5,047$ & $\$ 4,166$ \\
\hline 3 months (90 nights) & 4 & 90 & $\$ 5,898$ & $\$ 5,017$ \\
\hline \multicolumn{5}{|c|}{$\begin{array}{l}* \text { After initial deployment, the cost of each additional site visit is } \$ 101 \text { ( } \$ 4 \text { for batteries, } \\
\$ 62.50 \text { for labor, and } \$ 34.50 \text { for travel). }\end{array}$} \\
\hline
\end{tabular}

\section{Implementation issues}

This project highlights how acoustic information can help address a data gap in the ecology of at-risk species, which can be used to refine future survey methodology and management efforts. Ultimately, the utility of SPAM for underwater-calling species will depend on the species in question, the landscape in which it occurs, and technological considerations, such as technical expertise and resources available to the surveyor.

Our current understanding of underwater-calling behavior of frogs is largely limited to anecdotal information (e.g., Jensen, Palis, and Bailey 1995; Razzetti, Sacchi, and Platz 2006). There is no doubt that as biologists adopt and deploy SPAM the list of frogs that call underwater will grow rapidly. In addition, a growing body of literature is discovering a diversity of taxonomic groups that vocalize underwater, including turtles (Ferrara et al. 2017; Fer- 
rara et al. 2014; Giles et al. 2009) and fish (Rice et al. 2020; Rountree, Bolgan, and Juanes 2019; Rountree et al. 2006). In this demonstration, we documented nine species of anuran calling underwater on Fort Stewart, seven of which had not previously been reported vocalizing underwater. Ideally, practitioners would use SPAM when microphones or MCS are insufficient for detecting calls. However, without knowing if particular species sometimes, usually, or always call underwater, the decision on the proper method to use can be difficult. For instance, although we showed that SPAM effectively recorded Chiricahua leopard frog calls, microphones performed better, likely because it appears that most leopard frog calls were produced in the air, despite previous reports (Platz 1993). Practitioners surveying for Chiricahua leopard frogs can continue to use traditional methods such as MCS or PAM.

SPAM will be best suited for relatively deep wetlands without high densities of downed woody debris or vegetation that attenuate calls. To date, the frogs known to call underwater occupy a wide array of aquatic habitats (Brunetti et al. 2017; Razzetti, Sacchi, and Platz 2006; Jensen, Palis, and Bailey 1995). For example, Licht (1969) described a situation in which spotted frogs vocalized in water only a couple of centimeters deep, while red-legged frogs vocalized completely submerged in over $0.6 \mathrm{~m}$ of water in the same wetland. It is likely SPAM would be more effective at detecting the calls of the redlegged frog than the spotted frog in this wetland. Frog species breeding in woody, shallow, heavily vegetated wetlands are likely not good candidates for this technology. Practitioners will need to evaluate the habitat conditions used by their focal species, as well as survey goals (e.g., presence/absence vs. population estimates), before deciding if SPAM, PAM, or MCS is most practical.

Many DoD installations that host active military training present challenges for field biologists related to site accessibility and ambient noise. When access to monitoring sites is prohibited or restricted, SPAM and PAM both offer clear value by collecting data when an observer is not present. In noisy situations, SPAM offers an advantage because the underwater environment will be considerably quieter and frog calls will be easier to detect. The air-water interface limits the transmission of underwater sounds into the air and vice versa (Godin 2008), meaning many of the ambient noises that obscure detection of frog calls by MCS or microphones will not be present underwater. Practitioners monitoring frog populations 
near roads, airways, or active firing ranges will likely benefit from deployment of SPAM rather than MCS or PAM.

Finally, practitioners interested in adopting a SPAM approach need to (1) acquire the equipment, (2) acquire the software, (3) learn how to use the software, and (4) learn how to automate the software. We offer advice and considerations for each of these steps. We also offer a decision support tree to aid practitioners in deciding which passive acoustic monitoring technology is most suitable for their survey goals (Figure 25). Last, we provide a list of anuran species on DoD lands documented to call underwater (Appendix B). 


\section{Introduction}

\subsection{Background}

The management and recovery of threatened and endangered species (TES) on Department of Defense (DoD) lands necessarily rely on an understanding of their distribution and abundance. Many DoD installations spend considerable time and effort surveying for amphibians because they are one of the most imperiled taxa, and their populations continue to decline due to a number of interacting factors (Alford and Richards 1999; Stuart et al. 2004; Voyles et al. 2009). Fortunately, most anurans (frogs and toads) can be relatively easily surveyed because males make audible mating vocalizations during the breeding season that can be identified to the species level by trained observers.

Currently, the most widely used method for monitoring vocalizing anurans is manual calling surveys (MCS), a method analogous to point-count surveys conducted for breeding birds. Generally, MCS involve observers simply listening to the vocalizations of male frogs and recording all species detected for the duration of the survey at a specific location. In many surveys, observers may also attempt to roughly estimate abundances of each species heard vocalizing by evaluating the "strength" of the chorus. If sites are repeatedly sampled over time using the same methods, estimates of detection probability and occupancy (i.e., presence or absence of a species) can be generated (Dorcas et al. 2009; Marsh and Trenham 2008). Both of the largest amphibian monitoring programs in the United States, the Amphibian Research and Monitoring Initiative (ARMI, http://armi.usgs.gov/) and the recently retired North American Amphibian Monitoring Program (NAAMP, http://www.pwrc.usgs.gov/naamp/) (Weir and Mossman 2005), rely solely or primarily on MCS. Most DoD installations that actively survey for amphibians use a modification of one of these methods.

However, these methods have inherent limitations, and emerging research shows some frog species primarily or even exclusively call while submerged underwater (Degenhardt, Painter, and Price 1996; Dorcas et al. 2009; Jensen, Palis, and Bailey 1995; Mactague and Northen 1993; Palis and Fischer 1997). Biological sounds produced underwater may not radi- 
ate into the air (Godin 2007; Godin 2008) or may travel very short distances (e.g., less than 10 m) (Jensen, Palis, and Bailey 1995). Thus, MCS are unreliable for surveying for submerged species, many of which are atrisk and occur on numerous installations (see Appendix B for a list of anuran species on DoD lands).

Despite the widespread use of MCS, passive acoustic monitoring (PAM) technology has been increasingly used to detect anuran vocalizations and has proven to be particularly useful for intensive monitoring applications (Dorcas et al. 2009, Peterson and Dorcas 1994). PAM is also used to monitor a variety of terrestrial and marine acoustically active taxa (e.g., Acevedo and Villanueva-Rivera 2006; Digby et al. 2013; Rice, Dugan, and Clark 2010; Rice et al. 2016; Rice et al. 2014a), and ecosystems (e.g., Merchant et al. 2015; Rice et al. 2014b; Sueur et al. 2014).

Typically, PAM (consisting of a recording unit and microphone) is used to collect data intensively at one or more locations, whereas MCS provide more superficial data but typically for a larger number of sites. Passive acoustic recorders can be used to survey for anuran species in places or conditions difficult to access for MCS (such as during inclement weather or in areas of restricted access) and can be left in the field for extended periods of time, thus greatly increasing the probability of detecting a given species. Frogs often call during unexpected hours of the day, and calling activity varies widely by species, biasing results from MCS conducted during limited hours of the evening (Bridges and Dorcas 2000). PAM may be the only practical way to reliably detect species that have very short or unpredictable breeding seasons, such as gopher frogs (Lithobates capito), when only 3-10 min of observation at a location (typical MCS parameters) may not be sufficient for detection. PAM minimizes disturbance to calling anurans and provides a pervasive and permanent sampling record that can be evaluated by multiple experts if required (Dorcas et al. 2009; Mohr and Dorcas 1999; Todd, Cocklin, and Dorcas 2003).

When combined with information on environmental variation, data from PAM can be incorporated into models that can be used to optimize monitoring programs based on MCS (Bridges and Dorcas 2000, Oseen and Wassersug 2002). Data from PAM can also be used by sophisticated processing software-such as Cornell's Raven Pro (https://ravensoundsoftware.com/) (CCB 2017), SEDNA (Dugan et al. 2011), or Wildlife Acoustics' Kaleidoscope 
Pro (https://www.wildlifeacoustics.com/products/kaleidoscope-pro/) - to automatically identify detected calling species. Despite PAM's substantial improvements over MCS survey methods, it has the same limitations when applied to anuran species that vocalize primarily or exclusively underwater. It simply may not be the proper tool for documenting the presence and abundance of such species as the gopher frog, Chiricahua leopard frog (Lithobates chiricahuensis), or Oregon spotted frog (Lithobates pretiosa).

The ability to record animal underwater vocalizations does exist. Cornell University's Center for Conservation Bioacoustics (where author A. Rice is a Principal Ecologist) has used modified, subsurface PAM (hereafter SPAM) for nearly 30 years to document the occurrence, phenology, and movement of protected marine species in relation to military training exercises, industry activities, and protected species management efforts. These efforts often use the same recording technology as traditional PAM efforts but substitute hydrophones for microphones. In this demonstration, we transferred this technology to freshwater systems to survey for cryptic or rare, underwater-calling, at-risk anuran species occurring on DoD installations. The Chiricahua leopard frog, a federally threatened species, and the gopher frog, under review for federal listing, occur on military installations in the southwestern and southeastern United States, respectively. Both species communicate during the breeding season by calling underwater, at unpredictable times, and are challenging to detect using traditional survey methods (MCS and aerial PAM) (Dorcas and Gibbons 2008). Here, we demonstrated the use of SPAM to survey for these species and validated the utility of SPAM in comparison to MCS and PAM.

\subsection{Objective of the demonstration}

The objective of this project was to demonstrate how SPAM can be used to document and monitor the occurrence and relative abundance of two atrisk, underwater-calling frogs on DoD installations. Specifically, we aimed to (1) examine the influence of environmental factors on acoustic detectability (e.g., water depth, temperature, substrate type, vegetation density), (2) demonstrate and validate the ability of SPAM to detect frog calls generated below the water's surface, (3) demonstrate the effectiveness of SPAM data for estimating relative abundance, and (4) compare the cost-effectiveness of SPAM as a monitoring technology relative to traditional survey methods for amphibians on DoD installations. 


\subsection{Regulatory drivers}

All federal land management agencies must comply with federal environmental laws and regulations. This demonstration specifically addresses the compliance challenges posed by the Endangered Species Act (ESA) of 1973. Protection of threatened or endangered species under the ESA varies depending on whether the species is located on federal or private property. For listed species occurring on federal properties, Section 7A of the ESA requires that land managers consult with the U.S. Fish and Wildlife Service (USFWS) to ensure proposed land-use actions result in "no-take" of the listed species. The result of these consultations is often a Biological Opinion in which the land managers and USFWS agree on actions to minimize impacts and methods of monitoring to ensure impacts are avoided or minimized. Often, Biological Opinions rely on an understanding of the distribution and population size of target species, data that are often missing for cryptic wildlife species, such as amphibians. SPAM technology provides a tool for directly addressing this data gap and supports the ability of federal land managers to detect populations of at-risk species on federal lands. 


\section{Technology Description}

\subsection{Technology overview}

PAM is an increasingly robust survey methodology to sample for acoustically active species (e.g., Dorcas et al. 2009; Linke et al. 2018; Rice, Dugan, and Clark 2010; Sugai et al. 2018; Van Parijs et al. 2009). Resulting passive acoustic data can provide a continuous record of species behavior, occurrence, and abundance, as well as behavioral responses to weather and anthropogenic activities (Clark and Gagnon 2002). Once acoustic data are analyzed (either by human analysts or automated detection algorithms), the data are similar to those of other point surveys and can be used by natural resource managers to evaluate distributions and statuses of protected species of interest.

In its present form of a systematized workflow going from acoustic recording through data visualization (Figure 1), SPAM has been a staple of the U.S. Navy and marine mammal monitoring for nearly two decades (e.g., Charif et al. 2014; Clark and Gagnon 2002; Fristrup, Hatch, and Clark 2003; Stafford, Fox, and Clark 1998). The increases in technological capability (memory size, battery life, and computer processing speed) have led to massive increases in the spatial and temporal scale addressed by acoustic surveys (Clark et al. 2011). Although marine mammal surveys have received the bulk of the attention for technological capability, there have been recent advances in applying these same methods to other species groups, such as birds (Celis-Murillo, Deppe, and Allen 2009), fishes (e.g., Rice et al. 2020), bats (Stahlschmidt and Brühl 2012), elephants (Wrege et al. 2010), and anurans (Willacy, Mahony, and Newell 2015) in terrestrial, freshwater, and marine habitats around the world (Linke et al. 2018; Sueur et al. 2012; Sugai et al. 2018). 
Figure 1. Schematic of SPAM workflow, showing steps from data collection through data analysis, resulting in spatial occurrence and activity patterns of different species.

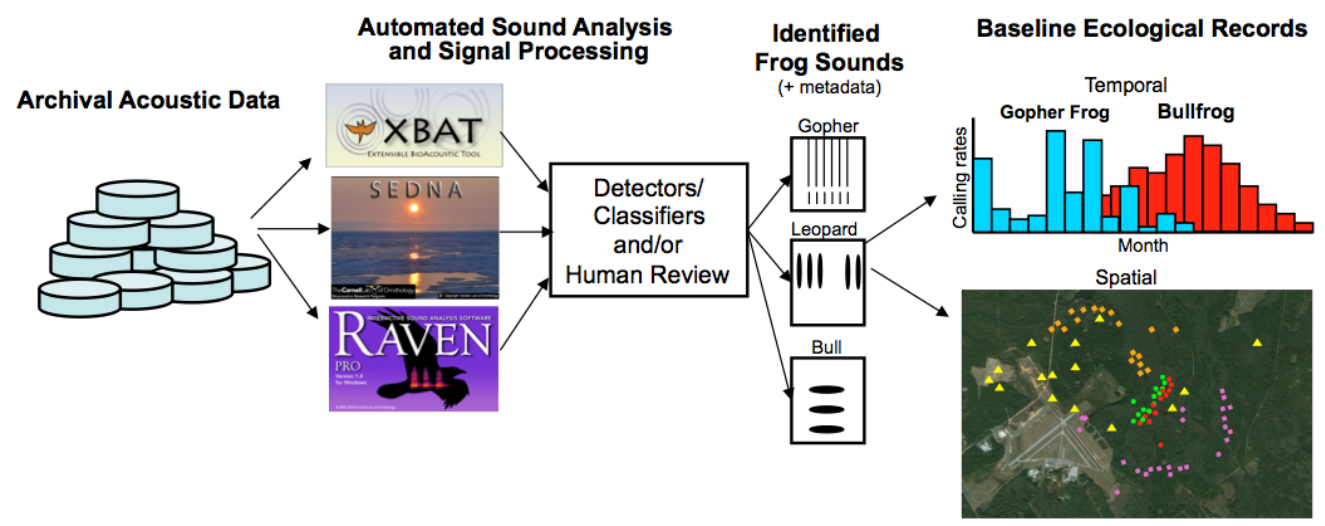

\subsection{Technology development}

We used archival acoustic recording units, modified from existing Cornell "Swift" Autonomous Recording Units (https://www.birds.cornell.edu/ccb/swift/), to enable simultaneous two-channel recording and extended battery life. To prepare the units, two hardware boards from Swifts were placed in a ruggedized Pelican case with a $16 \mathrm{D}$-cell battery power supply. One board was connected to an airborne microphone, and another board was connected to an HTI-96-min hydrophone (purchased from Wildlife Acoustics, Inc.). Each board recorded to 256 GB SDXC flash memory cards.

\subsection{Advantages and limitations of the technology}

PAM surveys are advantageous compared to traditional survey methods, such as visual or listening surveys, in that they can provide continuous coverage of a particular area for extended periods of time, they provide permanent raw data from the survey, and the recording sensors are not impacted by inclement weather or limited accessibility to a survey site to the same degree as humans. In some cases, especially on military installations, accessing areas required to conduct MCS at night, when anurans mostly vocalize, could be unsafe. Additionally, PAM causes no disturbance to calling anurans as a human presence might.

Further, SPAM may be advantageous in the presence of loud noise, such as on military installations with live-fire, aviation, or other noisy training exercises. Because the air-water interface limits the transmission of underwater sounds into the air and vice versa (Godin 2008), SPAM offers a clear 
advantage in noisy situations in which anuran calls are generated underwater. The same calls generated above the water's surface would be more difficult to detect in the presence of ambient noise.

Emerging research is just now highlighting the wide range of taxa that vocalize underwater, from turtles to fish (Giles et al. 2009; Linke et al. 2018; Mann, Locascio, and Wall 2016; Rice et al. 2020). With the rapidly increasing number of species being reviewed for addition to the list of federal TES, the DoD will need to rely on a wide range of survey technologies. PAM approaches are readily adaptable to many different species, and archived survey data are available for further analyses. They can be used retrospectively to resurvey for other species of interest (i.e., recordings originally collected for a bird survey can later be reanalyzed for anurans) or to verify previous identifications (Mohr and Dorcas 1999).

PAM has been demonstrated to be successful for recording and identifying many different frog species around the world. The limitation of SPAM is that it is designed specifically for subsurface applications. Thus, it does not replace the utility of PAM for aerial (above-surface) surveys but, rather, adds the capability of underwater monitoring. The applicability of SPAM is limited by our knowledge of species-specific life histories. For instance, although we have anecdotal information that particular species of frogs call underwater, it is unknown if these frogs always or occasionally vocalize underwater. As our understanding of the prevalence of underwater-calling behavior across taxa grows, it will become easier for practitioners to choose the most appropriate survey technology for their target species and ecosystem. 


\section{Performance Objectives}

The overarching objective of the project was to demonstrate the application of SPAM technology to document and monitor the occurrence and relative abundance of two at-risk, underwater-calling frogs and to compare the success and cost of SPAM to traditional PAM and MCS methods. Specifically, we used three quantitative criteria and one qualitative criterion to evaluate the success of our demonstration (Table 1).

Performance Objective 1 (PO1) was to examine the influence of environmental factors on acoustic detectability (e.g., water depth, temperature, substrate type, vegetation density). This is a quantitative metric pertaining to the ability of SPAM to detect frog calls generated under different wetland conditions and at different distances from speakers, which was achieved through a validation experiment at the Cornell Lab of Ornithology (CLO). In this experiment, we used waterproof speakers placed at known locations to broadcast prerecorded frog calls, enabling us to quantify the range of detection for SPAM in relation to various environmental factors. Frogs that call underwater generally cannot be heard by human observers more than $10 \mathrm{~m}$ from the calling frog (Jensen, Palis, and Bailey 1995). Thus, we considered SPAM successful if it detected submerged frog calls from greater than $10 \mathrm{~m}$. Detection probability via MCS ranges from 10\%-70\% (e.g., Heard, Robertson, and Scroggie 2006). Although no detection probabilities have been generated for underwater-calling frogs, SPAM should be considered a very successful technology if it can detect greater than $70 \%$ of generated calls.

Performance Objective 2 (PO2) was to (1) validate the ability of SPAM to detect anuran calls generated below the water's surface and (2) compare the ability of SPAM to detect real frog calls in field conditions relative to PAM and MCS. First, we conducted a controlled experiment at the CLO to validate the ability of SPAM to detect recordings of underwater-generated frog calls and to compare the performance of SPAM (hydrophone) to PAM (airborne microphone) and MCS (human listener) methods. Second, we conducted two long-term deployments of SPAM and PAM in actual field conditions. This demonstration was conducted at Fort Stewart, Georgia, and Coronado National Forest, Arizona. We quantified species detections by 
SPAM and PAM for each deployment. Third, we conducted a field experiment to compare SPAM, PAM, and MCS under actual field conditions with real calling Chiricahua leopard frogs at Coronado National Forest. We compared the number of frog calls detected by each of the three methods and considered SPAM technology successful if it detected an equal or greater number of calls than PAM and MCS. We predicted that, because detection probability is likely negatively biased for MCS and PAM, SPAM would detect more individuals than the other methods and, at a minimum, would record the same number of individuals.

Performance Objective $3\left(\mathrm{PO}_{3}\right)$ was to demonstrate the effectiveness of SPAM data for population estimation through direct counts of distinct individuals in recordings. Natural resource professionals are often interested in the number of calling individuals. To be adopted by managers, SPAM must be able to not only detect the presence of calling anurans but to be able to generate an estimate of the number of anurans calling that is at least as accurate as the categorical index employed in MCS. We evaluated the ability of SPAM to generate estimates of relative abundance from acoustic data at Coronado National Forest, compared to the minimum known number of frogs present (counted visually).

Performance Objective $4\left(\mathrm{PO}_{4}\right)$ was a qualitative performance objective pertaining to the cost of SPAM technology. Here, we made comparisons between the cost-effectiveness of SPAM relative to PAM and MCS. We calculated the material, data collection and analysis, and travel costs associated with each of the three survey methodologies as they would be put in practice. Although SPAM has an initial higher investment in equipment and supplies and requires more time-consuming and rigorous data analyses, it was expected to record a greater number of frogs with less effort than MCS and, thus, provide more value. As part of this assessment, we created a decision support diagram to aid practitioners in choosing the most suitable survey method (Figure 25). 
Table 1. Performance Objectives to evaluate subsurface passive acoustic monitoring (SPAM) technology.

\begin{tabular}{|c|c|c|c|c|}
\hline Performance objective & Metric & Data requirements & Success criteria & Results \\
\hline \multicolumn{5}{|c|}{ Quantitative performance objectives } \\
\hline $\begin{array}{l}\text { P01: Examine the influence } \\
\text { of environmental factors on } \\
\text { acoustic detectability } \\
\text { (validation experiment 1) }\end{array}$ & $\begin{array}{l}\text { - Number of speakers } \\
\text { emitting calls } \\
\text { - Signal to Noise Ratio } \\
\text { of recorded calls (dB) } \\
\text { - Distance from speaker } \\
\text { to recorder (m) } \\
\text { - Wetland } \\
\text { characteristics (depth, } \\
\text { turbidity, substrate) }\end{array}$ & $\begin{array}{l}\text { - Number of calls produced } \\
\text { - Frequency }(\mathrm{Hz}) \text { of recorded } \\
\text { call } \\
\text { - Detection range }(\mathrm{m}) \\
\text { - Wetland characteristics } \\
\text { (depth, turbidity, substrate) }\end{array}$ & 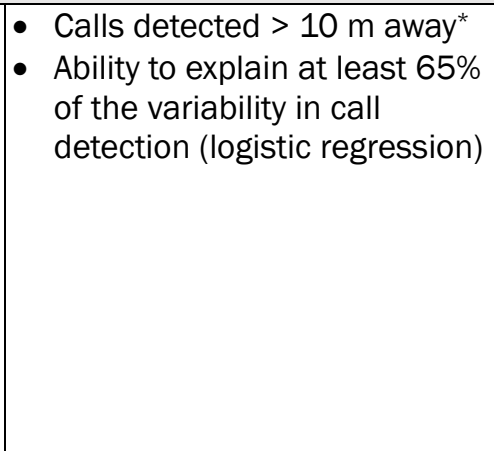 & $\begin{array}{l}\text { - In validation experiment } 1 \text {, } \\
\text { hydrophones detected } 54 \% \text { of } \\
\text { underwater playback. } \\
\text { - Underwater calls detected from } \\
\text { up to of } 65 \text { m away } \\
\text { - Number of submerged } \\
\text { obstacles between speaker } \\
\text { and recorder and water depth } \\
\text { explained substantial variation } \\
\text { in detection (AIC } \\
\text { weight }=0.84 \text { ). }\end{array}$ \\
\hline
\end{tabular}




\begin{tabular}{|c|c|c|c|c|}
\hline Performance objective & Metric & Data requirements & Success criteria & Results \\
\hline $\begin{array}{l}\text { PO2: Part 1: Validate the } \\
\text { ability of SPAM to detect } \\
\text { frog calls generated below } \\
\text { the water's surface } \\
\text { (validation experiment 2) }\end{array}$ & $\begin{array}{l}\text { Detection/non- } \\
\text { detection of focal frog } \\
\text { calls }\end{array}$ & $\begin{array}{l}\text { - SPAM data while } \\
\text { prerecorded frog calls } \\
\text { broadcast underwater }\end{array}$ & $\begin{array}{l}->70 \% \text { of emitted calls } \\
\text { detected by SPAM }{ }^{\dagger}\end{array}$ & $\begin{array}{l}\text { - In controlled conditions, SPAM } \\
\text { successfully detected } 79 \% \text { of } \\
\text { underwater-generated calls. } \\
\text { - SPAM was } 30 \text { times more likely } \\
\text { to detect underwater calls } \\
\text { relative to PAM }(t=-9.92, \\
\text { df }=559, P=0.001, \beta=-3.42) \\
\text { and } 8.5 \text { times more likely } \\
\text { relative to MCS }(t=-6.92, \\
\text { df }=559, P=0.001, \beta=-2.14) \text {. }\end{array}$ \\
\hline $\begin{array}{l}\text { Part 2: Compare the ability } \\
\text { of SPAM, PAM, and MCS to } \\
\text { detect real frog calls in field } \\
\text { conditions (field } \\
\text { demonstration) }\end{array}$ & 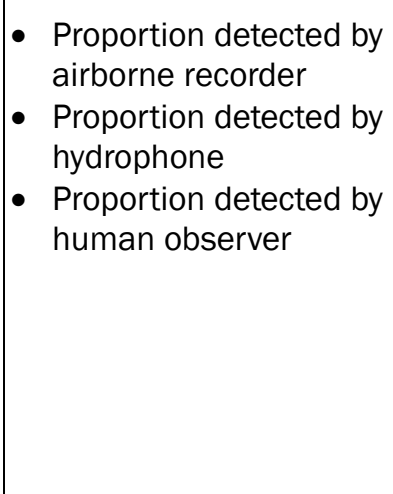 & $\begin{array}{l}\text { - SPAM, PAM, and MCS data } \\
\text { of focal species at } \\
\text { wetlands } \\
\text { - Proportion detected by } \\
\text { airborne recorder } \\
\text { - Proportion detected by } \\
\text { hydrophone } \\
\text { - Proportion detected by } \\
\text { human observer }\end{array}$ & $\begin{array}{l}\text { - Equal or greater number of } \\
\text { frogs detected with SPAM } \\
\text { than detected by PAM and } \\
\text { MCS } \\
\text { - Statistically more frogs } \\
\text { detected by SPAM than } \\
\text { traditional methods }(P<0.05)\end{array}$ & $\begin{array}{l}\text { - Under field conditions, PAM } \\
\text { and MCS outperformed SPAM } \\
\text { at detecting free-ranging } \\
\text { Chiricahua leopard frogs. } \\
\text { - In long-term deployment, SPAM } \\
\text { detected Chiricahua leopard } \\
\text { frog calls in } 42 \% \text { of samples; } \\
\text { PAM detected } 63 \% \text {. } \\
\text { - In long-term deployment, SPAM } \\
\text { detected two gopher frog calls } \\
\text { (PAM detected 1) over two } \\
\text { years of recording. }\end{array}$ \\
\hline $\begin{array}{l}\text { PO3: Demonstrate the } \\
\text { effectiveness of SPAM data } \\
\text { for population estimation } \\
\text { through field deployment }\end{array}$ & $\begin{array}{l}\text { - Estimated population } \\
\text { calculated from } \\
\text { number of individual } \\
\text { detections and sex } \\
\text { ratio of } 1: 1\end{array}$ & $\begin{array}{l}\text { - Number of distinct } \\
\text { individuals identified by } \\
\text { SPAM } \\
\text { - Number of individuals } \\
\text { counted visually }\end{array}$ & $\begin{array}{l}\text { Population estimate } \\
\text { generated by SPAM data is } \\
\text { close to actual population } \\
\text { value }\end{array}$ & $\begin{array}{l}\text { - Identified maximum of eight } \\
\text { distinct individuals at each of } \\
\text { two wetlands, resulting in } \\
\text { population estimates of } 16 \\
\text { individuals each, compared to } \\
\text { visual counts of } 17 \text { and } 15 \\
\text { individuals }\end{array}$ \\
\hline
\end{tabular}




\begin{tabular}{|c|c|c|c|c|}
\hline Performance objective & Metric & Data requirements & Success criteria & Results \\
\hline \multicolumn{5}{|c|}{ Qualitative performance objective } \\
\hline $\begin{array}{l}\text { PO4: Compare the cost- } \\
\text { effectiveness of SPAM as } \\
\text { monitoring technology } \\
\text { relative to traditional survey } \\
\text { methods for amphibians } \\
\text { (MCS and PAM) }\end{array}$ & $\begin{array}{l}\text { - } \text { Material costs } \\
\text { - Labor costs (data } \\
\text { collection and } \\
\text { analysis) } \\
\text { - Travel costs }\end{array}$ & $\begin{array}{l}\text { - } \text { Cost of equipment and } \\
\text { supplies for SPAM, PAM, } \\
\text { and MCS } \\
\text { - Labor costs associated } \\
\text { with deployment of SPAM } \\
\text { and PAM } \\
\text { - Labor associated with } \\
\text { conducting MCS } \\
\text { - Cost of mileage to and } \\
\text { from survey sites } \\
\text { - Cost per } 5 \text { min survey } \\
\text { (MCS) or cost per night of } \\
\text { data generated (SPAM and } \\
\text { PAM) }\end{array}$ & $\begin{array}{l}\text { - Total cost of SPAM is similar } \\
\text { or cheaper than PAM and } \\
\text { MCS }\end{array}$ & $\begin{array}{l}\text { - Single night of SPAM is more } \\
\text { expensive }(\$ 3,370) \text { than PAM } \\
\text { ( } \$ 2,489) \text { or MCS }(\$ 111.50) \text {. } \\
\text { - Initial cost of SPAM is high, but } \\
\text { value comes when detection } \\
\text { probability of species is low } \\
\text { and long-term deployment is } \\
\text { advantageous (cost per night } \\
<\$ 200 \text { after } 21 \text { nights, }<\$ 100 \\
\text { after } 52 \text { nights). } \\
\text { - If vocalizations are not } \\
\text { detectable by terrestrial } \\
\text { observers, although PAM and } \\
\text { MCS are cheaper, SPAM may } \\
\text { be the only way to effectively } \\
\text { detect species. }\end{array}$ \\
\hline
\end{tabular}




\section{Site Description}

\subsection{Cornell Lab of Ornithology, Ithaca, New York}

The CLO was the site of two validation (playback) experiments (Sections 5.4.2-5.4.3). It is located in the middle of the 230-acre Sapsucker Woods Wildlife Sanctuary in northeastern Ithaca, NY (Figure 2). Sapsucker Woods contains a diversity of habitats, including mature hardwood forests, wetlands, and ponds. These different habitats support a high diversity of bird and amphibian species. The ponds and wetlands at CLO provided an ideal location to conduct the validation experiments because they were immediately accessible from the lab facilities and infrastructure and because they contained a number of different wetland and pond habitats to capture a diversity of acoustic conditions.

Figure 2. Locations of wetlands (A-E) in Sapsucker Woods at the Cornell Lab of Ornithology, NY, where validation experiments were conducted in 2017 to examine the influence of environmental variable on detection by SPAM and to compare SPAM to PAM and MCS.

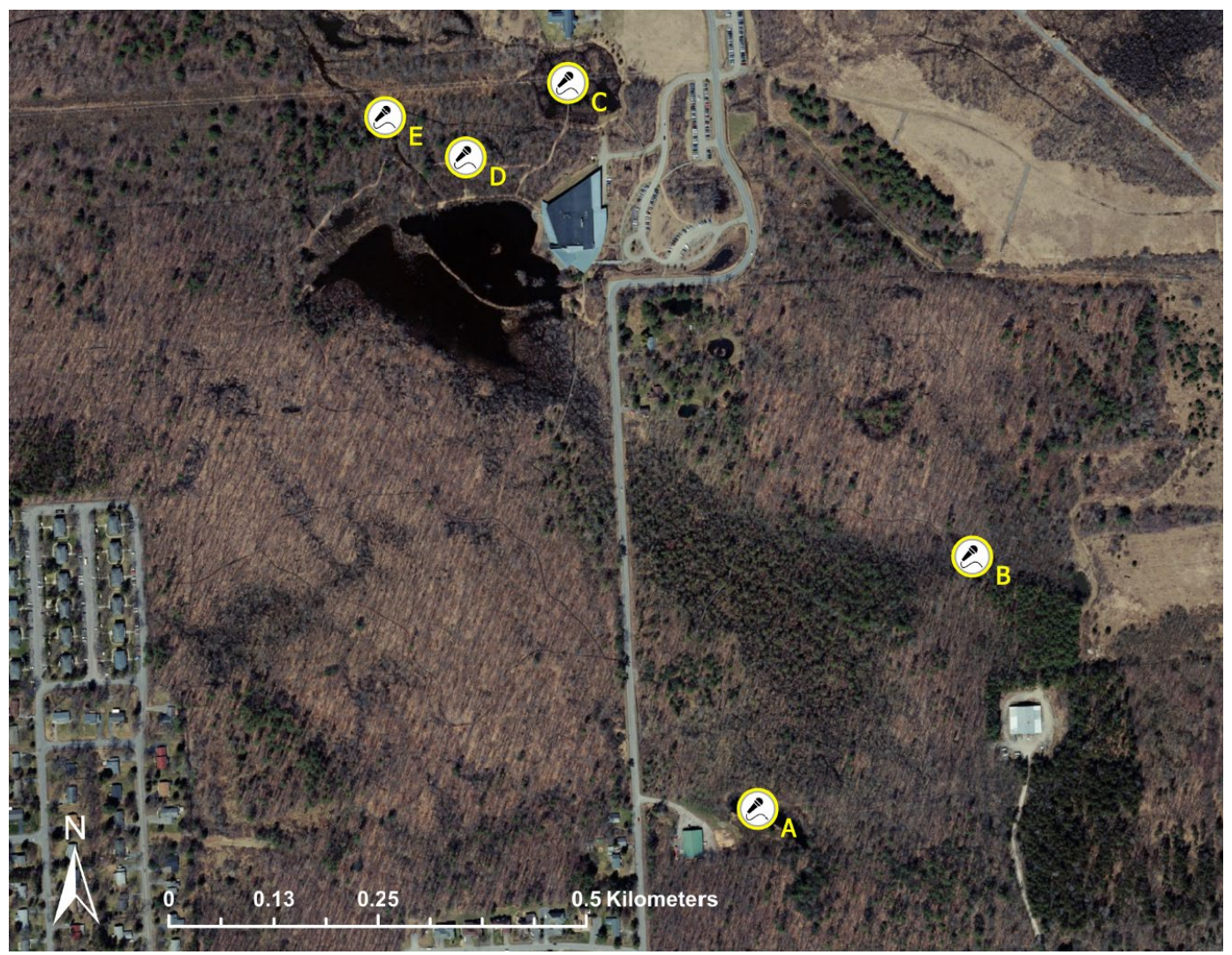


In the spring and summer, as many as 6-10 species of frogs can regularly be heard calling from these wetlands, indicating these habitats are desirable for amphibians. Because the location is well outside the range of both focal species in this project, there was no risk of accidentally recording real gopher frogs or Chiricahua leopard frogs during the validation experiments. This was important because it allowed us to control the "true number of frogs" calling during each of the experiments.

\subsection{Fort Stewart, Georgia}

U.S. Army Garrison Fort Stewart encompasses approximately 113,064 ha of the lower coastal plain of southeastern Georgia (Figure 3). The installation is home to extensive xeric sandhill communities including intact mature, longleaf pine-turkey oak-wiregrass habitat, young (5 to 15 years) to medium (16 to 40 years) slash or loblolly pine plantations, and recently restored longleaf pine habitats.

Figure 3. Locations of wetlands (A-E) on Fort Stewart, GA, where SPAM was deployed in 2018 and 2019.

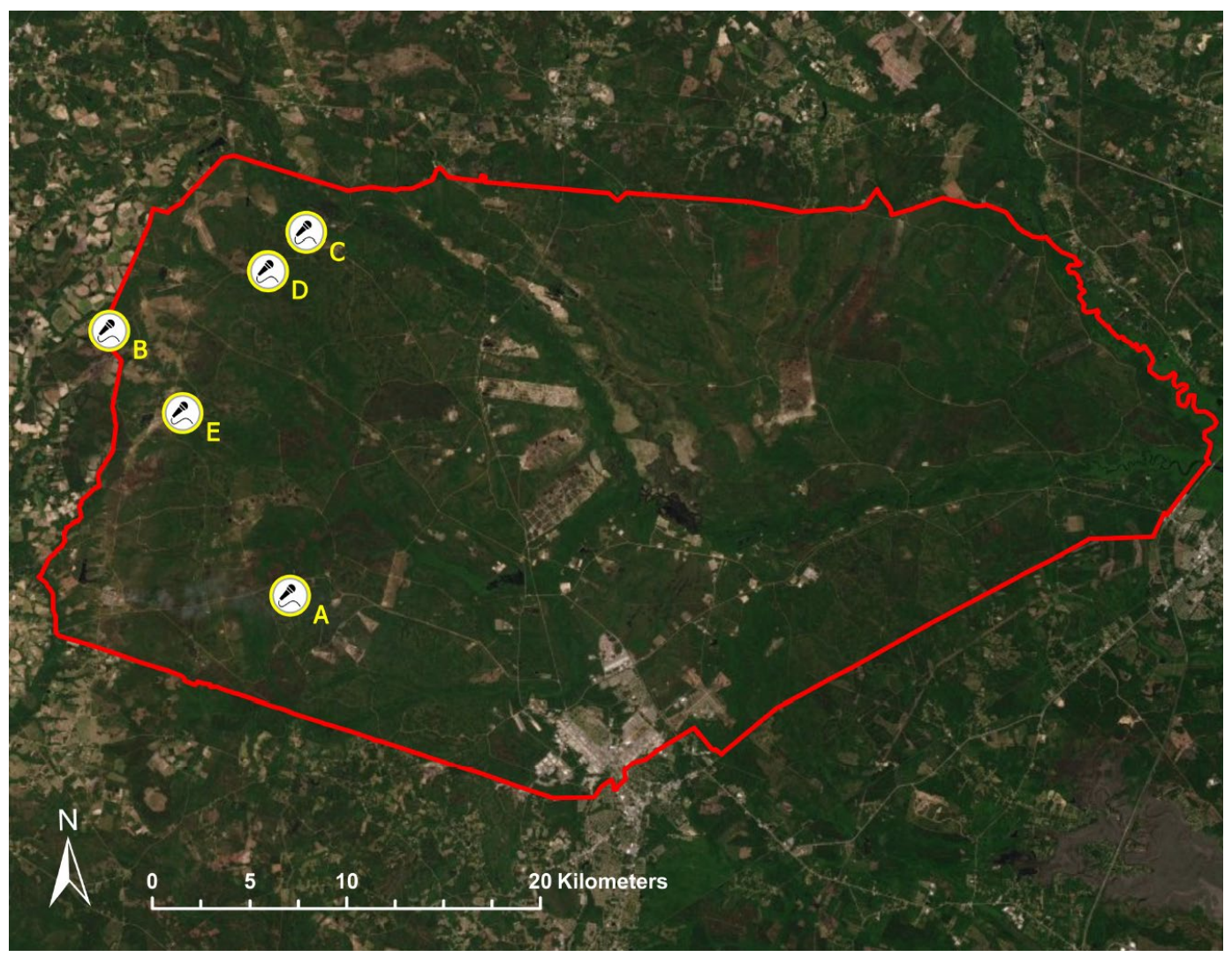


The xeric pine habitats are interspersed with mesic pine flatwoods, mixed pine-oak forests, bottomland hardwood habitats, depressional wetlands and blackwater creek swamps. Fort Stewart actively manages its land using prescribed burns, selective thinning, longleaf pine planting, wiregrass seeding, and control of xerophytic oaks via herbicide. These management practices not only maintain the open pine forests required by gopher tortoises (Gopherus polyphemus) and red-cockaded woodpeckers (Leuconotopicus borealis) but protect and maintain isolated ephemeral sandhills wetlands that are extremely diverse and rapidly declining across the southeast. These isolated upland wetlands are critically important for numerous pond-breeding amphibians, including the frosted flatwoods salamander (Ambystoma cingulatum) and gopher frog (Lithobates capito).

Overall, approximately one-third of the land area of Fort Stewart is classified as wetland. The Ogeechee River forms part of the boundary on the northeastern side of the installation, and the Canoochee River bisects the installation. These wetlands consist of ephemeral sandhills wetlands, bottomland hardwood forests, freshwater tidal marshes, fishing ponds, floodplains, and creeks. Fort Stewart is home to a diverse amphibian community due to its intact wetland ecosystems. The imperiled gopher frog is known to widely occur on Fort Stewart. Gopher frog sightings on Fort Stewart span five counties in Georgia, including Bryan, Evans, Liberty, Long, and Tattnall counties, but detections and distribution vary greatly from year to year. Many of the records of gopher frog sightings on Fort Stewart come from encounters on roads and road-side ditches, and more recently from environmental DNA (eDNA) surveys. Determining where they breed on Fort Stewart is a challenge.

\subsection{Coronado National Forest, Arizona}

Coronado National Forest spans 17 mountain ranges across 1,780,000 acres of federal land in southeastern Arizona. Our demonstration was conducted in the Huachuca Mountains within the National Forest, adjacent to Fort Huachuca, a 29,652 ha military installation located approximately $96 \mathrm{~km}$ (60 miles) southeast of Tucson and $24 \mathrm{~km}$ (15 miles) north of the Mexican border (Figure 4). The region has a dry climate with relatively mild winters and warm summers, with about $60 \%$ of annual precipitation falling during the summer "monsoon" season, which triggers frog breeding activity. 
Figure 4. Locations of wetlands (A-G) in Coronado National Forest, $A Z$, where SPAM was deployed in 2018 and 2019.

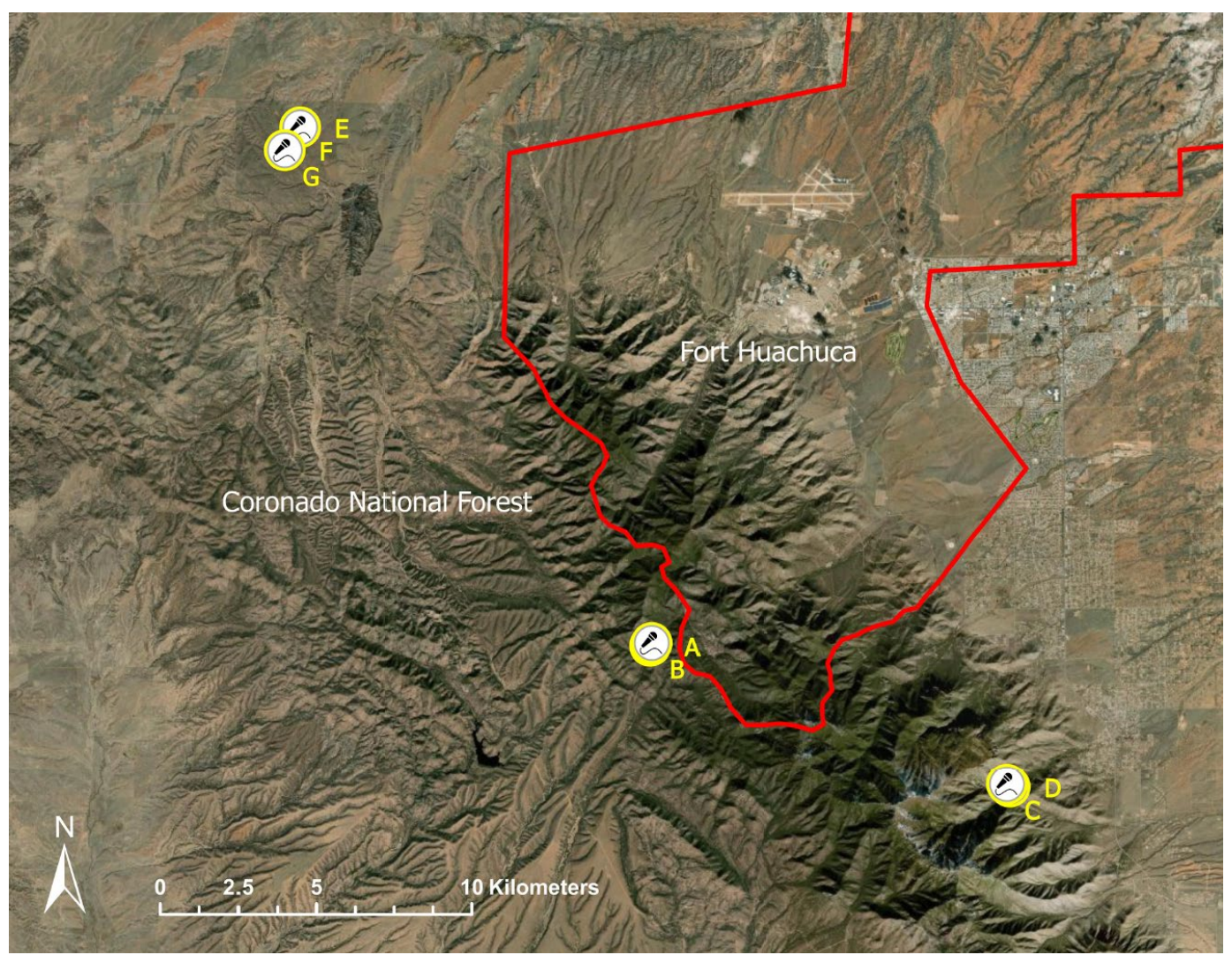

Chiricahua leopard frogs were historically known from many localities in the Huachuca Mountains, but now many of the breeding populations exist in manmade tanks and ponds. Coronado National Forest is the focus of active management by collaborative federal, state, and private agencies for recovery of the leopard frog. Leopard frogs are annually surveyed throughout the National Forest to inform the species' recovery plans. As such, the presence, absence, and status of populations on the installation and National Forest are well known and informed our demonstration site selection. Conservation efforts in Coronado National Forest are viewed as having a positive impact on Fort Huachuca's population, as suitable habitat does still exist on Fort Huachuca, and management for this species operates in a metapopulation framework with individuals traveling between wetlands. 


\section{Test Design}

\subsection{Conceptual test design}

Our demonstration consisted of several steps to both validate and demonstrate SPAM technology. Table 2 presents each component of our technical approach as it relates to our performance objectives. First, we conducted an extensive, controlled validation experiment to test the influence of environmental factors on the detectability of underwater-generated frog calls by SPAM (Section 5.4.2). Second, we validated the ability of SPAM to detect anuran calls generated below the water's surface and compared the ability of SPAM to detect frog calls relative to PAM and MCS in controlled conditions (Section 5.4.3). Third, we conducted long-term deployments of SPAM at two different demonstration sites to record the calls of free-ranging gopher frogs, a species under review for federal listing found on several military installations in the southeastern United States (Section 5.4.4.1), and Chiricahua leopard frogs, a federally threatened species that occurs in southeastern Arizona (Section 5.4.4.2.1). Fourth, we compared the efficacy of SPAM relative to PAM and MCS under field conditions in nightly surveys in Arizona (Section 5.4.4.2.2). Fifth, we demonstrated how data generated from SPAM can be used to make population estimates using data collected in the Arizona deployment (Section 5.4.5). Finally, we compared the cost-effectiveness of SPAM to PAM and MCS (Section 7). 
Table 2. Overview of conceptual test design, outlining the experiments or assessments conducted to address each performance objective, and the locations of their methods in this report.

\begin{tabular}{|c|c|c|c|c|c|c|}
\hline Performance objective & $\begin{array}{l}\text { Experiment/ } \\
\text { assessment }\end{array}$ & $\begin{array}{c}\text { Experiment/assessment } \\
\text { overview }\end{array}$ & Experiment/assessment description & Site(s) & $\begin{array}{l}\text { Wetland } \\
\text { type }\end{array}$ & $\begin{array}{l}\text { Report } \\
\text { section }\end{array}$ \\
\hline $\begin{array}{l}\text { P01: Identify wetland } \\
\text { characteristics that } \\
\text { determine SPAM } \\
\text { effectiveness }\end{array}$ & $\begin{array}{l}\text { Validation } \\
\text { experiment } 1\end{array}$ & SPAM detection range & $\begin{array}{l}\text { Test SPAM under controlled conditions to } \\
\text { determine its detection range and identify } \\
\text { wetland characteristics that most influence } \\
\text { detection range }\end{array}$ & $\begin{array}{l}\text { Cornell Lab of } \\
\text { Ornithology, } \\
\text { wetlands A-E }\end{array}$ & Natural & 5.4 .2 \\
\hline $\begin{array}{l}\text { P02: Part 1: Validate } \\
\text { the ability of SPAM to } \\
\text { detect frog calls } \\
\text { generated below the } \\
\text { water's surface }\end{array}$ & $\begin{array}{l}\text { Validation } \\
\text { experiment } 2\end{array}$ & $\begin{array}{l}\text { Validation of frog call } \\
\text { detection using SPAM }\end{array}$ & $\begin{array}{l}\text { Test the ability of SPAM to detect frog calls } \\
\text { generated underwater using prerecorded } \\
\text { frog calls } \\
\text { Compare efficacy of SPAM to PAM and MCS } \\
\text { in controlled conditions }\end{array}$ & $\begin{array}{l}\text { Cornell Lab of } \\
\text { Ornithology, } \\
\text { wetland D }\end{array}$ & Natural & 5.4 .3 \\
\hline \multirow[t]{2}{*}{$\begin{array}{l}\text { PO2, Part 2: Compare } \\
\text { the ability of SPAM, } \\
\text { PAM, and MCS to detect } \\
\text { real frog calls in field } \\
\text { conditions }\end{array}$} & $\begin{array}{l}\text { Field } \\
\text { demonstration, } \\
\text { long-term } \\
\text { deployment }\end{array}$ & $\begin{array}{l}\text { Compare SPAM and PAM in } \\
\text { field conditions in two } \\
\text { months-long deployments }\end{array}$ & $\begin{array}{l}\text { Compare efficacy of two methods, SPAM } \\
\text { and PAM, in a realistic, long-term } \\
\text { deployment scenario for detecting wild, } \\
\text { free-ranging gopher frogs and Chiricahua } \\
\text { leopard frogs at two demonstration sites }\end{array}$ & $\begin{array}{l}\text { Coronado } \\
\text { National } \\
\text { Forest, } \\
\text { wetlands A-D }\end{array}$ & $\begin{array}{l}\text { Natural } \\
\text { and } \\
\text { artificial }\end{array}$ & 5.4.4.1 \\
\hline & $\begin{array}{l}\text { Field } \\
\text { demonstration, } \\
\text { nightly surveys }\end{array}$ & $\begin{array}{l}\text { Compare SPAM, PAM, and } \\
\text { MCS in series of 5-min nightly } \\
\text { surveys }\end{array}$ & $\begin{array}{l}\text { Compare efficacy of three methods, SPAM, } \\
\text { PAM, and MCS, for detecting wild, free- } \\
\text { ranging Chiricahua leopard frogs }\end{array}$ & $\begin{array}{l}\text { Coronado } \\
\text { National } \\
\text { Forest, } \\
\text { wetlands E-G }\end{array}$ & $\begin{array}{l}\text { Natural } \\
\text { and } \\
\text { artificial }\end{array}$ & 5.4.4.2.2 \\
\hline
\end{tabular}




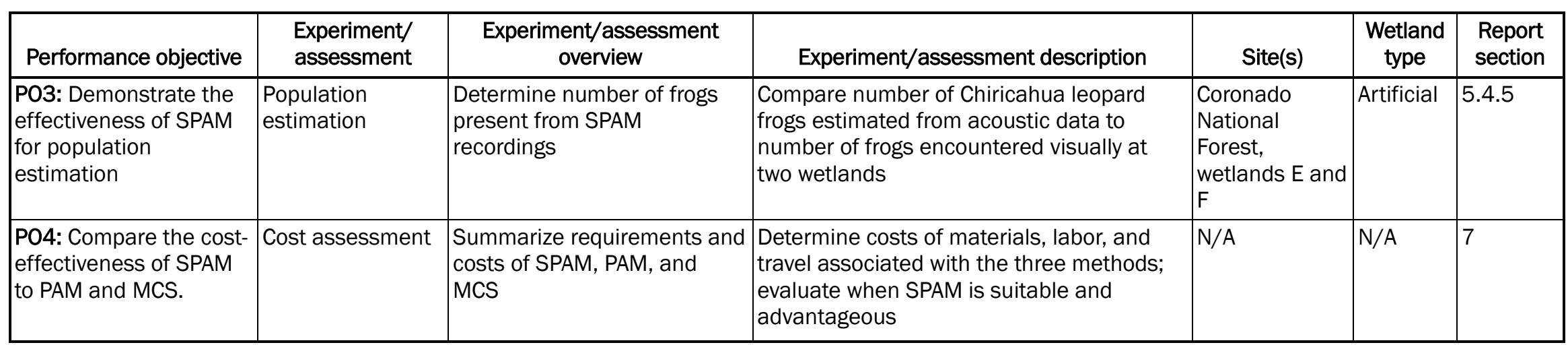




\subsection{Baseline characterization and preparation}

Before conducting our validation experiments, we first prepared the necessary audio equipment, described below (Section o). Before our field demonstration, we gathered baseline knowledge of our focal species at our demonstration sites to determine the optimal placement of SPAM units (Section 5.2.2).

\subsubsection{Preparation of audio equipment}

Our series of playback experiments (Sections 5.4.2 and 5.4.3) used a combination of underwater speakers for broadcasting sounds and a dip hydrophone system for recording. Underwater sounds were played using an underwater speaker (AQ339, Lubell Labs, Inc., Whitehall, OH; frequency response $20 \mathrm{~Hz}$ to $17 \mathrm{kHz}$ ) connected to a portable amplifier powered by a $12 \mathrm{~V}$ marine battery and to a laptop playing sounds. Sounds were recorded with an Aquarian H2a hydrophone (Aquarian Audio \& Scientific, Anacortes, WA; frequency sensitivity: $-180 \mathrm{~dB}$ re: $1 \mathrm{~V} / \mu \mathrm{Pa}$ ) connected to a two-channel hand-held audio recorder (Olympus LS-10, Olympus Corp, Center Valley, PA). Because the audio recorder had a variable gain, the system's signal chain was calibrated by comparison (sensu Bobber 1970), using a SoundTrap ST300 STD (Ocean Instruments, NZ) with an end-to-end calibrated sensitivity of $-176 \mathrm{~dB}$ re: $1 \mathrm{~V} / \mu \mathrm{Pa}$. Source levels of the playback sounds were estimated using the passive sonar equation $(\mathrm{SL}=\mathrm{RL}+\mathrm{TL}$ ) with cylindrical spreading transmission loss (Urick 1983). To quantify in-air detection of underwater sounds during the human listening trials, a shotgun microphone (MKH 60-1, Sennheiser Electronic GmbH \& Co, Old Lyme, CT) was connected to the audio recorder.

\subsubsection{Statuses of focal species at demonstration sites}

Operational scale demonstration of SPAM took place on Fort Stewart and Coronado National Forest. We identified specific locations to deploy SPAM through consultation with local biologists and land managers and on-the-ground visits in July 2017. Chosen wetlands were known to, or likely to, harbor our two focal species.

The gopher frog has been documented over the years at Fort Stewart, but its population status is relatively unknown (Palis and Fischer 1997; TNC 1995). The gopher frog spends the vast majority of its time buried underground, 
only emerging to breed in ephemeral wetlands under certain conditions, and even then, sporadically (Dorcas and Gibbons 2008). Therefore, its spatial distribution is difficult to track due to its cryptic habits and unpredictable breeding phenology. The Chiricahua leopard frog is known to occur in a relatively few discrete locations in Coronado National Forest. It occurs in permanent and ephemeral wetlands and breeds mainly during monsoon season in July, although breeding has been documented in every month of the year. Monitoring either species using MCS is particularly challenging because they call extensively underwater. Additionally, in the case of the gopher frog, it breeds so rarely and unpredictably that the likelihood of missing the species during MCS (i.e., false negative rate) is very high (Dorcas et al. 2009).

\subsection{Design and layout of technology components}

This project used archival acoustic recording units with two channels of audio input, modified from the Swift recorder developed by the Center for Conservation Bioacoustics at Cornell University (https://www.birds.cornell.edu/ccb/swift/). One channel was connected to an external hydrophone (HTI-96-min hydrophone, supplied by Wildlife Acoustics, Inc.) for recording underwater (SPAM component). The other channel was connected to an airborne microphone, built into the recording unit, for recording sounds in air (PAM component). The recorders stored data on SDXC flash cards and were powered by $16 \mathrm{D}$-cell batteries. The sampling rate was configured to record at a sampling rate of $10 \mathrm{kHz}$ for the hydrophone and 16 $\mathrm{kHz}$ for the microphone, which provided a usable frequency range of $\mathrm{O}-5$ $\mathrm{kHz}$ and $\mathrm{o}-8 \mathrm{kHz}$ bandwidth, respectively, for analysis. This range was sufficient to capture sounds produced by the two focal frog species. The units were capable of recording continuously for up to three months. Audio data were stored in lossless .wav format.

\subsection{Field testing}

\subsubsection{Sampling protocol}

Data were collected over three field seasons (Table 3). In October 2017, we conducted two field experiments to assess the efficacy of hydrophones for detecting underwater frog calls. The first evaluated the wetland characteristics that most influenced the detection distance of hydrophones (Section 5.4.2). The second confirmed the ability of hydrophones to detect underwater-generated frog calls and directly compared detection probabilities of 
hydrophones, microphones, and human observers (Section 5.4.3). Both experiments were conducted at the CLO. From February through May of 2018 and February to March of 2019, we performed a long-term field demonstration of SPAM technology at Fort Stewart to record gopher frogs above and below the water's surface in the absence of human observers (Section 5.4.4.1). Similarly, from June through August 2018, we performed a long-term field demonstration at Coronado National Forest to record Chiricahua leopard frogs (Section 5.4.4.2.1). In July 2019, we conducted a second field demonstration at Coronado National Forest to directly compare hydrophones, microphones, and human observers under real field conditions with free-ranging Chiricahua leopard frogs (Section 5.4.4.2.2).

Table 3. Timeline for validation of SPAM at the Cornell Lab of Ornithology, Ithaca, New York, and demonstration of SPAM at Fort Stewart, Georgia, and Coronado National Forest, Arizona.

\begin{tabular}{|l|l|l|}
\hline \multicolumn{1}{|c|}{ Activity } & \multicolumn{1}{|c|}{ Date range } & \multicolumn{1}{c|}{ Description } \\
\hline Site selection & July 2017 & $\begin{array}{l}\text { Field demonstration sites selected at Fort } \\
\text { Stewart and Coronado National Forest }\end{array}$ \\
\hline $\begin{array}{l}\text { Validation } \\
\text { experiments }\end{array}$ & October 2017 & $\begin{array}{l}\text { Two experiments conducted at CLO to } \\
\text { (1) evaluate factors influencing the detection } \\
\text { range of SPAM and (2) compare frog call } \\
\text { detection by SPAM, PAM, and MCS }\end{array}$ \\
\hline $\begin{array}{l}\text { Field } \\
\text { femonstration: }\end{array}$ & $\begin{array}{l}\text { February-May 2018; Stewart } \\
\text { February-March 2019 }\end{array}$ & $\begin{array}{l}\text { SPAM deployed at five wetlands on Fort Stewart } \\
\text { likely to harbor gopher frogs }\end{array}$ \\
\hline $\begin{array}{l}\text { Field } \\
\text { demonstration: } \\
\text { Coronado National } \\
\text { Forest }\end{array}$ & June-August 2018 2019 & $\begin{array}{l}\text { SPAM deployed at four wetlands likely to harbor } \\
\text { Chiricahua leopard frogs }\end{array}$ \\
\cline { 2 - 3 } & July & $\begin{array}{l}\text { Compared SPAM, PAM, and MCS at three } \\
\text { wetlands with free-ranging Chiricahua leopard } \\
\text { frogs }\end{array}$ \\
\hline
\end{tabular}

\subsubsection{Validation experiment 1: Factors influencing detection range}

To evaluate the influence of wetland characteristics on the detection of underwater-generated frog calls by hydrophones, we conducted playback trials in a series of diverse wetlands and measured underwater sound propagation. This experiment was conducted at the CLO in October 2017. We chose this location because of the availability of wetlands of varying sizes and characteristics, and at that time of year, no frogs were vocalizing to interfere with our broadcasted frog calls (Figure 2). Wetlands ranged in size from $100-1300 \mathrm{~m}^{2}$ (measured via satellite imagery) and covered a spectrum of habitat features, from completely nonvegetated, shallow, and ephemeral depressions to heavily vegetated, deep ponds with complex underwater structures such as logs, rocks, and debris. 
In five wetlands (Figure 5), we established a total of eight transects $10-70 \mathrm{~m}$ in length that crossed a range of habitat features. At one end of each transect, an underwater speaker was attached to a stake to ensure it did not move during a given trial. The speaker was connected via coaxial cable to an amplifier and laptop computer located on the shore and controlled by an author (Rice). The speaker was set to play a playback sequence that consisted of six synthesized control tones, followed by a sequence of gopher frog calls, followed by a sequence of Chiricahua leopard frog calls (Figure 6). This was a truncated version of the playback sequence described in further detail in validation experiment 2 (Section 5.4.3).

For each trial, one author (DeGregorio) stood $1 \mathrm{~m}$ in front of the speaker, holding the audio recorder attached to a hydrophone and headphones. The hydrophone was submerged so it was suspended at the midpoint of the water column. After waiting for the water around the hydrophone to settle (no audible noise on the headphones), the playback sequence was initiated and repeated in individual trials with the speaker positioned just under the surface of the water, in the middle of the water column, and at the bottom (Chiricahua leopard frog playback source level: $119 \mathrm{~dB}$ re $1 \mu \mathrm{Pa} @ 1 \mathrm{~m}$; gopher frog playback source level: $118 \mathrm{~dB}$ re $1 \mu \mathrm{Pa} @ 1 \mathrm{~m})$. After playback was completed at all three speaker depths, the hydrophone was moved back to a distance of $5 \mathrm{~m}$ from the speaker, and playback from all three depths was repeated. This process continued until the playback sequence was played at $5 \mathrm{~m}$ increments moving away from the speaker for the length of the transect (except for the initial $1 \mathrm{~m}$ distance). 
Figure 5. Wetlands at the CLO used to evaluate the influence of wetland characteristics on the detection of underwater-generated frog calls by hydrophones.
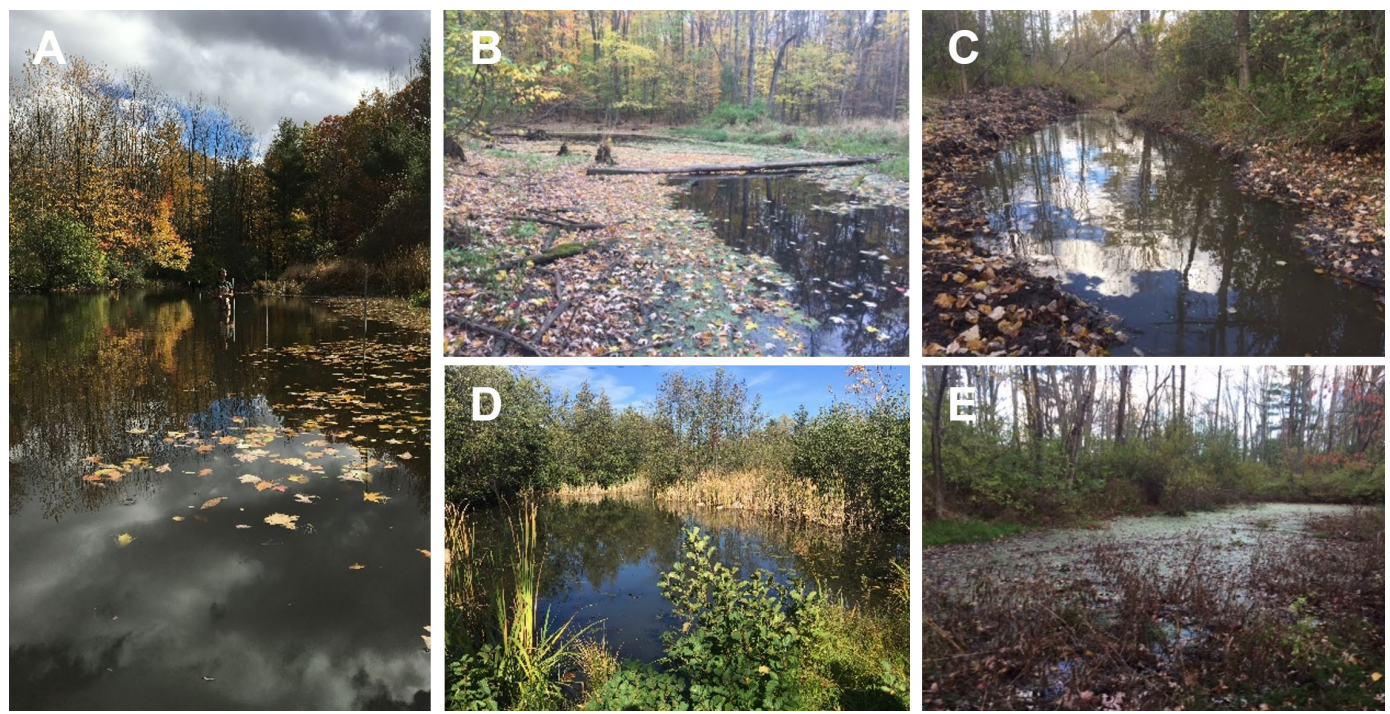

We measured the following habitat variables at every location the hydrophone was submerged: water depth (range $=14-91 \mathrm{~cm}$ ), turbidity (range $=6-240$ Neophelometric Turbidity Units [NTU]), substrate depth (range $=0-42 \mathrm{~cm}$ ), and number of submerged obstacles (e.g., logs) between the speaker and hydrophone (range $=0-12$ obstacles). Water depth and substrate depth were measured with a meter stick. Turbidity was measured in centimeters using a turbidity tube and converted to NTU. Water temperature was measured at the wetland level, but because of low variability among wetlands ( range $=15 \cdot 6^{\circ} \mathrm{C}-17.2^{\circ} \mathrm{C}$ ), this variable was excluded from analyses. 
Figure 6. Representative playback sounds with (top) waveform and (bottom) spectrogram (FFT $=2048$ ) of the playback sequence used to evaluate underwater frog-call attenuation in wetlands of varying habitat characteristics. The playback sequence begins with six $0.5 \mathrm{sec}$ pure tones at $100,200,500,750,1000,1500$, and $2000 \mathrm{~Hz}$, followed by a sequence of gopher frog calls and a sequence of Chiricahua leopard frog calls.
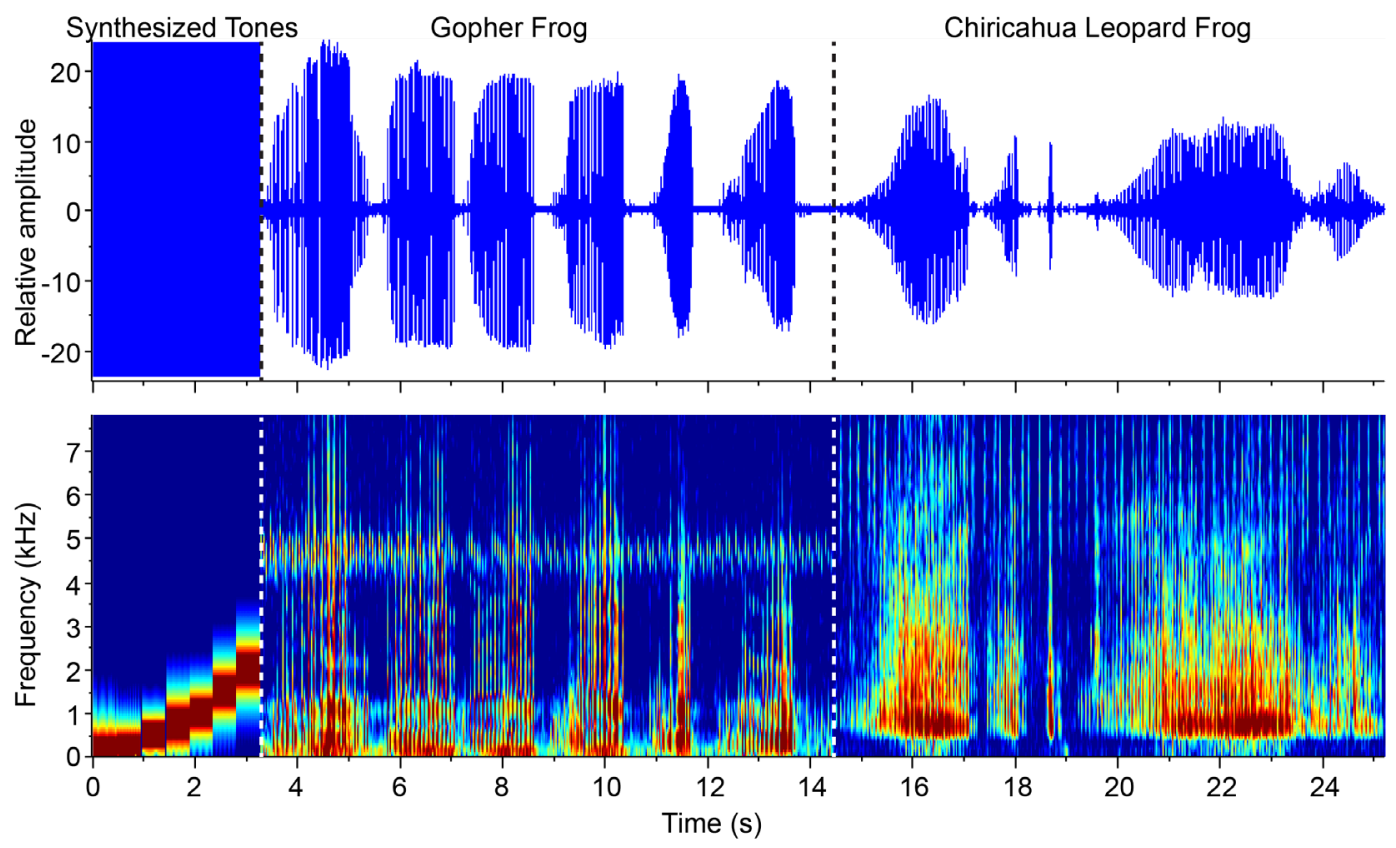

After all trials were completed, we used Kaleidoscope Pro software (Wildlife Acoustics, Inc., Maynard, MA) to label each individual frog call emitted during trials as detected or not detected by the hydrophone and microphone. We used a combination of listening and visual inspection of waveforms and spectrograms to determine whether each call emitted during a survey was detected by each method. If a call could be heard on the recording by either of the authors reviewing the data (DeGregorio and Wolff), it was marked as detected. Alternatively, if the waveform or spectrogram was distinct enough to indicate the presence of a frog call, it was also marked as detected. We chose this method as it likely reflects how the typical practitioner attempting to detect the presence of an underwater-calling species would approach the data.

To evaluate the influence of environmental covariates on detection by the hydrophone, we created generalized linear mixed models with a binomial response variable of detected (1) or not detected (o) and used a logit link function. We used function glmer in package lme 4 in Program R v. 3.6.1 ( $\mathrm{R}$ Core Team 2019). We evaluated the following fixed variables for their 
influence on detection: distance to speaker, water depth, turbidity, substrate depth, number of obstacles, speaker depth (near-surface, midwater column, or bottom), and species of call emitted (gopher frog or Chiricahua leopard frog). Substrate depth and number of obstacles were highly correlated $(r=0.51)$ and were not included in the same model. Wetland identity was included as a random block effect. We ranked 27 candidate models based on $\mathrm{AIC}_{\mathrm{c}}$ (Burnham and Anderson 2002) to determine the influence of wetland characteristics on detection by the hydrophone.

\subsubsection{Validation experiment 2: Confirming the efficacy of SPAM}

To confirm the ability of SPAM to detect underwater-generated frog calls and to compare the effectiveness of SPAM (hydrophones), PAM (microphones), and MCS (human observers), we conducted an experiment that tested all three methods simultaneously at a single wetland. Prerecorded gopher frog and Chiricahua leopard frog calls were broadcast from underwater speakers while a human observer stood near a shotgun-style microphone and a hydrophone. We compared the number of emitted calls that were detected by each method.

We first created a 3 min and 45 sec playback sequence consisting of 16 alternating gopher frog and Chiricahua leopard frog calls. Half of the call sequences were played at a high amplitude (source level: $118 \mathrm{dBRMS}$ re $1 \mu \mathrm{Pa}$ ) and half were emitted at a low amplitude (source level: $113 \mathrm{dBRMS}$ re 1 $\mu \mathrm{Pa}$ ). Representative calls were obtained from reference collections (Macaulay Library 1996, 2007; Figure 6). Because both species' calls are broadband (gopher frog: frequency range: 300-9000 Hz, peak frequency: $1055 \mathrm{~Hz}$; Chiricahua leopard frog frequency range: $450-11000 \mathrm{~Hz}$, peak frequency: $800 \mathrm{~Hz}$ ), we anticipated frequency-dependent signal attenuation in shallow water (e.g., Forrest, Miller, and Zagar 1993). We also included a series of $0.5 \mathrm{sec}$ pure tones at 100, 200, 500, 750, 1000, 1500, and $2000 \mathrm{~Hz}$ as positive controls to examine propagation distance as a function of signal frequency.

In a series of 16 trials, we placed two underwater speakers at preselected locations within the wetland (Figure 7). One speaker was placed at a distance of either $4 \mathrm{~m}$ or $8 \mathrm{~m}$ from the recording devices and human observer, and the other was placed at $12 \mathrm{~m}$ or $16 \mathrm{~m}$. Speakers were placed either just below the surface of the water or resting on the wetland bottom. 
Speaker locations and depths in the water column were changed between trials. Each speaker was attached to stakes to control its depth and to ensure that it did not move during the course of a trial.

Figure 7. Configuration of validation experiment 2 , from the perspective of the human observer. Although only two speakers emitted frog calls in any given trial, dummy stakes were placed at different distances in the wetland, so the observer did not know the distances from which calls were emitted.

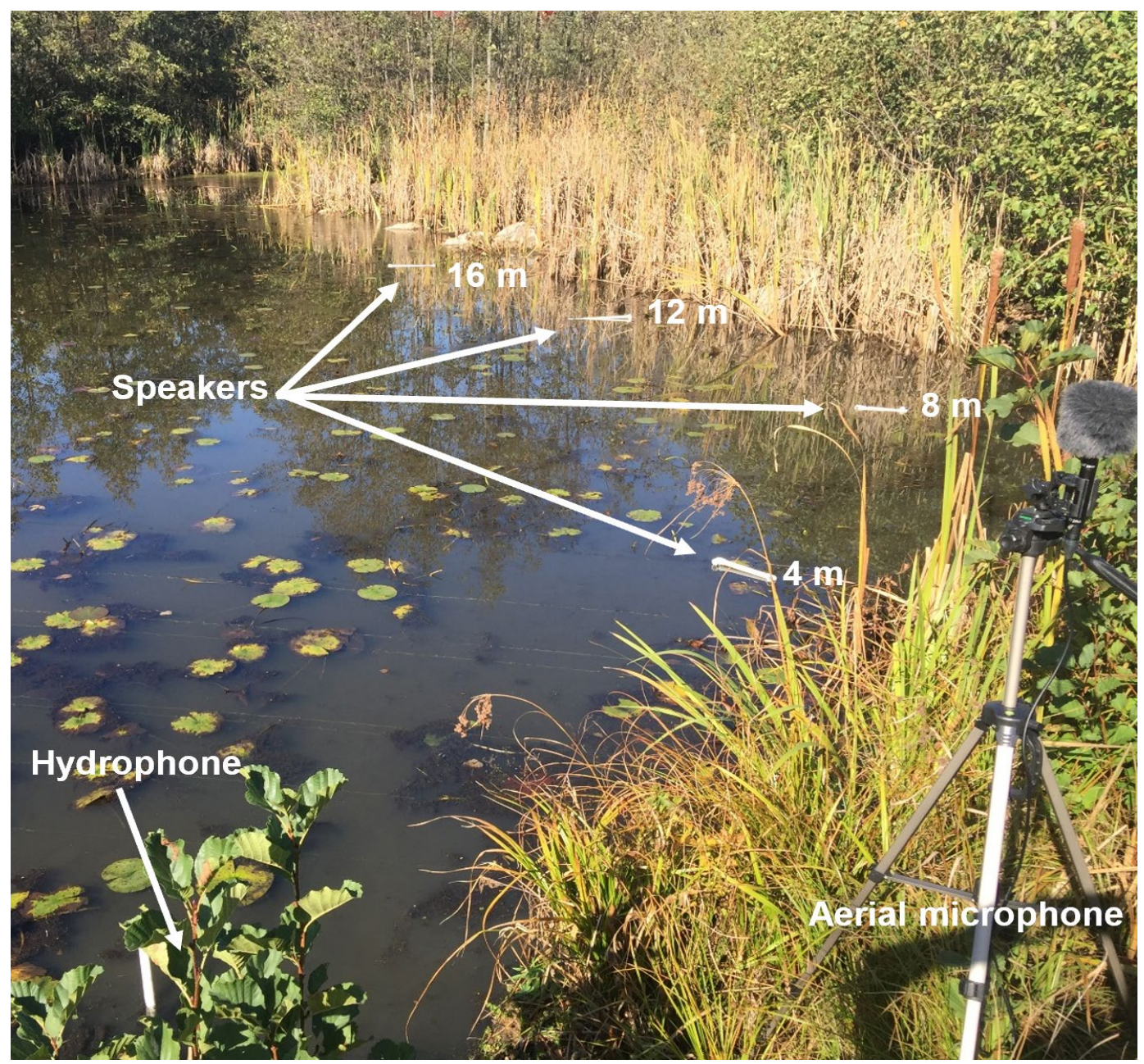

We placed dummy stakes at various locations in the wetland to prevent human observers from knowing where each of the speakers was deployed during their trial. During playback, only one call sequence was played at a time (i.e., speakers at different distances did not broadcast simultaneously).

We recruited student and employee volunteers from the CLO to participate in the trials. Each human observer participated in two trials, and the speakers were moved between trials. Volunteers were given several 
minutes to listen to and learn the calls of the two focal frog species. Then, one at a time (volunteers did not observe each other's trials), observers stood at the margin of the wetland beside the microphone and hydrophone and listened for the duration of the approximately 3 min 45 sec survey. Each time volunteers detected a frog call, they raised their hand to indicate a detection, and one of the authors recorded it and matched it to the call currently being emitted.

The observer was positioned next to a tripod holding the recorder. One channel was attached via coaxial cable to a hydrophone, and the other was attached to an in-air microphone. The microphone was placed at the edge of the wetland, and the hydrophone was placed just within the margin of the wetland in approximately $0.5 \mathrm{~m}$-deep water. The observer, microphone, and hydrophone were all less than $1 \mathrm{~m}$ from each other.

After all trials were completed, we processed the resulting acoustic data to label each frog call as detected or not detected by the hydrophone and microphone using the same methodology as in validation experiment 1 (Section 5.4.2 ). Each call was marked as detected or not detected by human observers based on whether they raised their hand while that call was emitted or not.

For analyses, we treated each emitted call as an independent unit. Thus, during each trial, there were 16 unique calls emitted (half gopher frog and half Chiricahua leopard frog). We used a binomial mixed model (Proc GLIMMIX in SAS 9.4) with a response variable of detected (1) or not detected (o). We evaluated the fixed factors of species (gopher frog or Chiricahua leopard frog), speaker depth (near-surface or bottom), distance ( $4 \mathrm{~m}, 8 \mathrm{~m}, 12 \mathrm{~m}$, or $16 \mathrm{~m}$ ), and amplitude (low or high) for their influence on detection. We used the observer trial number as a random factor to account for variation in background noise during each trial.

\subsubsection{Field demonstration}

We deployed SPAM systems over the course of two years at Fort Stewart (Figure 3) and Coronado National Forest (Figure 4) at several key locations known to, or likely to, harbor the species of interest. We used CLO's Swift recording units, described in Section 5.3 to compare underwater SPAM recording (hydrophone) with aerial PAM recording (microphone) simultaneously and directly. Systems were set to record continuously and stored data 
digitally (sound files; .wav format, $44.1 \mathrm{kHz}$ ) on local secure digital (SD) cards, which were downloaded at the end of the deployments. When put into practice by natural resource managers, each SPAM system would consist of both an aerial microphone and a hydrophone. In this demonstration, our long-term comparison of SPAM to PAM enabled us to quantify the additional data gleaned from the incorporation of a subsurface recording component. In Arizona, we also conducted a series of nightly MCS to directly compare traditional human observer methods to SPAM and PAM with wild frogs.

\subsubsection{Fort Stewart: comparing SPAM to PAM in a long-term deployment}

From 21 February to 30 May 2018, we deployed Swift recording units at five wetlands likely to host gopher frog breeding (Figure 8). Target wetlands were chosen to cover a large and geographically diverse area of Fort Stewart and to encompass different wetland characteristics (e.g., wooded wetlands and open-canopy ephemeral wetlands). We chose wetlands that had a high likelihood of detecting gopher frogs by first consulting with Fort Stewart biologist, Mr. Roy King. These were wetlands where gopher frogs had previously been encountered opportunistically, detected via eDNA sampling, or breeding was suspected to occur due to habitat suitability and/or the presence of other pond-breeding amphibians that often co-occur with gopher frogs.

Figure 8. Five wetlands at which SPAM and PAM were deployed to search for breeding gopher frogs (Lithobates capito) from February through May 2018. Three recording units were redeployed at wetland D in February 2019.
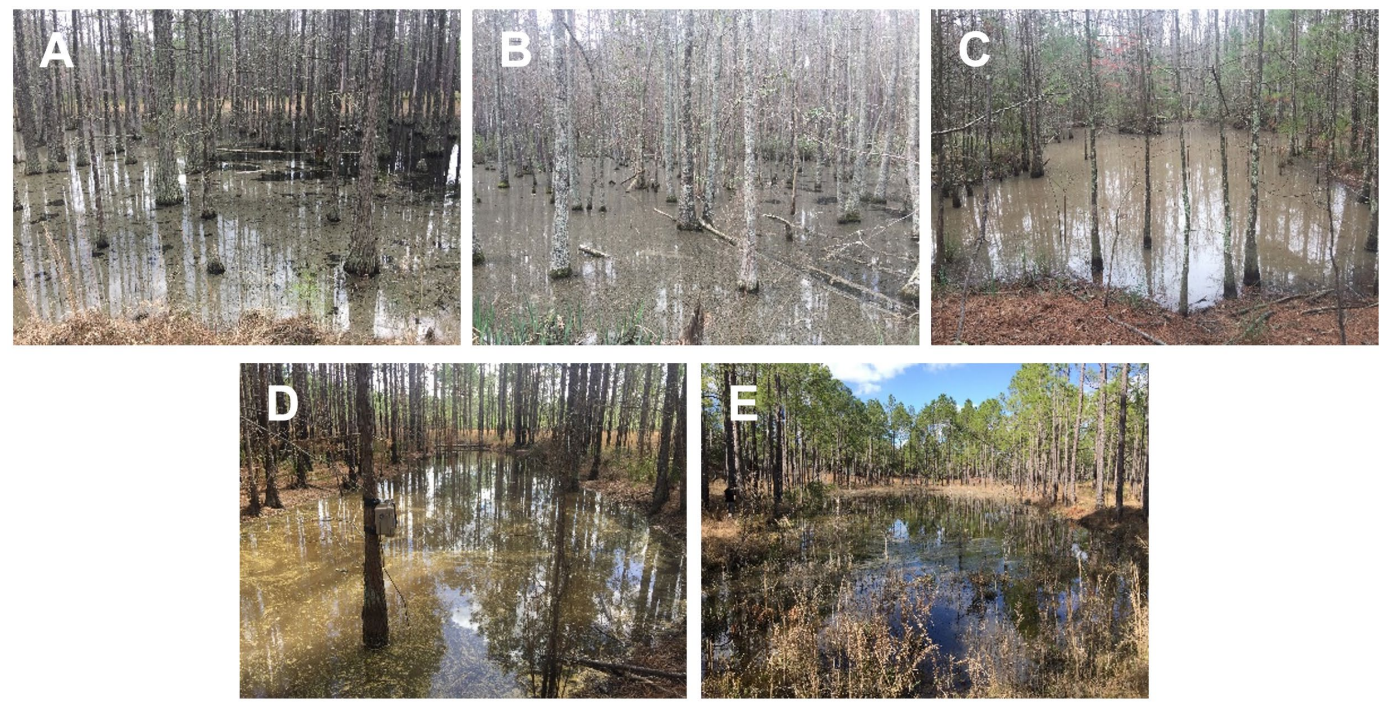
From 19 February 2019 to 3 March 2019, we deployed three Swifts at a single wetland in a triangular array spaced approximately $50 \mathrm{~m}$ apart (wetland D; Figure 9). At the time, Fort Stewart was experiencing a drought, and many of the breeding ponds had not filled with water. Water was present at this wetland because of deep pools associated with alligator (Alligator mississippiensis) activity. Additionally, this was a wetland where gopher frogs were suspected to have bred during the previous year based on preliminary review of acoustic files.

At each pond, we attached a two-channel Swift recorder to a tree either in the wetland or on the wetland margin (Figure 9). From each recorder, we ran a cabled hydrophone from the recorder to a nearby section of the wetland at least $50 \mathrm{~cm}$ deep. We used a $75 \mathrm{~cm}$-tall plastic garden stake to anchor the hydrophone at the mid-point of the water column. The hydrophone was attached to the stake by cables ties in a manner such that the hydrophone itself was floating in the water column and not in contact with vegetation or the stake to avoid picking up vibrations.

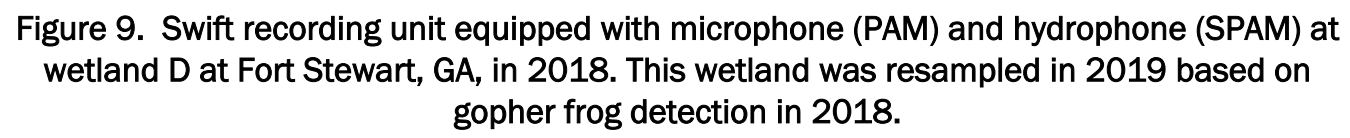

Figure 9. Swift recording unit equipped with microphone (PAM) and hydrophone (SPAM) at wetland D at Fort Stewart, GA, in 2018. This wetland was resampled in 2019 based on gopher frog detection in 2018.
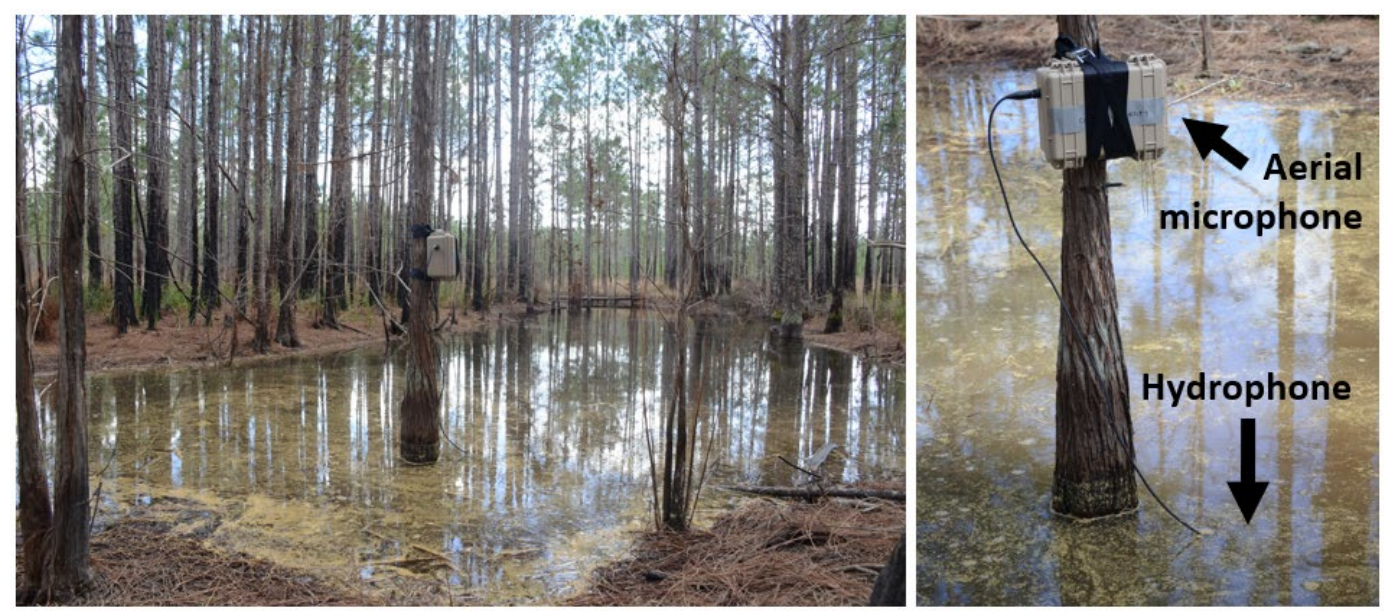

Each recorder also had a built-in omnidirectional microphone. We set the recording devices to record continuously from the moment of deployment to when we retrieved the units. Each unit was powered by $16 \mathrm{D}$-cell batteries and was capable of recording for up to three months before power expired and the SD memory cards (256 GB) were filled. 
We used Raven Pro acoustic analysis software to create an automated detection algorithm to automatically detect gopher frog calls. This algorithm was created using archived gopher from calls available from the Macaulay Library (https://www.macaulaylibrary.org/). Whenever a gopher frog was detected via the automated algorithm, a human observer listened to the recording to confirm its veracity. Additionally, we manually reviewed a subset of recordings to search for gopher frog vocalizations that were not detected by the automated algorithm. Additionally, we identified each species of frog that was detected on hydrophones.

\subsubsection{Coronado National Forest}

\subsection{Comparing SPAM to PAM in a long-term deployment}

From 19 June to 29 August 2018, we deployed Swift recording units at four wetlands (wetlands A-D; Figure 10). This coincided with monsoon season in southern Arizona, when frequent precipitation fills ephemeral wetlands and triggers frog breeding. Precipitation during this time is spatially and temporally unpredictable; thus, frog breeding is easy to miss if conducting single brief visits to study sites (as in MCS). We chose wetlands offering stark contrasts in habitat characteristics to assess the performance of SPAM technology across a range of wetlands that Chiricahua leopard frogs potentially occupy. We chose wetlands known to contain leopard frogs (wetlands $\mathrm{C}$ and $\mathrm{D}$, manmade pools built specifically for species recovery efforts; Figure 10) or that had a high likelihood of containing leopard frogs based on past occurrence data and consultation with U.S. Forest Service biologist, Mr. John Kraft (wetlands A and B; Figure 10).

Figure 10. SPAM and PAM were deployed at four wetlands to search for breeding Chiricahua leopard frogs (Lithobates chiricahuensis) from June through August 2018. Leopard frogs are known to occur at a variety of wetlands, from naturally occurring ponds $(A)$ and seeps $(B)$ to manmade, concrete-lined pools $(C)$. Wetland D, not pictured, was similar to wetland $C$.
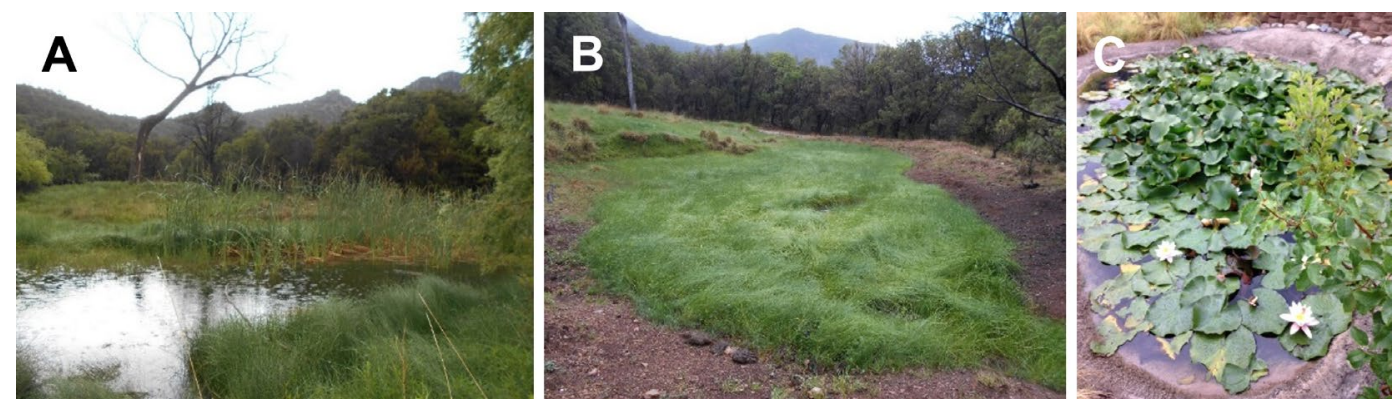
Like the Fort Stewart deployment, we attached a two-channel Swift recorder to a tree or on the wetland margin at each pond. From each recorder, we ran a cabled hydrophone from the recorder to a nearby section of the wetland. We used a $75 \mathrm{~cm}$-tall plastic garden stake or a rock to anchor the hydrophone, so it floated at the midpoint of the water column. The Swifts recorded continuously, and data were retrieved from SD cards at the end of the deployment.

We used Raven Pro software to manually review (visually and aurally) a subsample of the resulting long-term, continuous recordings from the hydrophones and microphones. We divided the continuous recordings into 5-min-long segments during the night (between 30 min after sunset to sunrise) and determined detection or nondetection of Chiricahua leopard frogs within each segment. We used this 5 -min segment length because it is a typical survey duration for MCS, and $30 \mathrm{~min}$ after sunset is the recommended time to begin sampling (see Section 5.4.4.2.2). Although MCS were not conducted during this deployment, this sample length allowed us to evaluate similar levels of effort. We used the $z$ test statistic to test for differences in the proportion of samples in which frogs were detected by SPAM and PAM at each site using a significance level of $\alpha=0.05$.

\subsection{Comparing SPAM, PAM, and MCS in nightly surveys}

In July 2019, we conducted a field demonstration to directly compare hydrophones (SPAM), microphones (PAM), and human observers (MCS) under real field conditions with free-ranging Chiricahua leopard frogs in a series of nightly surveys. This demonstration was conducted on the property of the Appleton-Whittell Research Ranch of the National Audubon Society in southeastern Arizona, adjacent to Fort Huachuca (wetlands E-G; Figure 4). We chose three recording locations at ponds known to contain leopard frogs. Chiricahua leopard frogs were historically known from many localities in the region, but now many of the breeding populations exist in manmade tanks and ponds. As such, two of our chosen locations were old cattle tanks that are now used in the U.S. Forest Service's population restoration efforts (wetlands E and F; Figure 11); the third was a naturally occurring, ephemeral wetland (wetland G; Figure 11). 
Figure 11. Wetland $\mathrm{E}$, a former cattle tank now used for Chiricahua leopard frog restoration, and wetland G, a natural, ephemeral wetland, where Swift recording units were deployed at Coronado National Forest, AZ, in 2019. Wetland F, not pictured, was similar to wetland E.
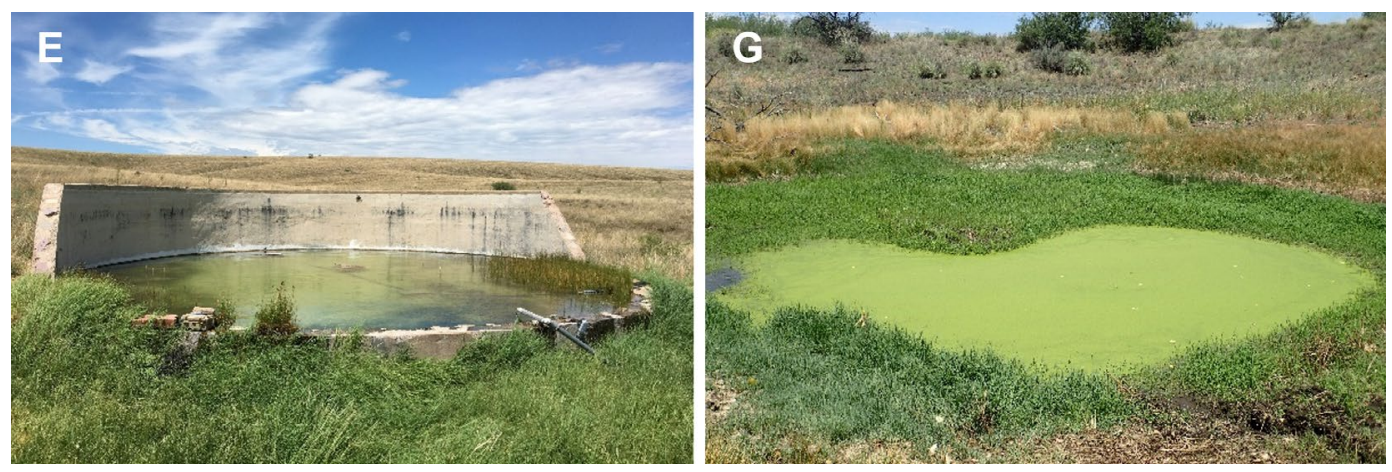

We placed two-channel Swift units in each of the three ponds to record simultaneously above and below the water's surface for three nights continuously. On each of the three nights, between three and six observers conducted one MCS, each following the NAAMP protocol, resulting in 36 total surveys. Each MCS consisted of a 5-minute survey window beginning at least 30 minutes after sunset.

During the survey, observers recorded whether they heard calling frogs or not, as well as a categorical index to describe the frog chorus $(0=$ no frogs calling; 1 = individuals could be counted because there was space between calls; 2 = calls and individuals could be distinguished, but there was some overlapping of calls; 3 = full chorus in which calls were constant, continuous and overlapping). Immediately following the surveys, the observers approached the wetland to visually count the number of individual leopard frogs visible, which were used as minimum population sizes for Section 5.5.4.

We compared the number of detections and nondetections of leopard frogs by the three methods (SPAM, PAM, and MCS) at each wetland. To further evaluate SPAM and PAM in the absence of human observers, we subsampled the continuous acoustic data in 5-min segments and examined differences in detection throughout the night as in Section 5.4.4.2.1.

\subsubsection{Population estimation}

PAM has been traditionally applied to detect presence or absence (or more appropriately, presence or nonpresence) of vocalizing species (Mellinger et al. 
2007; Van Parijs et al. 2009). In many natural resource management or protected species assessments, temporal or spatial occurrence provides sufficient actionable data to streamline or improve monitoring efforts or improve efficacy.

Recent quantitative approaches have improved the resolution of PAM data outputs to provide estimates of density or abundance of focal species (Marques et al. 2013). Animal calls can be counted as a proxy for vocalizing individuals, and with appropriate assumptions, the population can be estimated through counting sounds. There are several key caveats with this approach.

First, only vocalizing species or individuals can be counted; in many taxa, including anurans (Gerhardt and Huber 2002), males are the only sex that actively call. Consequently, abundance estimates of calling individuals must be modified to calculate the total population size present that is comprised of both calling and noncalling individuals.

Second, many survey methods-whether MCS or PAM-suffer from imperfect detection, and not all of the calls reported were actually produced; thus, calling data must be modified as a function of detection probability. In many survey methods, detection probability decreases with increasing distance from the individual, and quantitative approaches (such as distance sampling) include this in the detection function.

Third, abundance estimates are directly based on the number of calls, not necessarily the number of individuals. To translate number of calls to the number of individuals, the average individual call rate is a vital, but often neglected, metric (Marques et al. 2013). For most species studied with passive acoustic surveys, call rate is rarely known. Additionally, species' call rates can also change as a function of population, location, time of day, behavioral context, or season, and using call rates from locations other than the focal study can lead to misleading estimates.

For our passive acoustic survey demonstration, we sought to estimate the number of calling individuals in small populations of Chiricahua leopard frogs in Arizona. We used data from the three-night deployment at wetlands E, F, and G, described in Section 5.4.4.2.2. 
For both wetlands $\mathrm{E}$ and $\mathrm{F}$, the principal advantage was these artificial ponds represented closed populations from a survey perspective (i.e., all individuals occurred within the monitoring location). Chiricahua leopard frogs are obligate wetland inhabitants. Since the area surrounding the cattle tanks was grassland, there were no leopard frogs that could be detected on our recorders that were not at the pond. Consequently, all calls detected came from within the ponds being surveyed. At both wetlands F and G, single Swift recorders with both hydrophones and microphones were deployed. Units recorded at a $16 \mathrm{kHz}$ sample rate. At wetland E, three synchronized Swift recorders were deployed in an array to evaluate the feasibility of different population estimation approaches. At wetlands $\mathrm{E}$ and F, frogs could be easily seen by observers, and all individuals were counted at night for a population estimate to corroborate the acoustic estimates. Because we were able to record the entire population at wetlands $\mathrm{E}$ and $\mathrm{F}$ and had high detection probability, we could use direct counts to estimate the number of calling individuals at these sites (Marques et al. 2013).

Acoustic data collected by microphones and hydrophones from each site was analyzed in Raven Pro, and the number of distinct calls (based on acoustic features such as receive level, duration, frequency or amplitude modulation pattern, center frequency, etc.) were counted. Because most frogs are often stationary when calling (Gerhardt and Huber 2002), we assumed that calls with different sound levels in a short sequence $(<30 \mathrm{sec})$ represented different individuals, rather than a single individual moving to different locations.

\subsection{Sampling results}

\subsubsection{Validation experiment 1: Factors influencing detection range}

A total of 252 underwater frog call sequences were emitted at eight transects across five wetlands, $54 \%$ of which were detected by the hydrophone. There was substantial variation in detection across wetlands; for example, the hydrophone detected frog calls up to $65 \mathrm{~m}$ away in one transect but failed to detect calls from only $1 \mathrm{~m}$ away in another. With all calls played at the same source level across trials, it was clear that vegetation density had a significant impact on sound attenuation. The top-ranked model (AIC weight $=0.84$ ) indicated that the number of submerged obstacles and water depth had the greatest influences on detection by the hydrophone. No other model was competitive $\left(\Delta \mathrm{AIC}_{\mathrm{c}}<2\right)$, and this model substantially outperformed the intercept-only model $\left(\Delta \mathrm{AIC}_{\mathrm{c}}=133.13\right)$. 
Detection increased as the number of submerged obstacles between the speaker and hydrophone decreased $(\beta=-6.02, \mathrm{SE}=1.29, P<0.001$; Figure 12A). No calls were detected when greater than two submerged obstacles were between the speaker and hydrophone. Detection increased with increasing water depth $(\beta=0.09, \mathrm{SE}=0.02, P<0.001$; Figure 12B). Detection decreased as the hydrophone was placed farther from the speaker $(\beta=-0.05, \mathrm{SE}=0.01, P<0.001$; Figure 13). Lastly, detection was related positively to turbidity $(\beta=0.03, \mathrm{SE}=0.01, P<0.01)$ and substrate depth $(\beta=0.05, \mathrm{SE}=0.02, P=0.02)$.

Figure 12. Effects of the number of submerged obstacles $(A)$ and water depth $(B)$ on detection probability of underwater frog calls by a hydrophone (SPAM). Black line $=$ modelpredicted estimate; gray shading $=95 \%$ confidence interval.
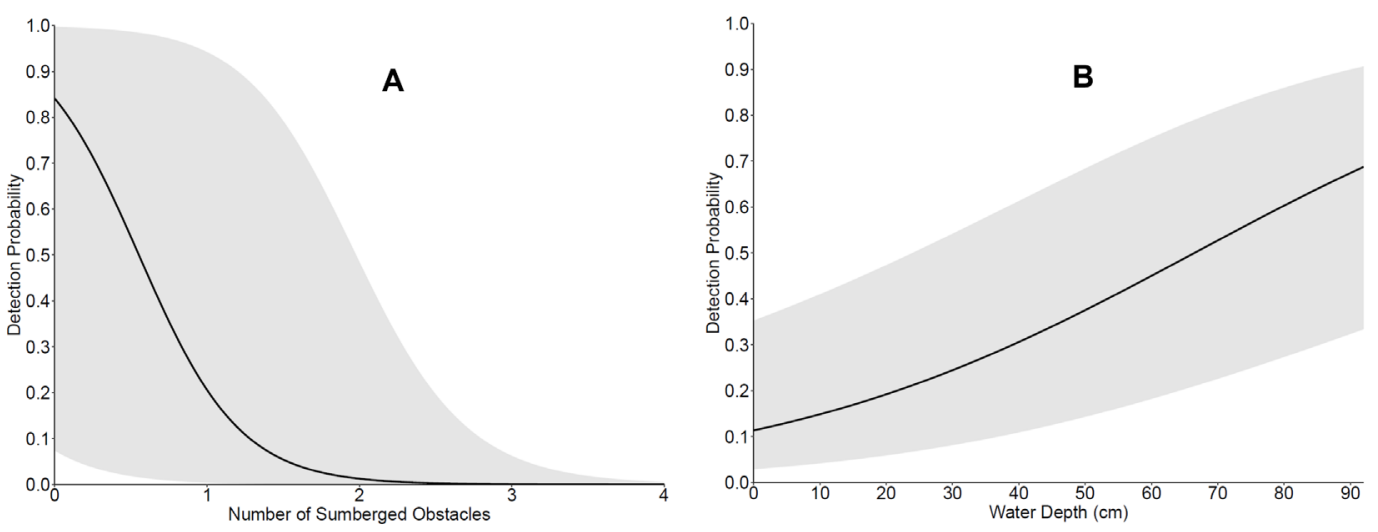
Figure 13. Spectrogram visualization of frog call attenuation during validation experiment 1 at the Cornell Lab of Ornithology, NY. Detection of the playback sequence decreased with increasing distance between the speaker broadcasting playback and the hydrophone.

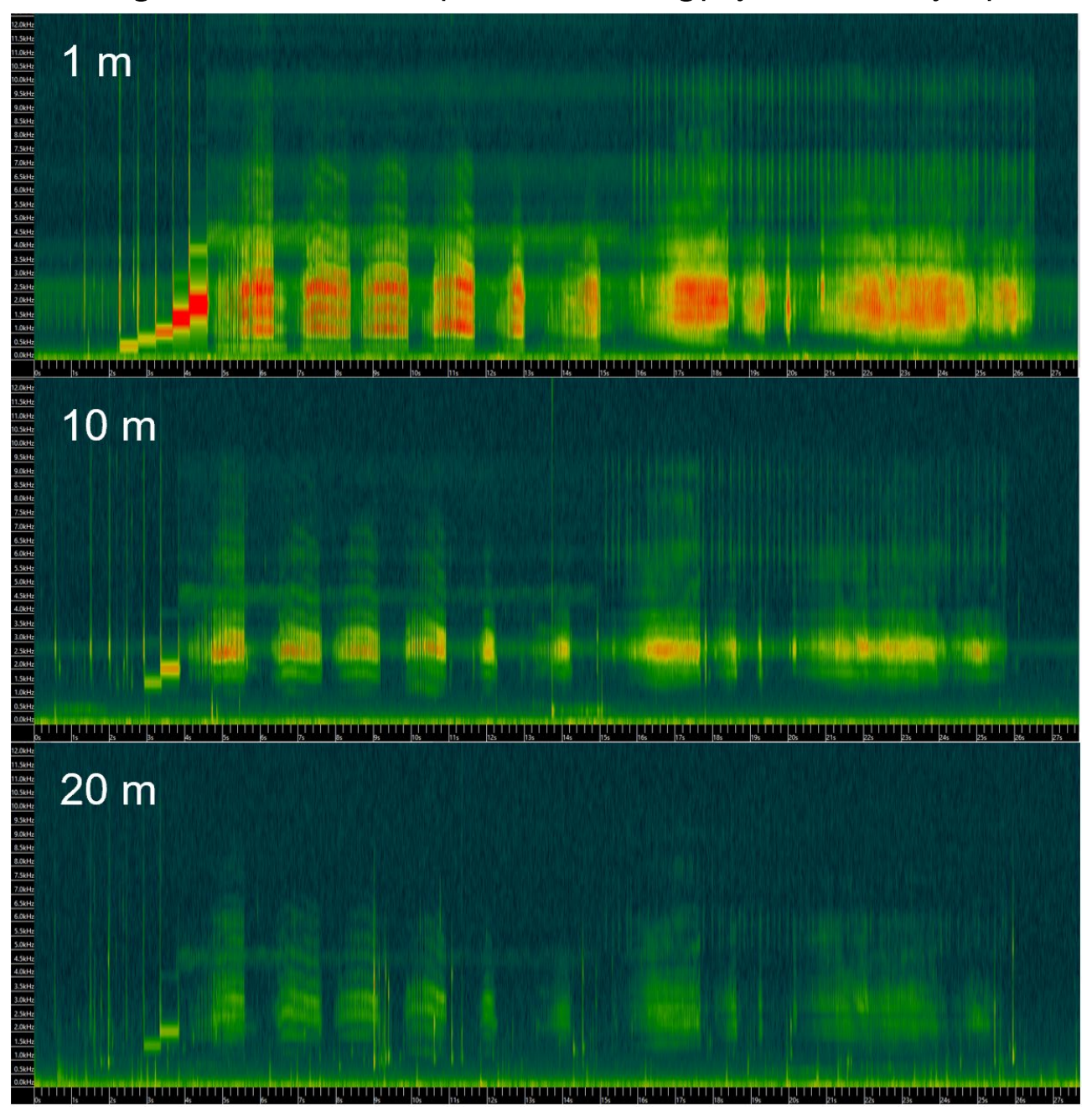

\subsubsection{Validation experiment 2: Confirming the efficacy of SPAM}

During the course of 16 trials by eight observers, 240 underwater frog call sequences were emitted. Overall, the survey method had a significant effect on the number of underwater calls detected $\left(F_{1,562}=53.78, P<0.001\right)$. Hydrophones detected $79 \%$ of calls, human observers detected $49 \%$, and microphones detected only $13 \%$ of calls (Figure 14). 
Figure 14. Percentage of broadcast gopher frog (Lithobates capito) and Chiricahua leopard frog (L. chircahuensis) calls detected by a hydrophone (SPAM), a microphone (PAM), and human observers (MCS).

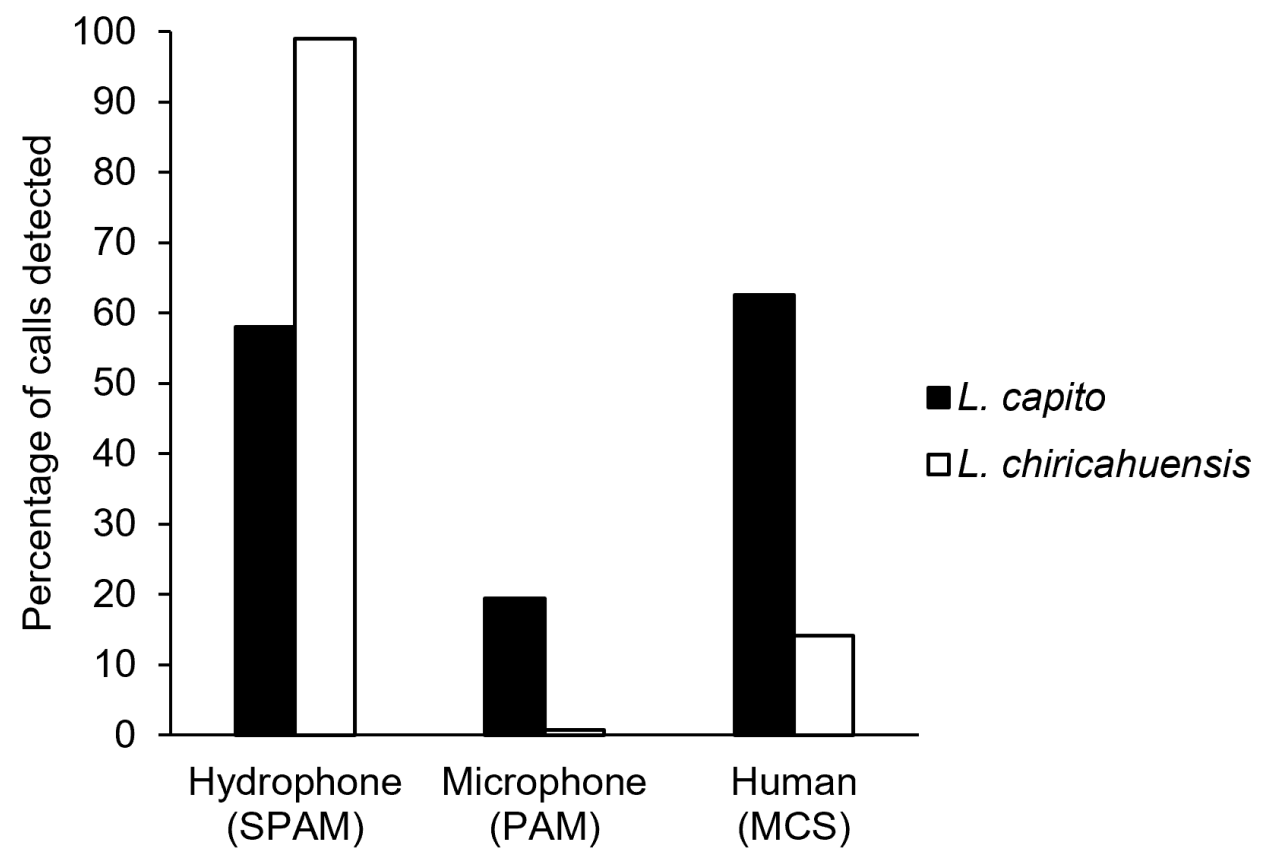

Hydrophones were 30 times more likely to detect underwater calls relative to microphones $(t=-9.92, \mathrm{df}=559, P=0.001, \beta=-3.42)$ and 8.5 times more likely relative to human observers $(t=-6.92, \mathrm{df}=559, P=0.001$, $\beta=-2.14)$. The amplitude at which a speaker emitted calls also had a significant effect on the likelihood of detection $\left(F_{1,561}=42.37, P<0.001\right)$, with louder calls more frequently detected than quieter ones $(t=-6.51$, $\mathrm{df}=561, P=0.001, \beta=1.341)$. The species of frog also had a significant effect on detection $\left(F_{1,561}=19.61, P<0.001\right)$ with gopher frog calls more frequently detected than leopard frog calls $(t=-4.43, \mathrm{df}=561, P=0.001$, $\beta=0.862)$. Surprisingly, the distance of the speaker to the recording unit and observer did not influence detection probability $\left(F_{1,561}=0.12\right.$, $P=0.726)$.

\subsubsection{Field demonstration}

\subsubsection{Fort Stewart: comparing SPAM to PAM in a long-term deployment}

We recorded both aerially and underwater continuously at five wetlands from $21 \mathrm{Feb}$ to 30 May 2018. We again recorded both underwater and aerially at one wetland from 19 Feb to 3 March 2019. 
Our automated detection algorithm identified four potential gopher frog calls in 2018. Manual review of the identified sounds confirmed one of these as a gopher frog call detected on 29 March 2018 on the hydrophone (and missed by the paired microphone), one as an owl, and two as the drumming of woodpeckers. Curiously, the spectrogram of woodpecker drumming is remarkably similar visually to the calls of gopher frogs (Figure 15).

Figure 15. Spectrograms showing the drumming of a woodpecker captured both by a microphone (top) and a hydrophone (center), and a spectrogram of an underwater-calling gopher frog (Lithobates capito) recorded by a hydrophone (bottom).

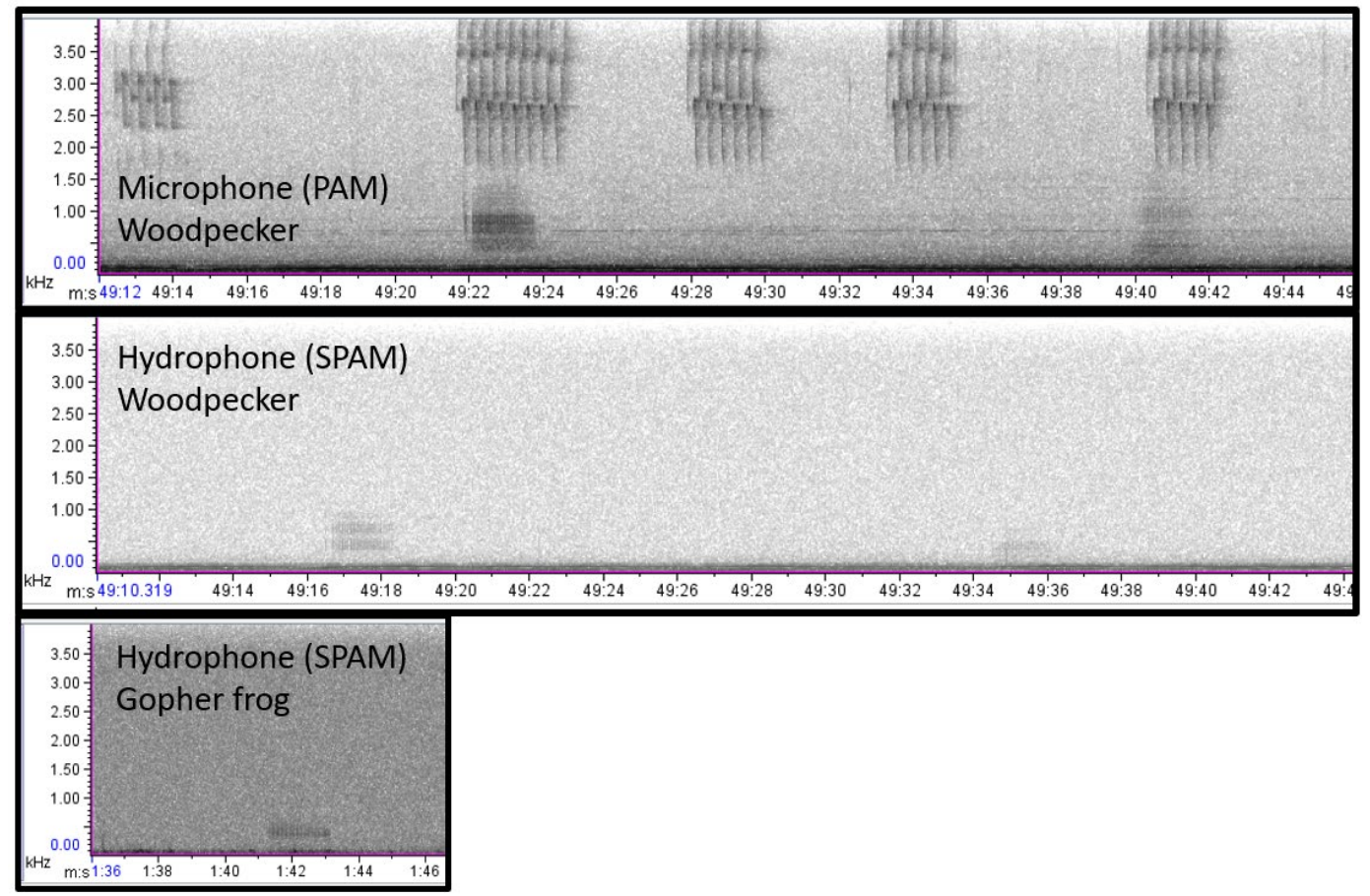

We manually reviewed a subset of additional recordings to search for gopher frogs that were not detected by the algorithm. We manually reviewed 975 hours of recordings and found one additional gopher frog recording (Figure 16). This frog was found calling on 2 April 2018 and was clearly detected on both the PAM and SPAM. 
Figure 16. Spectrograms of a gopher frog (Lithobates capito) recorded with a microphone (top) and a hydrophone (bottom) at Fort Stewart, GA, in 2018.

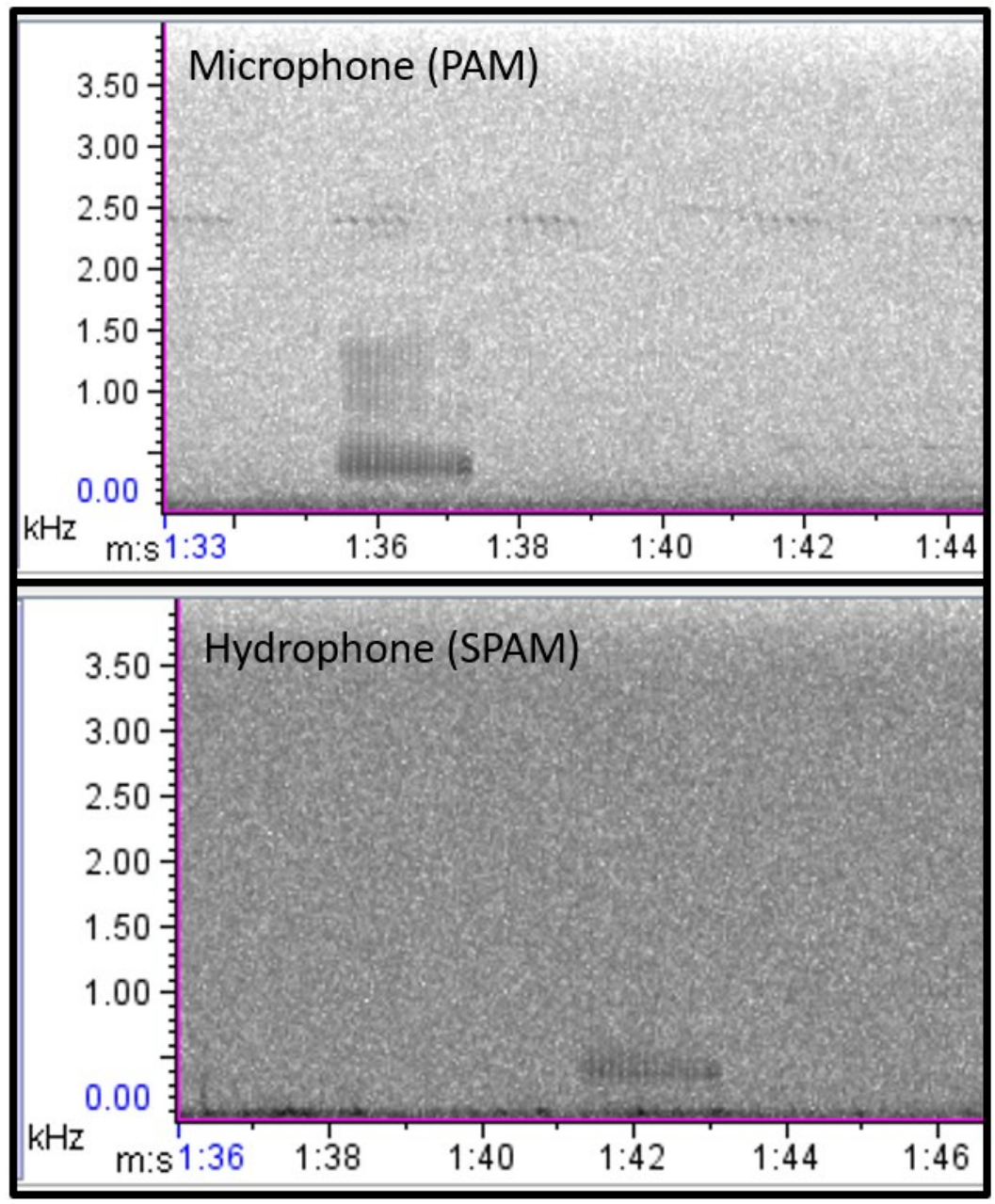

In addition to the underwater recording of the gopher frog, we documented seven other species of frogs, the calling of which was detected by both the hydrophone and the microphone (Table 4). A ninth species, the pine woods treefrog (Hyla femoralis), was detected on microphones but not on hydrophones.

In 2019, no gopher frogs were detected via SPAM or PAM. It is suspected that, due to drought, it was a widespread year of failed reproduction by gopher frogs across the southeastern United States. 
Table 4. Frogs detected by SPAM or PAM recorders at Fort Stewart, GA, during the 2018 anuran breeding season.

\begin{tabular}{|l|l|l|l|}
\hline \multicolumn{2}{|c|}{ Species } & \multicolumn{1}{c|}{$\begin{array}{c}\text { Detected on } \\
\text { hydrophone (SPAM) }\end{array}$} & $\begin{array}{c}\text { Detected on } \\
\text { microphone (PAM) }\end{array}$ \\
\hline Gopher frog & Lithobates capito & Y & Y \\
\hline American bull frog & Lithobates catesbiaena & Y & Y \\
\hline Southern leopard frog & $\begin{array}{l}\text { Lithobates } \\
\text { sphenocephalus }\end{array}$ & Y & Y \\
\hline Southern cricket frog & Acris gryllus & Y & Y \\
\hline Southern toad & Anaxyrus terrestris & Y & Y \\
\hline Barking tree frog & Hyla gratiosa & Y & Y \\
\hline Southern chorus frog & Pseudacris nigrita & Y & Y \\
\hline Cope's gray tree frog & Hyla chrysoscelis & Y & Y \\
\hline Pine woods tree frog & Hyla femoralis & N & Y \\
\hline
\end{tabular}

\subsubsection{Coronado National Forest}

\subsection{Comparing SPAM to PAM in a long-term deployment}

To compare SPAM to PAM for detection of Chiricahua leopard frogs during long-term deployments, we manually reviewed 328 5-min hydrophone and microphone recordings (1,640 total minutes) across four wetlands in 2018. Detection varied widely between wetlands with different habitat characteristics. At wetland A, a naturally occurring, deep, spring-fed pond with vegetated banks and organic bottom substrate (Figure 10), PAM detected significantly more leopard frog calls than SPAM $(z=-4.96, P$ $<0.0001)$. Leopard frogs were detected in $59 \%$ of microphone recordings compared to $5 \%$ of hydrophone recordings (Figure 17 ). 
Figure 17. Percentage of 5-min subsamples of long-term acoustic data in which Chiricahua leopard frogs (Lithobates chiricahuensis) were detected by the hydrophone (SPAM) and microphone (PAM) at wetlands A, C, and D in Coronado National Forest, AZ, in 2018. No frogs were detected at wetland $B$, so it is not shown. " $*$ " indicates a significant difference between SPAM and PAM at $\alpha=0.05$.

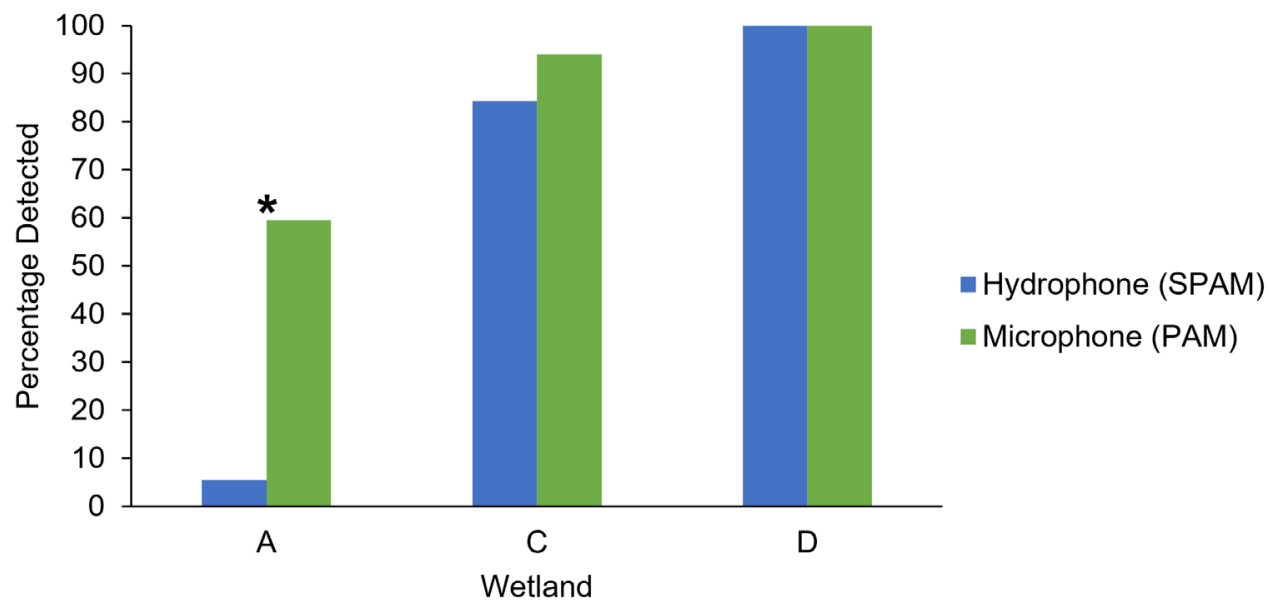

In wetland A, leopard frogs were rare, and no more than one frog was ever detected vocalizing at a given time. Vocalizations were few and far between. We believe the inability of SPAM to detect many vocalizations at this pond was a function of frogs calling at the surface and poor sound propagation underwater across the length of this large wetland.

No frogs were detected by either method at wetland B, a natural, grassy seep (Figure 10). Detection was similar between methods at wetlands C (SPAM $=84 \%$, PAM $=94 \% ; z=-1.59, P=0.06$; Figure 17) and D (SPAM $=100 \%$, PAM $=100 \%$; Figure 17 ); both wetlands were manmade, concrete-bottomed pools previously known to contain large numbers of frogs (Figure 10). We believe the ability of both SPAM and PAM to detect nearly identical numbers of calls in wetlands $C$ and $D$ was due to the extremely high density of leopard frogs in these small ponds. The acoustic environment was essentially saturated with frog calls, and because the wetlands were small, all instruments were within range to detect vocalizations.

Our results from long-term deployment monitoring of Chiricahua leopard frogs suggest this species likely vocalizes more rarely underwater than reported in the literature. Hence, even though underwater vocalizations can propagate long-distances, calls produced in air would need to be near hy- 
drophones for them to be detected via SPAM. For frogs primarily vocalizing above water, such as the Chiricahua leopard frog, PAM should be the preferred approach.

\subsection{Comparing SPAM, PAM, and MCS in nightly surveys}

During 36 trials, we recorded Chiricahua leopard frogs on hydrophones (SPAM) at all three wetlands in 2019 (Figure 18). Frogs were recorded on only two out of the three microphones (PAM) because the microphone at wetland $\mathrm{F}$ malfunctioned during the deployment, and no data were recorded. Human observers conducting MCS detected frogs at all three wetlands on all three nights.

Figure 18. Representative recordings of Chiricahua leopard frogs ( Lithobates chiricahuensis) on hydrophones $(A, B)$ and microphones $(C, D)$, shown as waveforms $(A, C)$ and spectrograms

$(B, D)$. Substantially more ambient noise (e.g., insects, wind) was present on microphone recordings because the air-water interface limits above-surface noise from reaching hydrophones.
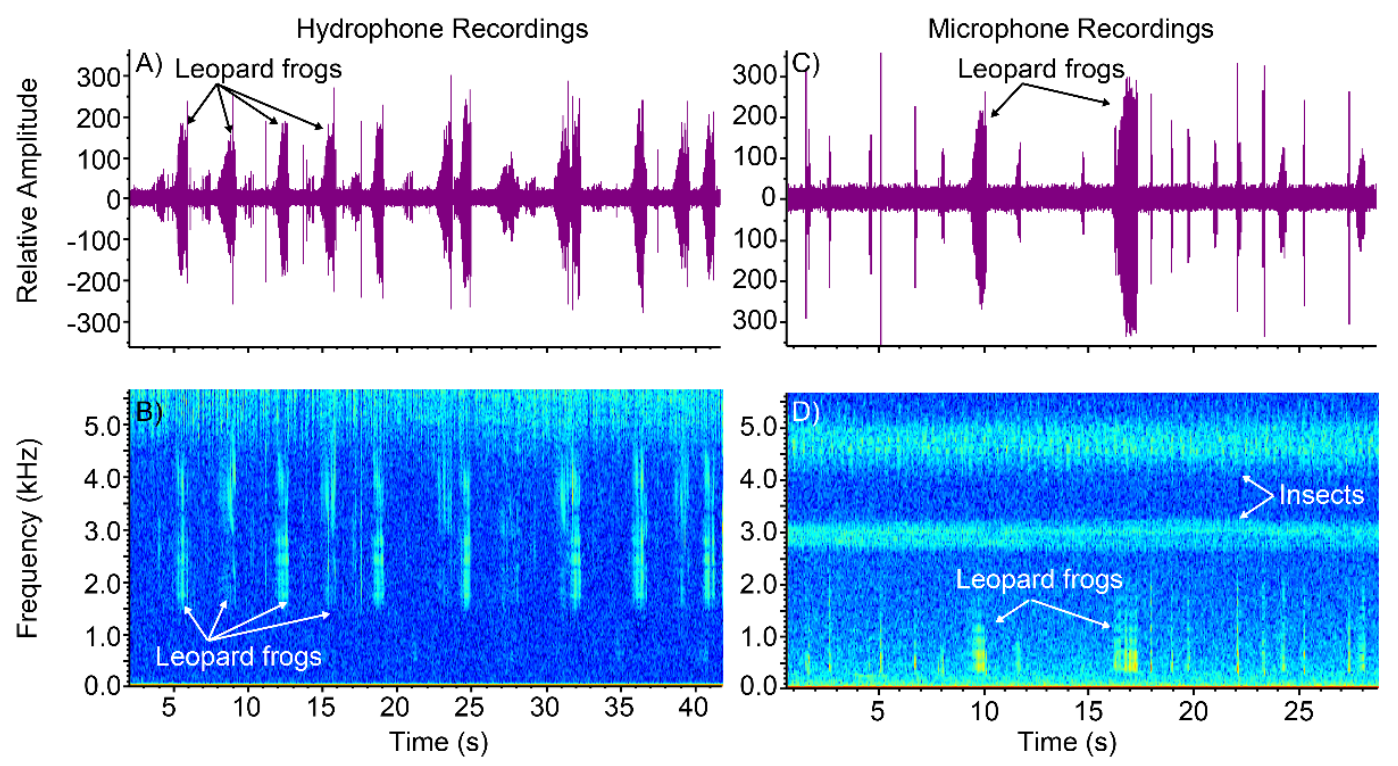

Overall, microphones and human observers outperformed hydrophones at all sites (Figure 19). SPAM did not detect a single frog at wetland G, likely due to its physical characteristics. This natural wetland had relatively shallow water and abundant vegetation, factors found to limit underwater sound propagation in validation experiment 1 (Section 5.5.1 above). Although hydrophones detected $50 \%$ and $75 \%$ of frogs at wetlands $\mathrm{E}$ and $\mathrm{F}$ (both concrete-lined cattle tanks), respectively, microphones and humans detected frogs during 100\% of surveys at these wetlands (Figure 19). 
Figure 19. Comparison of detection (mean $\pm \mathrm{SE}$ ) of Chiricahua leopard frogs (Lithobates chiricahuensis) via hydrophone (SPAM), microphone (PAM), and human observer (MCS) over three nights of surveys at Coronado National Forest, AZ, in 2019. Due to an equipment malfunction, no data were available for PAM at wetland $F(X)$. The $y$-axis represents the proportion of frog calls detected by each method averaged across all surveys.

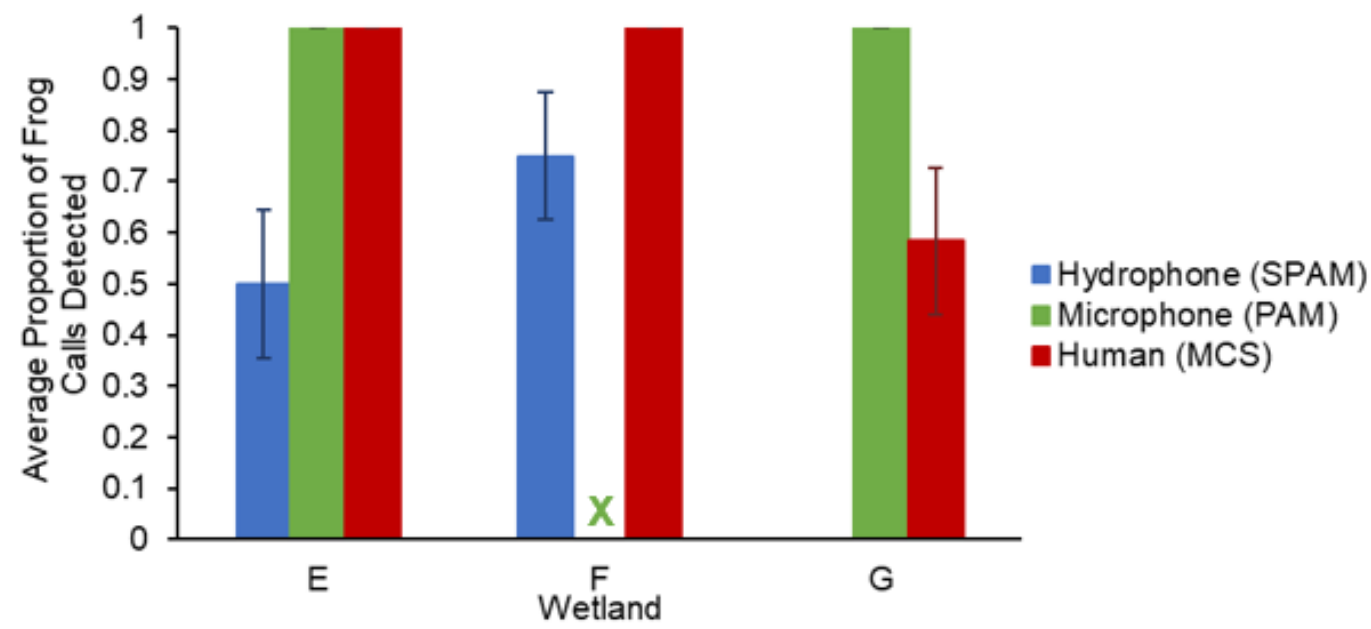

Again, these results suggest that Chiricahua leopard frogs vocalize more frequently in air than underwater. Hydrophones are likely only to be effective for this species when placed in small wetlands where the hydrophone instrument will be in close proximity to the calling individual.

We manually reviewed 1005 -min hydrophone and microphone recordings (500 total minutes) across three nights at two wetlands in 2019 (Figure 20). Overall detection was greater in the wetland E (cattle tank) than wetland G (natural wetland), and detection by microphones was greater than hydrophones at both sites (wetland E: $z=-5.56, P<0.0001$; wetland G: $Z=-2.42, P=0.008)$. 
Figure 20. Percentage of 5-min subsamples of acoustic data in which Chiricahua leopard frogs (Lithobates chiricahuensis) were detected by hydrophones (SPAM) and microphones

(PAM) at wetlands $E$ and $G$ in Coronado National Forest, AZ, in 2019. The microphone malfunctioned at wetland $\mathrm{F}$, so a comparison was not possible. “ $*$ " indicates a significant difference between SPAM and PAM at $\alpha=0.05$.

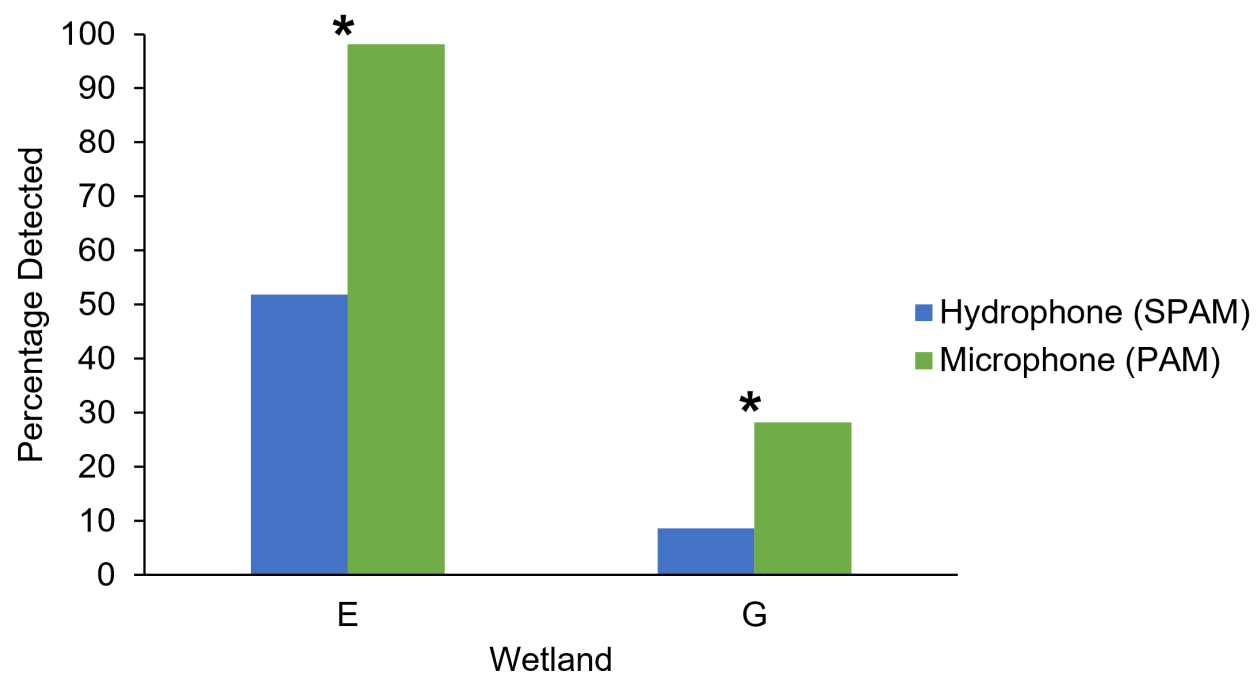

Of note, when frogs were visually counted by observers after conducting MCS, they were almost always seen above the water's surface, either completely on land or floating with their head above water (Figure 21). This is in contrast to the original species description of the Ramsey Canyon leopard frog (Rana subaquavocalis), which was asserted to only call underwater (Platz 1993); R. subaquavocalis was later synonymized with Lithobates chiricahuensis (Golberg, Field, and Sredl 2004). From our acoustic data in 2018 and 2019, it appears the exclusive underwater-calling behavior of $R$. subaquavocalis/L. chiricahuensis may be overstated, or it is context dependent and not fully understood.

Figure 21. Many Chiricahua leopard frogs (Lithobates chiricahuensis) were observed above the water's surface, rather than below, at wetlands E-G at Coronado National Forest, AZ, in 2019.
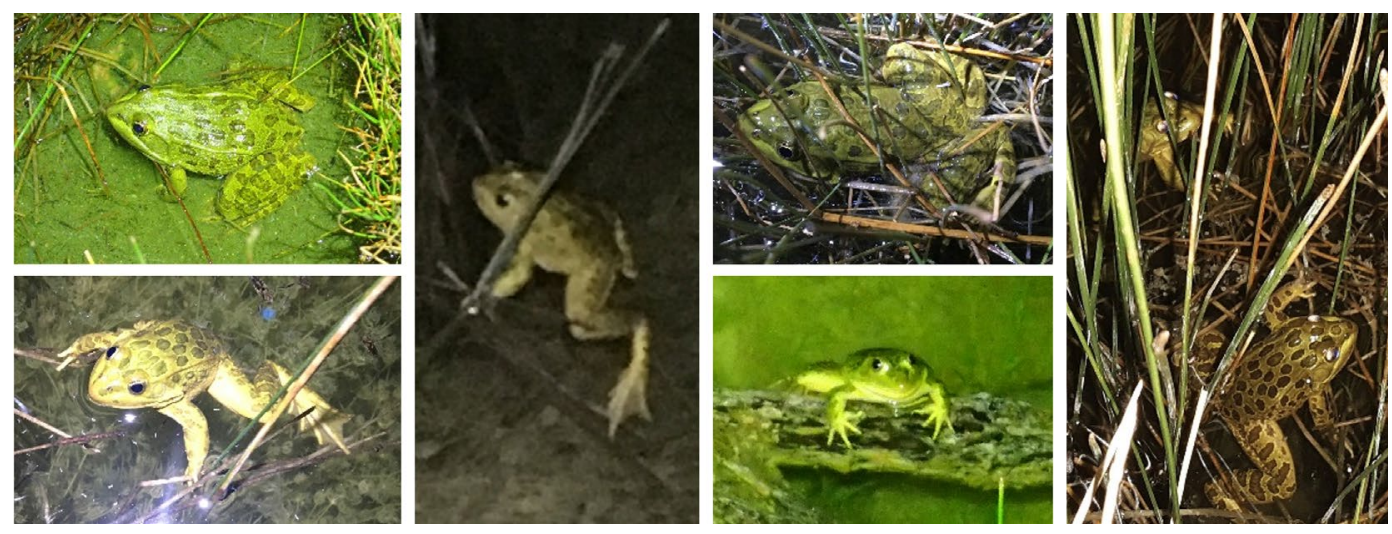


\subsubsection{Population estimation}

From visual surveys conducted at wetlands E and F, 17 and 15 individual leopard frogs were observed, respectively. Acoustic analysis of recordings for microphones and hydrophones identified 3-8 distinct individuals at each site that could be observed over repeated 5-minute periods (Figure 22).

Figure 22. Waveform $(A)$ and spectrogram $(B)$ of hydrophone from wetland $E$ in Arizona showing the number of detected calling Chiricahua leopard frogs (Lithobates chiricahuensis). The same individuals are numbered in both panels. Recording is from 27 July 2019 at 20:00.
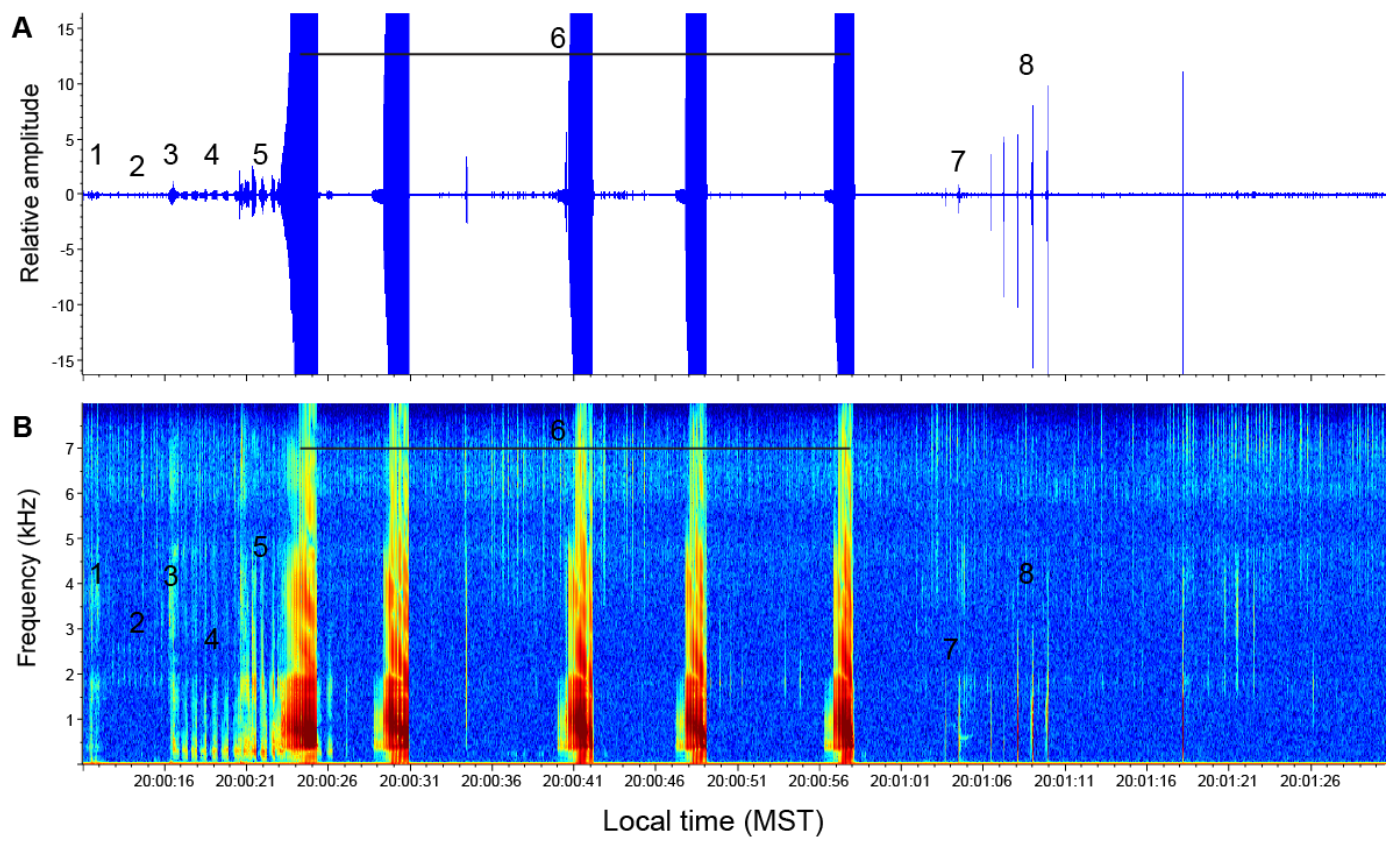

Assuming a 1:1 male:female sex ratio in leopard frogs (Elmberg 1990), we estimated both population sizes to be 16 individuals. These estimates closely correspond with the 17 and 15 total frogs visually counted across multiple nights. However, this method of relying on multiple samples of acoustic recordings requires reliance on numerous subsamples to avoid variance. This demonstrates that during periods of high vocal activity, the population could be accurately estimated. This was only possible by considering a large sample of the data in context. That is, if only segments of data with reduced vocal activity were analyzed (intentionally or unintentionally), the population could be underestimated.

We were unable to estimate the number of calling individuals at wetland $\mathrm{G}$ due to the low number of detected calls. 
The field of acoustic population assessment is advancing rapidly, with new statistical models being developed (Marques et al. 2013; Stevenson et al. 2020). We had hoped to be able to acoustically localize calling frogs on hydrophones and microphones (sensu Hawthorne and Salisbury 2016); however, the timing on one of our recording units was off due to erroneously dropped recording samples, and the precision of our time alignment could not be ensured. Future survey designs for calling frogs can incorporate these new approaches in the event that population size estimation is a monitoring goal or requirement. 


\section{Performance Assessment}

\subsection{Performance Objective 1: Examine the influence of environmental factors on acoustic detectability}

To evaluate the influence of wetland characteristics on the detection of underwater-generated frog calls by hydrophones, we conducted playback trials in a series of diverse wetlands and measured underwater sound propagation (Section 5.5.1). We found substantial variation in detection range across wetlands. Overall, five variables significantly influenced detection (Table 5), but model ranking indicated that two variables-number of submerged obstacles and water depth-had the greatest influences on detection by the hydrophone $\left(\mathrm{AIC}_{\mathrm{c}}\right.$ weight $\left.=0.84\right)$; no other model was competitive $\left(\Delta \mathrm{AIC}_{\mathrm{c}}<2\right)$. Detection increased as the number of submerged obstacles between the speaker and hydrophone decreased, and no calls were detected when greater than two submerged obstacles were between the speaker and hydrophone.

Table 5. Variables evaluated for their influence on detection of frog calls by hydrophones and the direction of their relationship to detection probability. Statistically significant variables at $\alpha=0.05$ based on univariate binomial generalized linear mixed models are shaded in gray. Prerecorded frog calls of gopher frogs (GF) and Chiricahua leopard frogs (CLF) were emitted on underwater speakers at variable depths below the surface in validation experiment 1 (see Section 5.4.2 for methods).

\begin{tabular}{|l|l|l|}
\hline \multicolumn{1}{|c|}{ Variable } & \multicolumn{1}{|c|}{ Relationship to detection } & $P$-value \\
\hline $\begin{array}{l}\text { Number of submerged obstacles between } \\
\text { underwater speaker and hydrophone }\end{array}$ & Negative & $<0.001$ \\
\hline Water depth & Positive & $<0.001$ \\
\hline $\begin{array}{l}\text { Distance between underwater speaker and } \\
\text { hydrophone }\end{array}$ & Negative & $<0.001$ \\
\hline Turbidity & Positive & $<0.01$ \\
\hline Substrate depth & Positive & 0.02 \\
\hline $\begin{array}{l}\text { Speaker depth (near-surface, midwater column, or } \\
\text { bottom) }\end{array}$ & $\begin{array}{l}\text { Midwater column }>\text { near- } \\
\text { surface }>\text { bottom } \\
\text { (not significant) }\end{array}$ & $>0.38$ \\
\hline $\begin{array}{l}\text { Species of call emitted (gopher frog or Chiricahua } \\
\text { leopard frog) }\end{array}$ & $\begin{array}{l}\text { GF }>\text { CLF } \\
\text { (not significant) }\end{array}$ & $>0.37$ \\
\hline
\end{tabular}


Our results indicate that SPAM is best suited for wetlands with deeper water and few underwater obstacles. For example, Licht (1969) described a situation in which spotted frogs vocalized in water only a couple of centimeters deep, while red-legged frogs vocalized completely submerged in over $0.6 \mathrm{~m}$ of water in the same wetland. It is likely that SPAM in this wetland would be more effective at detecting the calls of the red-legged frog than the spotted frog. Other underwater-calling species, such as the gopher frog, can inhabit diverse wetlands ranging from ephemeral Carolina bays to semipermanent wetlands with complex structure (Palis 1998), and the utility of SPAM for this species will be context-dependent. Frog species breeding in woody, shallow, heavily vegetated wetlands are likely not good candidates for this technology. Wetland characteristics will also affect the number of hydrophones needed to ensure adequate site coverage, with larger wetlands requiring multiple hydrophones and smaller wetlands being easily surveyed using only one hydrophone. Given the diversity of anuran habitats across North America, further research is warranted to more extensively explore the effects of environmental characteristics on underwater sound propagation in freshwater systems.

\subsection{Performance Objective 2: Validate the ability of SPAM to detect calls generated below the water's surface}

First, we conducted an experiment to test the ability of SPAM to detect frog calls generated underwater and directly compared the detection of calls by SPAM, PAM, and MCS in a controlled environment (Section 5.5.2). Overall, the survey method had a significant effect on the number of underwater calls detected $\left(F_{1,562}=53.78, P<0.001\right)$. Hydrophones were 30 times more likely to detect underwater calls relative to microphones $(t=-9.92, \mathrm{df}=559$, $P=0.001, \beta=-3.42)$ and 8.5 times more likely relative to human observers $(t=-6.92, \mathrm{df}=559, P=0.001, \beta=-2.14)($ Table 6$)$.

Table 6. Percentage of frog calls detected by SPAM, PAM, and MCS under controlled conditions in validation experiment 2.

\begin{tabular}{|l|l|}
\hline \multicolumn{1}{|c|}{ Survey method } & Percentage of frog calls detected \\
\hline SPAM (hydrophone) & $79 \%$ \\
\hline PAM (microphone) & $49 \%$ \\
\hline MCS (human observer) & $13 \%$ \\
\hline
\end{tabular}


Two variables influenced detection by the three survey methods (Table 7): amplitude at which a speaker emitted calls (louder calls more frequently detected than quieter ones) and species of frog (gopher frog more frequently detected than Chiricahua leopard frog).

Table 7. Variables evaluated for their influence on detection by SPAM, PAM, and MCS in a controlled experiment. Statistically significant variables at $\alpha=0.05$ based on univariate binomial generalized linear mixed models are shaded in gray. Prerecorded frog calls of gopher frogs (GF) and Chiricahua leopard frogs (CLF) were emitted on underwater speakers at variable distances and amplitudes in validation experiment 2 (see Section 5.4.3 for methods).

\begin{tabular}{|l|l|l|}
\hline \multicolumn{1}{|c|}{ Variable } & \multicolumn{1}{|c|}{$\begin{array}{c}\text { Relationship to } \\
\text { detection }\end{array}$} & \multicolumn{1}{|c|}{$\boldsymbol{P \text { -value }}$} \\
\hline Frog call amplitude (high or low) & Positive & $<0.001$ \\
\hline Species of call emitted (gopher frog or Chiricahua leopard frog) & GF $>$ CLF & $<0.001$ \\
\hline $\begin{array}{l}\text { Distance between speaker and } \\
\text { hydrophone/microphone/human (4, 8, 12, or } 16 \mathrm{~m})\end{array}$ & $\begin{array}{l}\text { Positive } \\
\text { (not significant) }\end{array}$ & 0.73 \\
\hline
\end{tabular}

Second, we conducted long-term field deployments to compare SPAM and PAM at Fort Stewart and Coronado National Forest. At Fort Stewart, we recorded continuously for over three months in 2018 (five wetlands) and for 12 days in 2019 (one wetland), resulting in the detection of only two gopher frog calls: one detected by SPAM only, and one detected by both SPAM and PAM (Section 5.5.3.1). Interestingly, we documented an additional seven anuran species on hydrophones not previously known to call underwater. We still know relatively little about how frequently frogs employ this interesting behavior, and there is no doubt that the list of frogs that call underwater will grow rapidly as biologists adopt and deploy SPAM. Further research is needed to explore the prevalence of underwater-calling behavior to better inform monitoring decisions using SPAM and PAM.

At Coronado National Forest, we recorded at four wetlands (two natural and two manmade) from June to August 2018 (Section 5.5.3.2.1). During this time, both SPAM and PAM recorded numerous calls of the Chiricahua leopard frog from three of the four wetlands. Detection varied widely between wetlands with different habitat characteristics and densities of frogs. At wetland A, a natural, deep, spring-fed pond with very few frogs, PAM detected significantly more leopard frog calls than SPAM $(z=-4.96$, $P<0.0001)$. Leopard frogs were detected in $59 \%$ of microphone recordings 
compared to $5 \%$ of hydrophone recordings. In the two concrete-lined cattle tanks (wetlands $\mathrm{C}$ and $\mathrm{D}$ ), detection was similar between methods (wetland C: $\mathrm{SPAM}=84 \%, \mathrm{PAM}=94 \% ; z=-1.59, P=0.06$; wetland $\mathrm{D}: \mathrm{SPAM}=$ $100 \%$, PAM $=100 \%)$.

Third, we conducted a field experiment to compare detection of free-ranging Chiricahua leopard frogs by SPAM, PAM, and MCS in nightly surveys (Section 5.5.3.2.2). Overall, PAM and MCS were similarly effective, and both outperformed SPAM. Hydrophones did not detect a single frog at the natural wetland site, which had relatively shallow water and abundant vegetation, characteristics found to limit underwater sound propagation in PO1. Although SPAM did detect frogs in $50 \%$ and $75 \%$ of trials at the two artificial wetlands (cattle tanks), PAM and MCS detected frogs in $100 \%$ of surveys. We subsampled the continuous recordings produced during the three-night deployment and found that detection by microphones was greater than hydrophones at both sites evaluated (wetland $\mathrm{E}: z=-5.56$, $P<0.0001$; wetland G: $z=-2.42, P=0.008)$.

Our results from long-term deployment monitoring of Chiricahua leopard frogs suggest this species likely vocalizes more rarely underwater than previously reported. Hence, even though underwater vocalizations can propagate long distances, calls produced in air would need to be near hydrophones for them to be detected via SPAM. For frogs primarily vocalizing above water, such as the Chiricahua leopard frog, microphones should be the preferred approach. In small wetlands (such as wetlands C and D), the high density of frogs in limited space makes either recording approach similarly effective, but in more natural conditions, microphones are expected to outperform hydrophones.

\subsection{Performance Objective 3: Demonstrate the effectiveness of SPAM data for population estimation through direct counts of distinct individuals in recordings}

We used SPAM data collected at two artificial ponds (cattle tanks) in Coronado National Forest in 2019 to estimate populations of Chiricahua leopard frogs. Because we were able to record the entire population and had high detection probability for visually counting frogs to corroborate our acoustic estimates, we used direct counts in the acoustic data to estimate the number of calling individuals. We identified a maximum of eight 
distinct individuals at each of the two wetlands. We assumed a sex ratio of 1:1, male (calling):female (not calling), to calculate population estimates of 16 individuals at each site. Compared to visual counts of 17 and 15 individuals, we deemed our acoustic estimate highly accurate. The field of acoustic population assessment is advancing rapidly, with new statistical models being developed. If population size estimation is a monitoring goal or requirement, future survey designs for calling frogs can incorporate these new approaches (see Figure 25 for examples).

\subsection{Performance Objective 4: Compare costs associated with SPAM relative to traditional MCS}

See chapter 7 . 


\section{Cost Assessment}

Before considering the cost of implementing SPAM, PAM, and MCS, one must first determine the suitability of each method for the survey goals. Then, and only then, should cost be a deciding factor. Ultimately, the utility of SPAM for underwater-calling species will depend on the focal species and the landscape where it occurs (see Sections 8.1 and 8.2). There will be situations in which one method is more expensive, but it may be the only way to effectively detect a species. To aid in making this determination, a decision support tree that takes into account the calling behavior of the focal species, habitat, and the goal of the survey effort is provided in Section 8 (Figure 25). In this section, we evaluate the costs associated with each survey method.

\subsection{Cost model}

To evaluate the costs of using SPAM, PAM, and human observers conducting MCS for frogs, we quantified the cost of field data collection and data analysis for each of the three methods (Table 8). We calculated costs of materials for both SPAM and PAM (no materials are required for MCS), labor involved in deploying equipment or conducting MCS, labor associated with data analysis, and travel associated with each method. Because a distinct advantage of SPAM and PAM over MCS is continuous coverage of the study area for an extended period of time (which may be necessary to detect certain species), it is impractical for an investigator to conduct a SPAM or PAM survey for the short duration typical of MCS (5 min per site), making direct comparisons between methods difficult. Therefore, in this assessment, we present the total cost for each method at different levels of effort (i.e., survey durations) that represent realistic scenarios a biologist might use in practice (see Section 7.3). 
Table 8. Cost model for a single-night anuran survey via SPAM, PAM, and MCS at a single site.

\begin{tabular}{|c|c|c|c|c|c|}
\hline $\begin{array}{l}\text { Cost } \\
\text { element }\end{array}$ & Cost item & Description & SPAM & PAM & MCS \\
\hline \multirow{6}{*}{ Materials } & Acoustic recorder & Cost of Wildlife Acoustics Song Meter SM4 Acoustic Recorder & $\$ 849$ & $\$ 849$ & - \\
\hline & Microphone & Cost of built-in microphone (included with recorder) & $\$ 0$ & $\$ 0$ & - \\
\hline & Hydrophone & Cost of Wildlife Acoustics SM3/SM4 Hydrophone & $\$ 875$ & $\$ 0$ & - \\
\hline & $\begin{array}{l}\text { Both SPAM and PAM: Batteries, memory cards, } \\
\text { cable locks }\end{array}$ & $\begin{array}{l}\text { Both SPAM and PAM: Cost of batteries ( } 4 \text { per recorder at } \$ 1 \\
\text { each), } 256 \text { GB SD card (1 per recorder at } \$ 100) \text {, cable lock } \\
\text { (\$15) }\end{array}$ & $\$ 119$ & $\$ 119$ & - \\
\hline & SPAM only: stakes, zip ties & SPAM only: stake $(\$ 1)$, zip ties $(\$ 5)$ & $\$ 6$ & - & - \\
\hline & Acoustic analysis software & $\begin{array}{l}\text { Cost of subscription to Wildlife Acoustics Kapeidoscope Pro } \\
\text { Analysis Software }\end{array}$ & $\$ 399$ & $\$ 399$ & - \\
\hline $\begin{array}{l}\text { Materials } \\
\text { Total }\end{array}$ & All equipment and supplies & Sum of all materials & $\$ 2,248$ & $\$ 1,367$ & $\$ 0$ \\
\hline \multirow{5}{*}{ Labor } & \multirow{2}{*}{$\begin{array}{l}\text { Labor for equipment deployment, site visit, or } \\
\text { survey }\end{array}$} & $\begin{array}{l}\text { SPAM and PAM: travel to field site ( } 2 \text { hours round-trip), } \\
\text { deployment of equipment ( } 30 \mathrm{~min} \text { ) }\end{array}$ & $\$ 25 \times 2.5=\$ 62.50$ & $\$ 25 \times 2.5=\$ 62.50$ & - \\
\hline & & $\begin{array}{l}\text { MCS: travel to field site ( } 2 \text { hours round-trip), conduct survey } \\
(5 \mathrm{~min})\end{array}$ & - & - & $\$ 25 \times 2.08=\$ 52$ \\
\hline & \multirow{3}{*}{ Labor for data analysis } & $\begin{array}{l}\text { SPAM and PAM: } 40 \text { hours needed for untrained personnel to } \\
\text { learn acoustic analysis software }\end{array}$ & $\$ 25 \times 40=\$ 1,000$ & $\$ 25 \times 40=\$ 1,000$ & - \\
\hline & & $\begin{array}{l}\text { SPAM and PAM: } 1 \text { hour per survey night to manually review post- } \\
\text { processed recordings }\end{array}$ & $\$ 25 \times 1=\$ 25$ & $\$ 25 \times 1=\$ 25$ & - \\
\hline & & MCS: 1 hour for data entry and summation & - & - & $\$ 25 \times 1=\$ 25$ \\
\hline Travel & Mileage & $\begin{array}{l}\text { Travel to field site: } 96 \mathrm{~km} \text { (60 miles) round-trip per visit at } \$ 0.36 \\
\text { per } \mathrm{km}(\$ 0.575 \text { per mile) }\end{array}$ & $\$ 0.575 \times 60=\$ 34.50$ & $\$ 0.575 \times 60=\$ 34.50$ & $\$ 0.575 \times 60=\$ 34.50$ \\
\hline \multicolumn{3}{|c|}{ Total Cost (single-night survey) } & $\$ 3,370$ & $\$ 2,489$ & $\$ 111.50$ \\
\hline
\end{tabular}




\subsubsection{Costs associated with materials}

MCS does not require equipment and, thus, has no material costs. Both PAM and SPAM rely on a very similar set of equipment and supplies, and thus, the costs will be comparable, with the only substantial addition being a hydrophone for SPAM. Here, we assume that practitioners will choose userfriendly and commercially available materials. Many options exist, but for this assessment, we used costs of recording units, associated accessories, and acoustic analysis software from Wildlife Acoustics, Inc. (https://www.wildlifeacoustics.com), a popular and reputable brand of wildlife acoustic monitoring tools. For additional supplies not available through Wildlife Acoustics, we estimated costs from Amazon.com.

\subsubsection{Costs associated with labor}

Labor from trained personnel is required to configure and deploy SPAM and PAM and to conduct MCS. Once a surveyor has arrived at a study site, we assumed a time of $30 \mathrm{~min}$ to deploy SPAM or PAM, and 5 min to conduct MCS, at a labor rate of $\$ 25 / \mathrm{hr}$ (the labor rate of a postdoctoral researcher). For the analysis of SPAM and PAM data, we calculated costs associated with using specialized acoustic software to analyze recordings to detect and identify the calls of focal anuran species based on the labor rate of $\$ 25 / \mathrm{hr}$. We included a one-time cost of 1 week (40 hrs) to familiarize oneself with the software and conduct an automated classifier analysis. Then, we estimated that manually vetting the resulting acoustic data would take an average of 1 labor hour per survey night of recordings. It should be noted that automated data analysis is not necessary to identify species in recordings but, rather, streamlines the processing of acoustic data. A practitioner could forego automated analysis and instead manually review recordings. This would still require a basic acoustic software program to visualize and listen to recordings (some of which are freely available and discussed in Section 8.3) and would extend the overall data processing time. Ultimately, it is up to the individual practitioner, given available technical expertise and resources, to determine the appropriate approach for their situation.

\subsubsection{Costs associated with travel}

We calculated costs of mileage to and from field sites to deploy SPAM and PAM, and to conduct MCS at a rate of $\$ 0.36 / \mathrm{km}(\$ 0.575 / \mathrm{mile})$. The cost 
of travel for a single round-trip to a single site on a single night is equal between methods, so the relative costs for each method scales according to the number of site visits required. Therefore, for the purpose of this assessment, we used a hypothetical study site that was located $48 \mathrm{~km}$ (30 miles) from the surveyor's starting point and assumed it would take 1 hour to arrive at the site. Because SPAM and PAM are typically deployed for longer than a single night, they require at least a second site visit to retrieve equipment. Months- or years-long deployments would also require periodic visits to check and replace batteries and download memory cards, as necessary. Therefore, for scenarios greater than 1 month in duration (see Section 7.3), we included the cost of one additional visit per month.

\subsection{Cost drivers}

The cost of SPAM and PAM are identical except for the additional cost of a hydrophone and materials to secure the hydrophone for SPAM. This cost is not trivial; for example, in this exercise, it doubles the cost of the recording unit alone. However, cheaper hydrophone models are available (e.g., Aquarian Audio \& Scientific H1a Hydrophone = \$159), and acceptable trade-offs between cost and audio quality may readily enable more cost-effective deployment of SPAM arrays at larger scales.

The majority of costs associated with SPAM and PAM are derived from the procurement of equipment and data analysis. Because SPAM and PAM both produce massive datasets, substantial labor is required to analyze these data using either automated software or manual inspection of recordings. Alternatively, MCS requires little more than data entry and tabulation at the end of the survey. Therefore, the cost of MCS is minimal because no equipment is required (just ears), and the cost of a given night of surveys is simply a function of the number of sites and distances between them.

\subsection{Cost analysis and comparison}

The costs presented above were estimated for a single anuran survey at a single site on a single night. However, this is an unlikely scenario for natural resource managers. More realistically, several SPAM or PAM units would be distributed across the landscape for weeks or months at a time. Similarly, biologists conducting MCS would visit many sites along a route for several nights during the breeding season. To more accurately reflect 
how SPAM, PAM, and MCS are used in practice, we extrapolated our cost model to different levels of survey effort.

For MCS, the number and spatial configuration of sites in a night will dictate cost. Table 9 lists a representative average cost of a 5 -min survey via MCS at different levels of effort in a single night. Here, we increased the labor cost based on the number of surveys conducted, adding 1 additional hour of effort for every five additional surveys. Surveys covered the period from 30 minutes after sunset through 01:00 (the recommended nightly survey period for NAAMP), with 1 hour added on either end to account for driving to the first site and back from the last site. In this example, we used a sunset time of 20:30, resulting in a maximum of 6 hours of labor for a night with 20 surveys. We allotted a minimum time of 1 hour for data entry and added 15 minutes for every five additional surveys conducted. Similarly, we assumed a minimum driving distance of $96 \mathrm{~km}$ (6o miles) and a cost of 16 additional $\mathrm{km}$ (10 miles) for every five additional sites surveyed.

Table 9. Cost of MCS surveys at different levels of effort. The cost of MCS is a function of the number of sites surveyed in a night and their distance apart. One survey is a 5-min period during which a human observer listens and records the presence of focal species.

\begin{tabular}{|l|l|l|l|l|l|}
\hline MCS per night & Survey hours & Data entry hours & Travel km (miles) & Total cost & Cost per survey \\
\hline 1 & 2.08 & 1 & $96(60)$ & $\$ 111.50$ & $\$ 111.50$ \\
\hline 5 & 3 & 1.25 & $113(70)$ & $\$ 146.50$ & $\$ 29.30$ \\
\hline 10 & 4 & 1.5 & $129(80)$ & $\$ 183.50$ & $\$ 18.35$ \\
\hline 15 & 5 & 1.75 & $145(90)$ & $\$ 220.50$ & $\$ 14.70$ \\
\hline 20 & 6 & 2 & $161(100)$ & $\$ 257.50$ & $\$ 12.88$ \\
\hline
\end{tabular}

For SPAM and PAM, we calculated the total cost of deployment at a single site for durations of 1 night, 2 weeks, 1 month, 2 months, and 3 months (Table 10). For both methods, there were fixed, one-time costs associated with the purchase of materials (recording unit, hydrophone or microphone, and acoustic analysis software), labor and travel for the initial deployment, and labor to learn the software (Table 8). For deployments longer than 1 month, we added the costs of materials, labor, and travel for one extra site visit per month to refresh batteries and download memory cards (\$101 total) (Table 8). We included 1 labor hour for data analysis per night of recordings (Table 8). 
Table 10. The cost of SPAM and PAM for deployments of varying lengths at a single site. Onetime costs of materials, labor for travel for initial deployment, and labor to learn acoustic analysis software were added to recurring costs of subsequent site visits and labor for data analysis, depending on the length of deployment (survey length).

\begin{tabular}{|l|l|l|l|l|}
\hline \multicolumn{1}{|c|}{ Survey length } & \multicolumn{1}{|c|}{$\begin{array}{c}\text { Number of site } \\
\text { visits }^{*}\end{array}$} & $\begin{array}{c}\text { Data analysis hours } \\
(1 \text { hour per survey } \\
\text { night) }\end{array}$ & $\begin{array}{c}\text { SPAM total } \\
\text { cost }\end{array}$ & $\begin{array}{c}\text { PAM total } \\
\text { cost }\end{array}$ \\
\hline 1 night & 1 & 1 & $\$ 3,370$ & $\$ 2,489$ \\
\hline $\begin{array}{l}2 \text { weeks (14 } \\
\text { nights) }\end{array}$ & 2 & 14 & $\$ 3,796$ & $\$ 2,915$ \\
\hline $\begin{array}{l}1 \text { month (30 } \\
\text { nights) }\end{array}$ & 2 & 30 & $\$ 4,196$ & $\$ 3,315$ \\
\hline $\begin{array}{l}2 \text { months (60 } \\
\text { nights) }\end{array}$ & 3 & 60 & $\$ 5,047$ & $\$ 4,166$ \\
\hline $\begin{array}{l}3 \text { months (90 } \\
\text { nights) }\end{array}$ & 4 & 90 & $\$ 5,898$ & $\$ 5,017$ \\
\hline
\end{tabular}

${ }^{*}$ After initial deployment, cost of each additional site visit is $\$ 101$ ( $\$ 4$ for batteries, $\$ 62.50$ for labor, $\$ 34.50$ for travel)

† Data analysis cost is $\$ 25$ per hour

To demonstrate the cost-benefit of long-term deployment, we estimated the total cumulative costs of SPAM and PAM surveys (Figure 23) and the cost per night of data generated by SPAM and PAM (Figure 24).

Figure 23. Estimated total cost of SPAM and PAM deployments. The higher starting cost of SPAM is due to the cost of a hydrophone, then costs for both methods accrue at the same rate. Increases at 30 and 60 days are incurred by extra site visits needed to check and refresh memory cards and batteries.

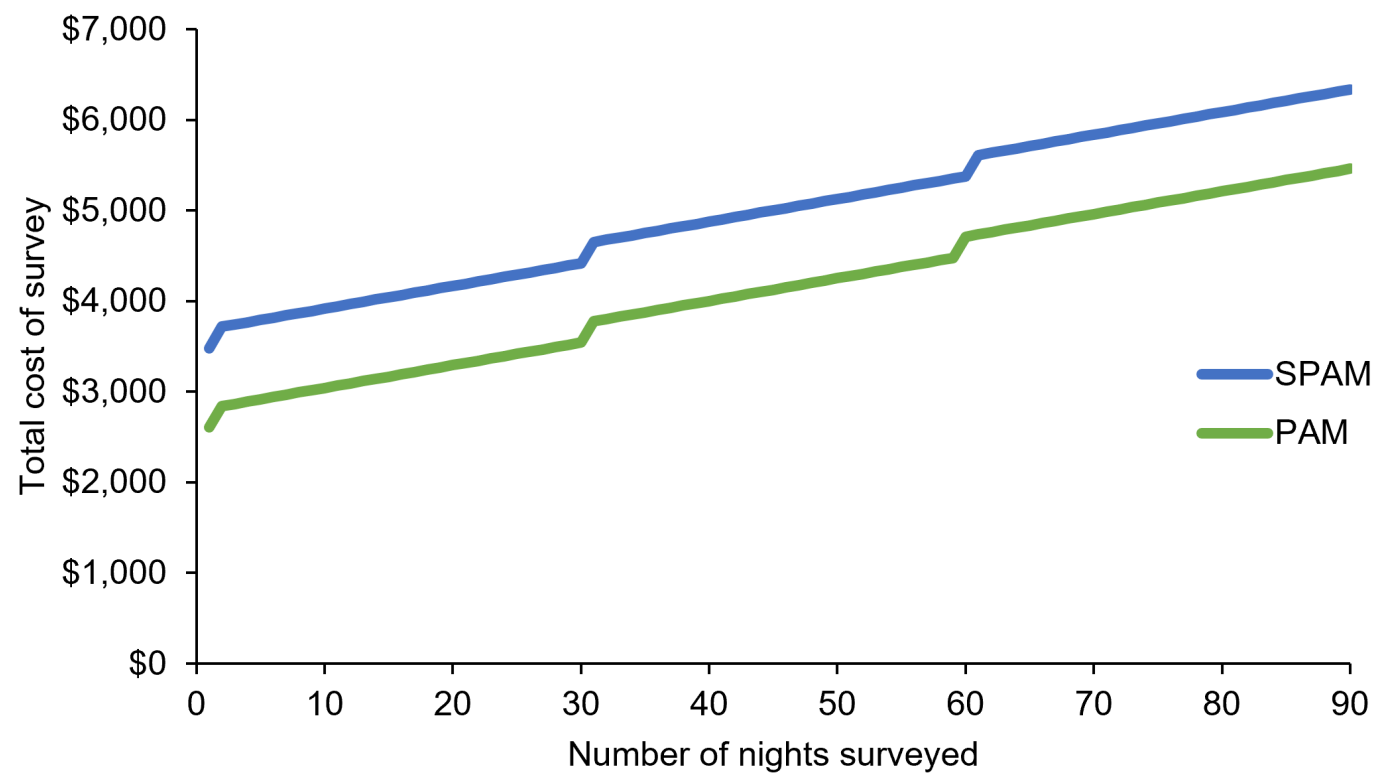


Figure 24. Estimated cost per night of data generated by SPAM and PAM long-term deployments. The higher starting cost of SPAM is due to the cost of a hydrophone.

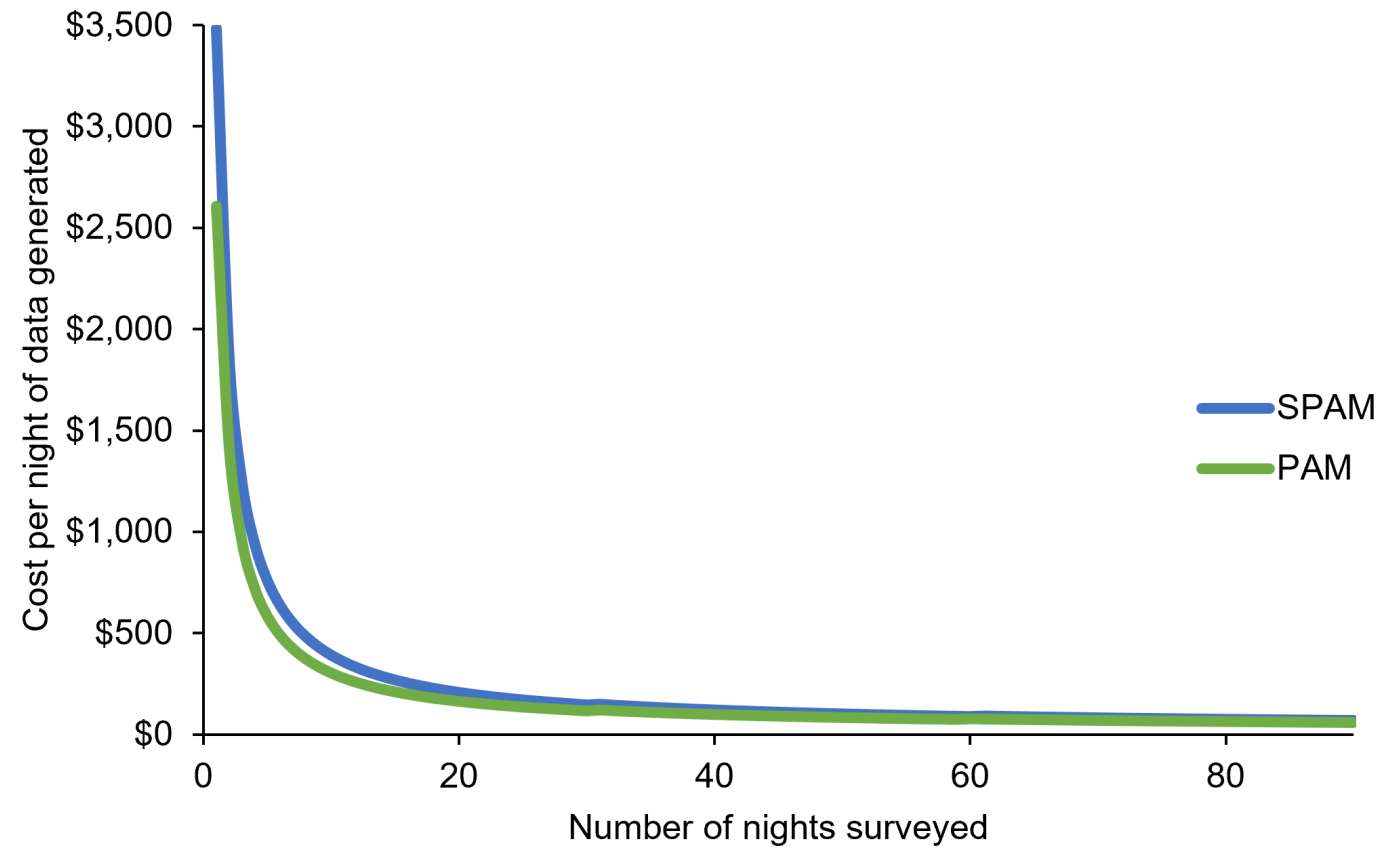

Our analysis demonstrates that after the substantial up-front costs related to materials and the time to learn to use acoustic software, in the longterm, costs for SPAM and PAM grow incrementally based on the steady accumulation of data. Overall, costs of SPAM and PAM will always be substantially greater than those associated with MCS. However, a primary benefit of SPAM and PAM technologies is that they enable the user to drastically increase the temporal coverage of surveys. In some situations, it may make the most sense for the practitioner to simply choose the cheapest option. If a species is conspicuous, SPAM or PAM may not be necessary. MCS is a cheap and effective methodology when applied in the appropriate context. However, in other situations, SPAM may be the only way to effectively detect species (see examples in Section 8.2). We must stress that SPAM may be critical to detecting underwater-calling species if their vocalizations are not detectable by terrestrial observers. In these situations, although PAM and MCS will be cheaper than SPAM, they may not accomplish the objective. 


\subsection{Conclusions}

First and foremost, the suitability of the survey method for detecting the focal species in the focal habitat should be evaluated before cost is considered (see Section 8). One could expect the following costs when implementing SPAM, PAM, and MCS.

- Practitioners interested in deploying one SPAM unit to survey for a focal species during a defined breeding period should be able to acquire all the equipment and software commercially for approximately $\$ 2,250$. Additional costs related to travel and data analysis will depend on the scope of the survey effort.

- To get started with PAM, practitioners can expect an up-front cost of approximately $\$ 1,400$ for the necessary equipment and software to field one recording unit.

- MCS will always be a cheap survey option (approximately $\$ 100-\$ 250$ per night of surveys, depending on the number of sites, labor rate of the surveyor, and travel distance). 


\section{Implementation Issues}

Our results demonstrate that PAM is a highly efficient data collection method that can be especially useful to document species with unpredictable calling activity patterns or that occur in variable habitats that may influence calling patterns or the detectability of calls. For example, a single 5-minute human-listener survey may not detect frogs depending on when that survey is conducted during the night, whereas PAM keeps a continuous record of the whole night and increases the ability to detect calls whenever they may occur. However, these increases in data resolution and survey power come with increased costs related to materials and data analyses.

This project highlights how acoustic information can help address a data gap in the ecology of at-risk species, which can be used to refine future survey methodology and management efforts. Ultimately, the utility of SPAM for underwater-calling species will depend on the species in question, the landscape in which it occurs, and technological considerations, such as technical expertise and resources available to the surveyor. To aid practitioners in deciding which passive acoustic monitoring technology is most suitable for their purpose, we created a decision support tree that takes into account the calling behavior of the focal species, habitat, and the goal of the survey effort (Figure 25). 
Figure 25. A decision support tree for evaluating the suitability of the use of passive acoustic monitoring approaches for anuran species, taking into account calling behavior of the focal species, the calling environment, and reporting requirements. Gray boxes represent decision points, and white boxes represent recommendations. Dashed lines represent the next set of questions following a recommendation. Begin at the top-left.

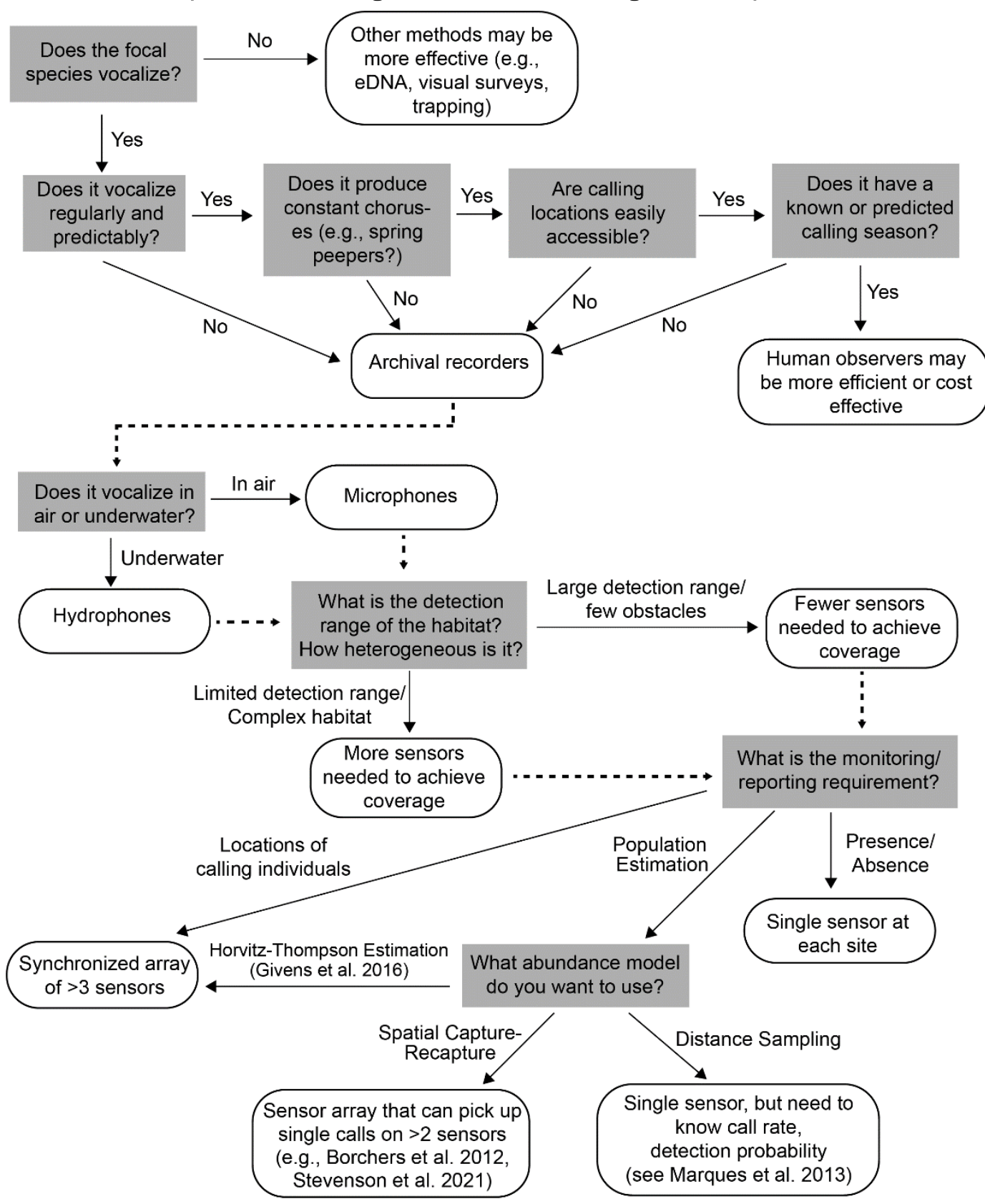

\subsection{Focal species}

Currently, our understanding of underwater-calling behavior of frogs is largely limited to anecdotal information (e.g., Jensen, Palis, and Bailey 
1995; Razzetti, Sacchi, and Platz 2006). It has mostly been treated as a curiosity and with few exceptions, mostly in Europe (e.g., Dutilleux and Curé 2020; Frommolt et al. 2008), lacks rigorous study of calling behavior. There is no doubt the list of frogs that call underwater will grow rapidly as biologists adopt and deploy SPAM (see Appendix B for DoD-relevant species known to call underwater). In addition, a growing body of literature is discovering a diversity of taxonomic groups that vocalize underwater, including turtles (Ferrara et al. 2017; Ferrara et al. 2014; Giles et al. 2009) and fish (Rice et al. 2020; Rountree, Bolgan, and Juanes 2019; Rountree et al. 2006). In this demonstration, we documented nine species of anuran calling underwater on Fort Stewart, seven of which had not previously been reported vocalizing underwater. We still know relatively little about how frequently frogs employ this interesting behavior. Ideally, practitioners would use SPAM when microphones or MCS are insufficient for detecting calls. However, without knowing if particular species sometimes, usually, or always call underwater, the decision on the proper method to use can be difficult. For instance, although we showed SPAM effectively recorded Chiricahua leopard frog calls, microphones performed better, likely because it appears that most leopard frog calls were produced in the air, despite previous reports (Platz 1993). Practitioners surveying for Chiricahua leopard frogs can continue to use traditional methods such as MCS or PAM.

\subsection{Focal landscapes}

Habitat type matters. SPAM will be best suited for relatively deep wetlands without high densities of downed woody debris or vegetation that attenuate calls. To date, the frogs that are known to call underwater occupy a wide array of aquatic habitats ranging from high-elevation Andean lakes

(Telmatobius coleus, Brunetti et al. 2017) to flowing streams (Rana italica, Razzetti, Sacchi, and Platz 2006) to ephemeral depression wetlands (Lithobates capito, Jensen, Palis, and Bailey 1995). Licht (1969) described a situation in which spotted frogs vocalized in water only a couple of centimeters deep while red-legged frogs vocalized completely submerged in over $0.6 \mathrm{~m}$ of water in the same wetland. It is likely that SPAM in this wetland would be more effective at detecting the calls of the red-legged frog than the spotted frog. Similarly, the European common spadefoot calls from relatively deep underwater where it can rarely be seen or heard from shore 
(Dutilleux and Curé 2020; Frommolt et al. 2008) and would make an excellent candidate for SPAM. Likewise, Telmatobius coleus calls while submerged in 2-3 $\mathrm{m}$ of lake water, clinging to vegetation and presents an ideal situation for underwater recording (Brunetti et al. 2017). Frog species breeding in woody, shallow, heavily vegetated wetlands are likely not good candidates for this technology. Practitioners will need to evaluate the habitat conditions used by their focal species, as well as survey goals (occupancy vs. population estimates), before deciding if SPAM, PAM, or MCS is most practical.

Site accessibility can be difficult. Many DoD installations that host active military training present challenges for field biologists. As with any work on active installations, biologists should be sure that field activities do not disrupt base operations and appropriate safety precautions are taken when in the field. When access to monitoring sites is prohibited or restricted, SPAM and PAM both offer clear value by collecting data when an observer is not present. The choice between SPAM, PAM, or a paired design will, then, be based on what is known about the calling behavior of the focal species and the breeding habitat.

Many military installations are noisy. In these situations, SPAM offers clear advantages because the underwater environment will be considerably quieter and frog calls will be easier to detect. The air-water interface limits the transmission of underwater sounds into the air and vice versa (Godin 2008), meaning that many of the ambient noises that obscure detection of frog calls by MCS or microphones will not be present underwater. Practitioners monitoring frog populations near roads, airways, or active firing ranges will likely benefit from deployment of SPAM rather than MCS or PAM.

Habitat size matters. Our validation experiments showed that underwater frog calls propagate variable distances based on habitat characteristics. When conditions are good, calls can be picked up by hydrophones up to $65 \mathrm{~m}$ away. The number of SPAM deployed at a site will vary both on the site's size and the habitat. Larger wetlands will need multiple hydrophone recorders, and smaller ones can easily be completely surveyed using only one. Most frogs stay in shallow water near the margins of larger wetlands. Deploying SPAM at a larger wetland will require numerous units spaced regularly along the margins, which increases both the cost of monitoring 
as well as the amount of data collected that will need to be reviewed and analyzed.

\subsection{Technological considerations}

Practitioners interested in adopting a SPAM approach need to (1) acquire the equipment, (2) acquire the software, (3) learn how to use the software, and (4) learn how to automate the software. Each of these steps is discussed below for practitioners interested in using a SPAM system to survey for underwater-calling frogs.

At the most basic, a SPAM system consists of a recording device and a hydrophone. Each of these components is commercially available from several different sources. A common, robust, and user-friendly acoustic recorder model is the Song Meter SM4 from Wildlife Acoustics, Inc. These units retail for $\$ 849$. The SM4 comes with two input channels with microphones. However, users can purchase a hydrophone made to work with this unit for an additional $\$ 875$. This outfits the unit to record with a microphone and a hydrophone simultaneously. Otherwise, users need only purchase batteries (SM4 takes 4 D-cells), SD memory cards (SM4 fits up to two 1 TB SD cards), and various stakes or straps to deploy the equipment in the field. Other options include Swift units produced by Cornell Lab of Ornithology (the units we used for this demonstration). Swifts are more adaptable and inexpensive ( $\$ 300$ per unit) but require more specialized setup and are less user-friendly.

Whether one is using microphones or hydrophones, automated recording units collect a lot of data. Manual review of all recorded acoustic data is not feasible. Users will benefit from using acoustic software to play back, visualize, and analyze collected acoustic data. Raven Pro is available through the Cornell Lab of Ornithology and costs between $\$ 50$ (for students) to $\$ 800$ (for commercial application). A free version, called Raven Lite, is available with fewer features but should suffice for most survey applications. Kaleidoscope Pro is available through Wildlife Acoustics for \$399. There are also free software products such as Audacity (http://www.audacity.org), PAMGuard (http://www.pamguard.org), Seewave (Sueur, Aubin, and Simonis 2008), WarbleR (Araya-Salas and Smith-Vidaurre 2017) and monitoR (Katz, Hafner, and Donovan 2016). Each software bundle has strengths and weaknesses; the 
appropriate one will depend on the practitioner's experience level with coding, budget, and goals for data analysis. Many of these software programs have available free online tutorials geared towards beginners or more experienced users.

For those practitioners collecting large amounts of data, such as someone deploying numerous SPAM or leaving their SPAM out for extended periods, automated detection of focal species calling will almost certainly be necessary. In Raven Pro, this will likely be through the application of automated detection algorithms (band-limited energy detection, template detection), where numerous files are automatically searched for specific parameters associated with focal species' calls. In Kaleidoscope Pro, cluster analysis uses pattern recognition algorithms to sort sounds, which can be labeled and used to train species-specific classifiers to identify species in larger datasets. Other software refers to this as cross correlation analysis. Learning how to do these automated analyses will require some time but may be worth the investment. The strength of a classifier will rely on the ability to train it on high-quality example recordings. For common species, these will be available in public repositories such a Xeno Canto and the Macaulay Library. For rare species, these exemplars may be rare, low in quality, or nonexistent. Species classifiers are most effective when trained with calls from the local study area, which can be iteratively improved as one locates calls within their own data to further refine the classifier.

Practitioners interested in deploying one SPAM unit to survey for a focal species during a defined breeding period should be able to acquire all of the equipment and software commercially for between $\$ 1,700$ and $\$ 2,250$ and should be able to build a classifier and scan the collected data in less than two weeks. Once a classifier is built, future recording analyses will be faster, easier, and more effective. 


\section{References}

Acevedo, M. A., and L. J. Villanueva-Rivera. 2006. "Using Automated Digital Recording Systems as Effective Tools for the Monitoring of Birds and Amphibians." Wildlife Society Bulletin 34:211-214.

Alford, R. A., and S. J. Richards. 1999. "Global Amphibian Declines: a Problem in Applied Ecology.” Annual Review of Ecology and Systematics 30:133-165.

Araya-Salas, M., and G. Smith-Vidaurre. 2017. "warbleR: An R Package to Streamline Analysis of Animal Acoustic Signals." Methods in Ecology and Evolution 8:184191.

Barbour, R. W. 1971. Amphibians and Reptiles of Kentucky. Lexington, KY: University of Kentucky Press.

Boatright-Horowitz, S. S., C. A. Cheney, and A. M. Simmons. 1999. "Atmospheric and Underwater Propagation of Bullfrog Vocalizations.” Bioacoustics: The International Journal of Animal Sound and its Recording 9:257-280.

Bobber, R. J. 1970. Underwater Electroacoustic Measurements. Orlando, FL: Naval Research Laboratory.

Bogert, C. M. 1998. Sounds of North American Frogs: The Biological Significance of Voice in Frogs Audio CD. Washington, DC: Smithsonian Institution.

Borchers, D. 2012. "A Non-technical Overview of Spatially Explicit Capture-Recapture Models.” Journal of Ornithology 152(Suppl 2):S435-S444.

Bridges, A. S., and M. E. Dorcas. 2000. "Temporal Variation in Anuran Calling Behavior: Implications for Surveys and Monitoring Programs.” Copeia 2000:587-592.

Brown, H. A. 1975. "Reproduction and Development of the Red-legged Frog, Rana aurora, in Northwestern Washington." Northwest Science 49:241-252.

Brunetti, A. E., A. Munoz Saravia, J. S. Barrionuevo, and S. Reichle. 2017. "Silent Sounds in the Andes: Underwater Vocalizations of Three Frog Species with Reduced Tympanic Middle Ears (Anura: Telmatobiidae: Telmatobius)." Canadian Journal of Zoology 95:335-343.

Burnham, K. P., and D. R. Anderson. 2002. Model selection and multi-model inference: a practical information-theoretic approach. New York, NY: Springer.

Celis-Murillo, A., J. L. Deppe, and M. F. Allen. 2009. "Using Soundscape Recordings to Estimate Bird Species Abundance, Richness, and Composition.” Journal of Field Ornithology 80:64-78.

Center for Conservation Bioacoustics (CCB). 2017. Raven Pro 2.0: Interactive Sound Analysis Software. Ithaca, NY: Cornell Lab of Ornithology. http://www.birds.cornell.edu/brp/raven/RavenOverview.html. 
Charif, R., C. Oedekoven, A. Rahaman, B. Estabrook, L. Thomas, and A. N. Rice. 2014. Passive Acoustic Monitoring of Whales and Mid-Frequency Active Sonar: Onslow Bay, NC and Jacksonville, FL. Ithaca, NY. Technical Report submitted U.S. Navy NAVFAC Atlantic. Cornell Lab of Ornithology.

Clark, C. W., and G. J. Gagnon. 2002. "Low-Frequency Vocal Behaviors of Baleen Whales in the North Atlantic: Insights from Integrated Undersea Surveillance System Detections, Locations, and Tracking from 1992 to 1996." U.S. Navy Journal of Underwater Acoustics 52:609-640.

Clark, C. W., A. N. Rice, D. W. Ponirakis, and P. J. Dugan. 2011. "Marine Acoustic Ecologies and Acoustic Habitats: Concepts, Metrics, and Realities.” Journal of the Acoustical Society of America 130:2320.

Davidson, C. 1995. Frog \& Toad Calls of the Pacific Coast: Vanishing Voices Audio CD. Ithaca, NY: Cornell Lab of Ornithology.

Degenhardt, W. G., C. W. Painter, and A. H. Price. 1996. Amphibians \& Reptiles of New Mexico. Albuquerque, NM: University of New Mexico Press.

Digby, A., M. Towsey, B. D. Bell, and P. D. Teal. 2013. "A Practical Comparison of Manual and Autonomous Methods for Acoustic Monitoring." Methods in Ecology and Evolution 4:675-683.

Dorcas, M. E., and W. Gibbons, 2008. Frogs and Toads of the Southeast. Athens, GA: University of Georgia Press.

Dorcas, M. E., S. J. Price, S. C. Walls, and W. J. Barichivich. 2009. "Auditory Monitoring of Anuran Populations.” In C. K. Dodd, Jr. (ed.) Amphibian Ecology and Conservation: A Handbook of Techniques. Oxford, U.K.: Oxford University Press. pp. 281-298.

Dugan, P. J., D. W. Ponirakis, J. A. Zollweg, M. S. Pitzrick, J. L. Morano, A. M. Warde, A. N. Rice, C. W. Clark, and S. M. Van Parijs. 2011. "SEDNA-Bioacoustic Analysis Toolbox." IEEE OCEANS 2011:1-10.

Dutilleux, G., and C. Curé. 2020. "Automated Acoustic Monitoring of Endangered Common Spadefoot Toad Populations Reveals Patterns of Vocal Activity.” Freshwater Biology 65:20-36.

Elmberg, J. 1990. "Long-Term Survival, Length of Breeding Season, and Operational Sex Ratio in a Boreal Population of Common Frogs, Rana temporaria L." Canadian Journal of Zoology 68:121-127.

Ferrara, C. R., R. C. Vogt, C. C. Eisemberg, and J. S. Doody. 2017. "First Evidence of the Pig-Nosed Turtle (Carettochelys insculpta) Vocalizing Underwater." Copeia 105:29-32.

Ferrara, C. R., R. C. Vogt, R. S. Sousa-Lima, B. M. R. Tardio, and V. Campos Diniz Bernardes. 2014. "Sound Communication and Social Behavior in an Amazonian River Turtle (Podocnemis expansa)." Herpetologica 70:149-156. 
Forrest, T. G., G. L. Miller, and J. R. Zagar. 1993. "Sound Propagation in Shallow Water: Implications for Acoustic Communication by Aquatic Animals.” Bioacoustics 4:259- 270 .

Fristrup, K. M., L. T. Hatch, and C. W. Clark. 2003. "Variation in Humpback Whale (Megaptera Novaeangliae) Song Length in Relation to Low-Frequency Sound Broadcasts." Journal of the Acoustical Society of America 113:3411-3424.

Frommolt, K. H., M. Kaufmann, S. Mante, and M. Zadow. 2008. "Die Lautäußerungen der Knoblauchkröte (Pelobates fuscus) und Möglichkeiten einer akustischen Bestandserfassung der Art.” Rana 5:101-112.

Gerhardt, H. C., and F. Huber. 2002. Acoustic Communication in Insects and Anurans: Common Problems and Diverse Solutions. Chicago, IL: University of Chicago Press.

Giles, J. C., J. A. Davis, R. D. McCauley, and G. Kuchling. 2009. "Voice of the Turtle: the Underwater Acoustic Repertoire of the Long-Necked Freshwater Turtle, Chelodina oblonga." Journal of the Acoustical Society of America 126:434-443.

Given, M. 2008. "Does physical or acoustical disturbance cause male pickerel frogs, Rana palustris, to vocalize underwater?” Amphibia-Reptilia 29:177-184.

Givens, G. H., S. L. Edmondson, J. C. George, R. Suydam, R. A. Charif, A. Rahaman, D. Hawthorne, B. Tudor, R. A. DeLong, and C. W. Clark. 2016. "Horvitz-Thompson Whale Abundance Estimation Adjusting for Uncertain Recapture, Temporal Availability Variation, and Intermittent Effort." Environmetrics 27:134-146.

Godin, O. A. 2007. "Transmission of Low-Frequency Sound through the Water-to-Air Interface." Acoustical Physics 53:305-312.

Godin, O. A. 2008. "Sound Transmission through Water-Air Interfaces: New Insights into an Old Problem.” Contemporary Physics 49:105-123.

Golberg, C. S., K. J. Field, and M. J. Sredl. 2004. "Mitochondrial DNA Sequences Do Not Support Species Status of the Ramsey Canyon Leopard Frog (Rana subaquavocalis).” Journal of Herpetology 38:313-319.

Hawthorne, D. L., and D. P. Salisbury. 2016. "Passive Acoustic Localization of North Atlantic Right Whales Using a Modified near-Field Bartlett Beamformer.” Journal of the Acoustical Society of America 140:3181.

Hayes, M. P., and D. M. Krempels. 1986. "Vocal Sac Variation among Frogs of the Genus Rana from Western North America.” Copeia 1986:927-936.

Hayes, M. P., and M. M. Miyamoto. 1984. "Biochemical, Behavioral and Body Size Differences between Rana aurora and R. a. draytoni." Copeia 1984:1018-1022.

Heard, G. W., P. Robertson, and M. P. Scroggie. 2006. “Assessing Detection Probabilities for the Endangered Growling Grass Frog (Litoria raniformis) in Southern Victoria." Wildlife Research 33:557-576. 
James, J. J. 1998. "Status of the Columbia spotted frog (Rana luteiventris) in Alberta." Alberta Environmental Protection, Fisheries and Wildlife Management Division, and Alberta Conservation Association. Alberta Wildlife Status Report No. 17, Edmonton, AB. 21 pp.

Jensen, J. B., J. G. Palis, and M. A. Bailey. 1995. “Rana capito sevosa (Dusky Gopher Frog) Submerged Vocalization.” Herpetological Review 26:98-99.

Jones, M. S., B. Stiles, L. J. Livo, and B. Christman. 2000. "Natural History Notes: Anura." Herpetological Review 31(2):99.

Katz, J., S. D. Hafner, and T. Donovan. 2016. "Tools for Automated Acoustic Monitoring within the R Package monitoR.” Bioacoustics 25:197-210.

Licht, L. E. 1969. Comparative Breeding "Behavior of the Red-Legged Frog (Rana aurora aurora) and the Western Spotted Frog (Rana pretiosa pretiosa) in Southwestern British Columbia." Canadian Journal of Zoology 47:1287-1299.

Linke, S., T. Gifford, C. Desjonquères, D. Tonolla, T. Aubin, L. Barclay, C. Karaconstantis, M. J. Kennard, F. Rybak, and J. Sueur. 2018. "Freshwater Ecoacoustics as a Tool for Continuous Ecosystem Monitoring." Frontiers in Ecology and the Environment 16:231-238.

Macaulay Library. 1996. Vanishing Voices: Frog and Toad Calls of the Rocky Mountains and Southwest Audio CD. Ithaca, NY: Cornell Lab of Ornithology.

Macaulay Library, 2007. Voices of the Night: the Calls of the Frogs and Toads of Eastern North America Audio CD. Ithaca, NY: Cornell Lab of Ornithology.

Mactague, L., and P. T. Northen. 1993. "Underwater Vocalization by the Foothill YellowLegged Frog (Rana boylii).” Transactions of the Western Section of the Wildlife Society 29:1-7.

Mann, D., J. Locascio, and C. Wall. 2016. "Listening in the Ocean: New Discoveries and Insights on Marine Life from Autonomous Passive Acoustic Recorders.” In W. W. L. Au, M. O. Lammers (eds.). Listening in the Ocean. New York, NY: Springer New York. pp. 309-324.

Marques, T. A., L. Thomas, S. W. Martin, D. K. Mellinger, J. A. Ward, D. J. Moretti, D. Harris, and P. L. Tyack. 2013. "Estimating Animal Population Density Using Passive Acoustics.” Biological Reviews 88:287-309.

Marsh, D. M., and P. C. Trenham. 2008. "Current Trends in Plant and Animal Population Monitoring.” Conservation Biology 22:647-655.

Mellinger, D. K., K. M. Stafford, S. E. Moore, R. P. Dziak, and H. Matsumoto. 2007. "An Overview of Fixed Passive Acoustic Observation Methods for Cetaceans." Oceanography 20:36-45.

Merchant, N. D., K. M. Fristrup, M. P. Johnson, P. L. Tyack, M. J. Witt, P. Blondel, and S. E. Parks. 2015. "Measuring Acoustic Habitats." Methods in Ecology and Evolution 6:257-265. 
Mohr, J. R., and M. E. Dorcas. 1999. "A Comparison of Anuran Calling Patterns at Two Carolina Bays in South Carolina.” Journal of the Elisha Mitchell Scientific Society $115: 63-70$.

Morris, R. L. 1967. The ecology of the Western Spotted Frog, Rana pretiosa pretiosa, Baird and Girard: A Life History Study. M.S. Thesis, Brigham Young University, Provo, UT.

Oseen, K. L., and R. J. Wassersug. 2002. "Environmental Factors Influencing Calling in Sympatric Anurans.” Oecologia 133:616-625.

Palis, J. G., and R. A. Fischer. 1997. Species Profile: Gopher Frog (Rana capito spp.) on Military Installations in the Southeastern United States. WES/TR/SERDP-97-5. Vicksburg, MS: U.S. Army Engineer Waterways Experiment Station.

Peterson, C. R., and M. E. Dorcas. 1994. “Automated Data Acquisition.” In W. R. Heyer, R. W. McDiarmid, M. Donnelly, and L. Hayek (eds.). Measuring and Monitoring Biological Diversity - Standard Methods for Amphibians. Washington, DC: Smithsonian Institution Press. pp. 47-57.

Platz, J. E.. 1993. "Rana subaquavocalis, a Remarkable New Species of Leopard Frog (Rana pipiens complex) from Southeastern Arizona that Calls under Water." Journal of Herpetology 27:154-162.

Pope, C. H. 1944. Amphibians and Reptiles of the Chicago Area. Chicago, IL: Chicago Natural History Museum Press.

R Core Team. 2019. "R: A Language and Environment for Statistical Computing." $R$ Foundation for Statistical Computing. Vienna, Austria. https://www.R-project.org.

Razzetti, E., R. Sacchi, and J. E. Platz. 2006. "First Description of the Acoustic Repertoire, of Rana italica (Anura, Ranidae).” Herpetological Journal 16:229-231.

Rice, A. N., P. J. Dugan, and C. W. Clark. 2010. "Finding the Calls of Whales in a Sea of Sound." Sea Technology 51:25-29.

Rice, A. N., J. L. Morano, K. B. Hodge, and C. A. Muirhead. 2016. "Spatial and Temporal Patterns of Toadfish and Black Drum Chorusing Activity in the South Atlantic Bight." Environmental Biology of Fishes 99:705-716.

Rice, A. N., K. J. Palmer, C. A. Muirhead, J. T. Tielens, and C. W. Clark. 2014a. "Potential Bryde's Whale (Balaenoptera edeni) Calls Recorded in the Northern Gulf of Mexico.” Journal of the Acoustical Society of America 135:3066-3076.

Rice, A. N., J. T. Tielens, B. J. Estabrook, C. A. Muirhead, A. Rahaman, M. Guerra, and C. W. Clark. 2014b. "Variation of Ocean Acoustic Environments along the Western North Atlantic Coast: A Case Study in Context of the Right Whale Migration Route.” Ecological Informatics 21:89-99.

Rice, A. N., S. C. Farina, A. J. Makowski, I. M. Kaatz, P. S. Lobel, W. E. Bemis, and A. H. Bemis. 2020. "Evolution and Ecology in Widespread Acoustic Signaling Behavior across Fishes.” bioRxiv DOI:10.1101/2020.1109.1114.296335. 
Rountree, R. A., M. Bolgan, and F. Juanes. 2019. "How Can We Understand Freshwater Soundscapes without Fish Sound Descriptions?” Fisheries 44:137-143.

Rountree, R. A., R. G. Gilmore, C. A. Goudey, A. D. Hawkins, J. J. Luczkovich, and D. A. Mann. 2006. "Listening to Fish: Applications of Passive Acoustics to Fisheries Science.” Fisheries 31:433-446.

Stafford, K. M., C. G. Fox, and D. S. Clark. 1998. "Long-Range Acoustic Detection and Localization of Blue Whale Calls in the Northeast Pacific Ocean." The Journal of the Acoustical Society of America 104:3616-3625.

Stahlschmidt, P., and C. A. Brühl. 2012. "Bats as Bioindicators: the Need of a Standardized Method for Acoustic Bat Activity Surveys." Methods in Ecology and Evolution 3:503-508.

Stebbins, R. C. 1962. Amphibians of Western North America. Berkeley, CA: University of California Press.

Stebbins, R. C. 2003. A Field Guide to Western Reptiles and Amphibians. Boston, MA: Houghton Mifflin Company.

Stebbins, R. C., and S. M. McGinnis. 2012. Field Guide to Amphibians and Reptiles of California. Berkeley, CA: University of California Press.

Stevenson, B. C., P. van Dam-Bates, C. K. Y. Young, and J. Measey. 2021. “A Spatial Capture-Recapture Model to Estimate Call Rate and Population Density from Passive Acoustic Surveys." Methods in Ecology and Evolution 12:432-442.

Storm, R. M. 1960. "Notes of the Breeding Biology of the Red-legged Frog (Rana aurora aurora)." Herpetologica 16:251-259.

Stuart, S. N., J. S. Chanson, N. A. Cox, B. E. Young, A. S. L. Rodrigues, D. L. Fischman, and R. W. Waller. 2004. "Status and Trends of Amphibian Declines and Extinctions Worldwide.” Science 306:1783-1786.

Sueur, J., A. Farina, A. Gasc, N. Pieretti, and S. Pavoine. 2014. "Acoustic Indices for Biodiversity Assessment and Landscape Investigation.” Acta Acustica United with Acustica 100:772-781.

Sueur, J., A. Gasc, P. Grandcolas, and S. Pavoine. 2012. "Global Estimation of Animal Diversity Using Automatic Acoustic Sensors.” In J. F. Le Galliard, J. M. Guarini, and F. Gaill (eds.). Sensors for Ecology: Towards Integrated Knowledge of Ecosystems. Paris: CNRS. pp. 101-119.

Sueur, J., T. Aubin, and C. Simonis. 2008. "Seewave: a Free Modular Tool for Sound Analysis and Synthesis.” Bioacoustics 18:213-226.

Sugai, L. S. M., T. S. F. Silva, J. W. Ribeiro, Jr., and D. Llusia. 2018. "Terrestrial Passive Acoustic Monitoring: Review and Perspectives.” BioScience 69:15-25. 
TNC (The Nature Conservancy). 1995. Fort Stewart Inventory, Final Report. Fort Stewart, GA: U.S. Department of Defense, Department of the Army, Headquarters 24th Mechanized Division.

Tobias, M. L., A. Corke, J. Korsh, D. Yin, and D. B. Kelley. 2010. "Vocal Competition in Male Xenopus laevis Frogs." Behavioral Ecology and Sociobiology 64:17911803 .

Todd, M. J., R. R. Cocklin, and M. E. Dorcas. 2003. "Temporal and Spatial Variation in Anuran Calling Activity in the Western Piedmont of North Carolina." Journal of the North Carolina Academy of Science 119:103-110.

Urick, R. J. 1983. Principles of Underwater Sound, Third Edition. Los Altos, CA: Peninsula Publishing.

Van Parijs, S. M., C. W. Clark, R. S. Sousa-Lima, S. E. Parks, S. Rankin, D. Risch, and I. C. Van Opzeeland. 2009. Management and Research Applications of RealTime and Archival Passive Acoustic Sensors over Varying Temporal and Spatial Scales. Marine Ecology Progress Series 395:21-36.

Voyles, J., S. Young, L. Berger, C. Campbell, W. F. Voyles, A. Dinudom, D. Cook, R. Webb, R. A. Alford, L. F. Skerratt, and R. Speare. 2009. "Pathogenesis of Chytridiomycosis, a Cause of Catastrophic Amphibian Declines." Science 326:582-585.

Weir, L. A., and M. J. Mossman. 2005. “North American Amphibian Monitoring Program (NAAMP).” In M. J. Lannoo (ed.). Amphibian Declines: Conservation Status of United States Species. Berkeley, CA: University of California Press. pp. 307-313.

Willacy, R. J., M. Mahony, and D. A. Newell. 2015. "If a Frog Calls in the Forest: Bioacoustic Monitoring Reveals the Breeding Phenology of the Endangered Richmond Range Mountain Frog (Philoria richmondensis).” Austral Ecology 40:625-633.

Wrege, P. H., E. D. Rowland, B. G. Thompson, and N. Batruch. 2010. "Use of Acoustic Tools to Reveal Otherwise Cryptic Responses of Forest Elephants to Oil Exploration." Conservation Biology 24:1578-1585.

Ziesmer T. C. 1997. "Vocal behavior of foothill and mountain yellow legged frogs (Rana boylii and Rana muscosa).” M.S. Thesis, California State University, Sonoma, CA.

Zweifel, R. G. 1955. Ecology, distribution, and systematics of frogs of the Rana boylei group. Berkeley, CA: University of California Press. 


\section{Acronyms and Abbreviations}

\begin{tabular}{|l|l|}
\hline Abbreviation & \\
\hline ARMI & Amphibian Research and Monitoring Initiative \\
\hline CERL & Construction Engineering Research Laboratory \\
\hline CLO & Cornell Lab of Ornithology \\
\hline DoD & Department of Defense \\
\hline eDNA & Environmental DNA \\
\hline ERDC & Engineer Research and Development Center \\
\hline ESA & Endangered Species Act \\
\hline ESTCP & Environmental Security Technology Certification Program \\
\hline MCS & Manual calling survey \\
\hline NAAMP & North American Amphibian Monitoring Program \\
\hline NTU & Neophelometric Turbidity Units \\
\hline PAM & Passive Acoustic Monitoring \\
\hline PO & Performance Objective \\
\hline RC & Resource Conservation and Resiliency \\
\hline SERDP & Strategic Environmental Research and Development Program \\
\hline SD & Secure digital \\
\hline SDXC & Secure digital extended capacity \\
\hline SPAM & Subsurface Passive Acoustic Monitoring \\
\hline TES & Threatened and endangered species \\
\hline USFWS & U.S. Fish and Wildlife Service \\
\hline
\end{tabular}




\section{Appendix A: Points of Contact}

\begin{tabular}{|c|c|c|c|}
\hline $\begin{array}{c}\text { Point of } \\
\text { contact } \\
\text { name }\end{array}$ & $\begin{array}{l}\text { Organization name } \\
\text { Address }\end{array}$ & $\begin{array}{l}\text { Phone } \\
\text { E-mail }\end{array}$ & Role in project \\
\hline Patrick Wolff & $\begin{array}{l}\text { U.S. Army Engineer Research } \\
\text { and Development Center } \\
\text { Construction Engineering } \\
\text { Research Laboratory } \\
2902 \text { Newmark Dr } \\
\text { Champaign, IL } 61822\end{array}$ & $\begin{array}{l}\text { 217-373-5847 } \\
\text { patrick.j.wolff@usace.army.mil }\end{array}$ & PI \\
\hline $\begin{array}{l}\text { Brett } \\
\text { DeGregorio }\end{array}$ & $\begin{array}{l}\text { U.S. Army Engineer Research } \\
\text { and Development Center } \\
\text { Construction Engineering } \\
\text { Research Laboratory } \\
\text { 2902 Newmark Dr } \\
\text { Champaign, IL 61822 } \\
\text { Current affiliation: } \\
\text { U.S. Geological Survey } \\
\text { Arkansas Cooperative Fish } \\
\text { and Wildlife Research Unit } \\
\text { Fayetteville, AR } 72701\end{array}$ & $\begin{array}{l}\text { 260-416-4242 } \\
\text { bdegrego@uark.edu }\end{array}$ & Co-PI \\
\hline Aaron Rice & $\begin{array}{l}\text { Center of Conservation } \\
\text { Bioacoustics } \\
\text { Cornell Lab of Ornithology } \\
\text { Cornell University } \\
159 \text { Sapsucker Woods Road } \\
\text { Ithaca, NY } 14850\end{array}$ & $\begin{array}{l}\text { 607-254-2178 } \\
\text { arice@cornell.edu }\end{array}$ & Co-PI \\
\hline Roy King & $\begin{array}{l}\text { USAG Fort Stewart } \\
\text { Directorate of Public Works } \\
\text { Fish and Wildlife Branch } \\
\text { BLDG } 1145 \\
1177 \text { Veterans Parkway } \\
\text { Fort Stewart, GA } 31314\end{array}$ & $\begin{array}{l}\text { 912-767-2353 } \\
\text { roy.l.king2.civ@mail.mil }\end{array}$ & $\begin{array}{l}\text { Demonstration site } \\
\text { liaison, } \\
\text { Technology end- } \\
\text { user }\end{array}$ \\
\hline John Kraft & $\begin{array}{l}\text { U.S. Forest Service } \\
\text { Coronado National Forest } \\
\text { Sierra Vista Ranger District } \\
4070 \text { S. Avenida Saracino } \\
\text { Hereford, AZ } 85615\end{array}$ & $\begin{array}{l}\text { 520-803-2827 } \\
\text { jpkraft@fs.fed.us }\end{array}$ & $\begin{array}{l}\text { Demonstration site } \\
\text { liaison, } \\
\text { Technology end- } \\
\text { user }\end{array}$ \\
\hline
\end{tabular}




\section{Appendix B: Suitability of Anuran Species Found on DoD Lands for Detection via Subsurface Passive Acoustic Monitoring}

Table B-1 lists all anuran (frog and toad) species documented to occur on DoD lands in the continental United States (based on the DoD PARC Herpetofauna Database, literature review, and expert knowledge), their listing status under the Endangered Species Act (ESA), and whether they have been documented calling underwater. Species that have been documented calling underwater, and are thus most suitable for SPAM, are highlighted and references are provided. 
Table B-1. Anuran species documented to occur on DoD lands in the United States.

\begin{tabular}{|c|c|c|c|c|}
\hline Scientific name & Common name & ESA status & Documented calling underwater & Reference(s) \\
\hline Acris blanchardi & Blanchard's cricket frog & & $\mathrm{N}$ & \\
\hline Acris crepitans & Eastern cricket frog & & $\mathrm{N}$ & \\
\hline Acris gryllus & Southern cricket frog & & $\mathrm{Y}$ & This study \\
\hline Anaxyrus americanus & American toad & & $\mathrm{N}$ & \\
\hline Anaxyrus californicus & Arroyo toad & Endangered & $\mathrm{N}$ & \\
\hline Anaxyrus canorus & Yosemite toad & Threatened & $\mathrm{N}$ & \\
\hline Anaxyrus fowleri & Fowler's toad & & $\mathrm{N}$ & \\
\hline Anaxyrus nelsoni & Amargosa toad & & $\mathrm{N}$ & \\
\hline Anaxyrus punctatus & Red-spotted toad & & $\mathrm{N}$ & \\
\hline Anaxyrus terrestris & Southern toad & & $\mathrm{Y}$ & This study \\
\hline Anaxyrus williamsi & Dixie Valley toad & Under Review & $\mathrm{N}$ & \\
\hline Anaxyrus woodhousii & Woodhouse's toad & & $N$ & \\
\hline Bufo houstonensis & Houston toad & Endangered & $\mathrm{N}$ & \\
\hline Bufo microscaphus & Arizona toad & Under Review & $\mathrm{N}$ & \\
\hline Eleutherodactylus coqui & Coqui & & $\mathrm{N}$ & \\
\hline $\begin{array}{l}\text { Eleutherodactylus } \\
\text { cystignathoides }\end{array}$ & Rio Grande chirping frog & & $\mathrm{N}$ & \\
\hline $\begin{array}{l}\text { Eleutherodactylus } \\
\text { planirostris }\end{array}$ & Greenhouse frog & & $\mathrm{N}$ & \\
\hline $\begin{array}{l}\text { Gastrophryne } \\
\text { carolinensis }\end{array}$ & $\begin{array}{l}\text { Eastern narrow- } \\
\text { mouthed toad }\end{array}$ & & $\mathrm{N}$ & \\
\hline Hyla andersonii & Pine Barrens tree frog & & $\mathrm{N}$ & \\
\hline Hyla cadaverina & California tree frog & & $\mathrm{N}$ & \\
\hline
\end{tabular}




\begin{tabular}{|c|c|c|c|c|}
\hline Scientific name & Common name & ESA status & Documented calling underwater & Reference(s) \\
\hline Hyla chrysoscelis & Cope's gray tree frog & & $\mathrm{Y}$ & This study \\
\hline Hyla cinerea & Green tree frog & & N & \\
\hline Hyla femoralis & Pine woods tree frog & & $\mathrm{N}$ & \\
\hline Hyla gratiosa & Barking tree frog & & Y & This study \\
\hline Hyla squirella & Squirrel tree frog & & N & \\
\hline Hyla versicolor & Gray tree frog & & N & \\
\hline Lithobates areolatus & Crawfish frog & & Y & Barbour 1971; Jones et al. 2000 \\
\hline Lithobates berlandieri & Rio Grande leopard frog & & $\mathrm{N}$ & \\
\hline Lithobates blairi & Plains leopard frog & & $\mathrm{N}$ & \\
\hline Lithobates capito & Gopher frog & Under Review & Y & Jensen, Palis, and Bailey 1995 \\
\hline Lithobates catesbeianus & American bullfrog & & Y & Boatright-Horowitz, Cheney, and Simmons 1999 \\
\hline Lithobates palustris & Pickerel frog & & $\mathrm{Y}$ & Given 2008 \\
\hline Lithobates pipiens & Northern leopard frog & & $\mathrm{Y}$ & Pope 1944; Bogert 1998 \\
\hline $\begin{array}{l}\text { Lithobates } \\
\text { sphenocephalus }\end{array}$ & Southern leopard frog & & Y & This study \\
\hline Lithobates sylvaticus & Wood frog & & $Y$ & Pope 1944; Stebbins 1962 \\
\hline $\begin{array}{l}\text { Osteopilus } \\
\text { septentrionalis }\end{array}$ & Cuban tree frog & & $\mathrm{N}$ & \\
\hline Pseudacris crucifer & Spring peeper & & $\mathrm{N}$ & \\
\hline
\end{tabular}




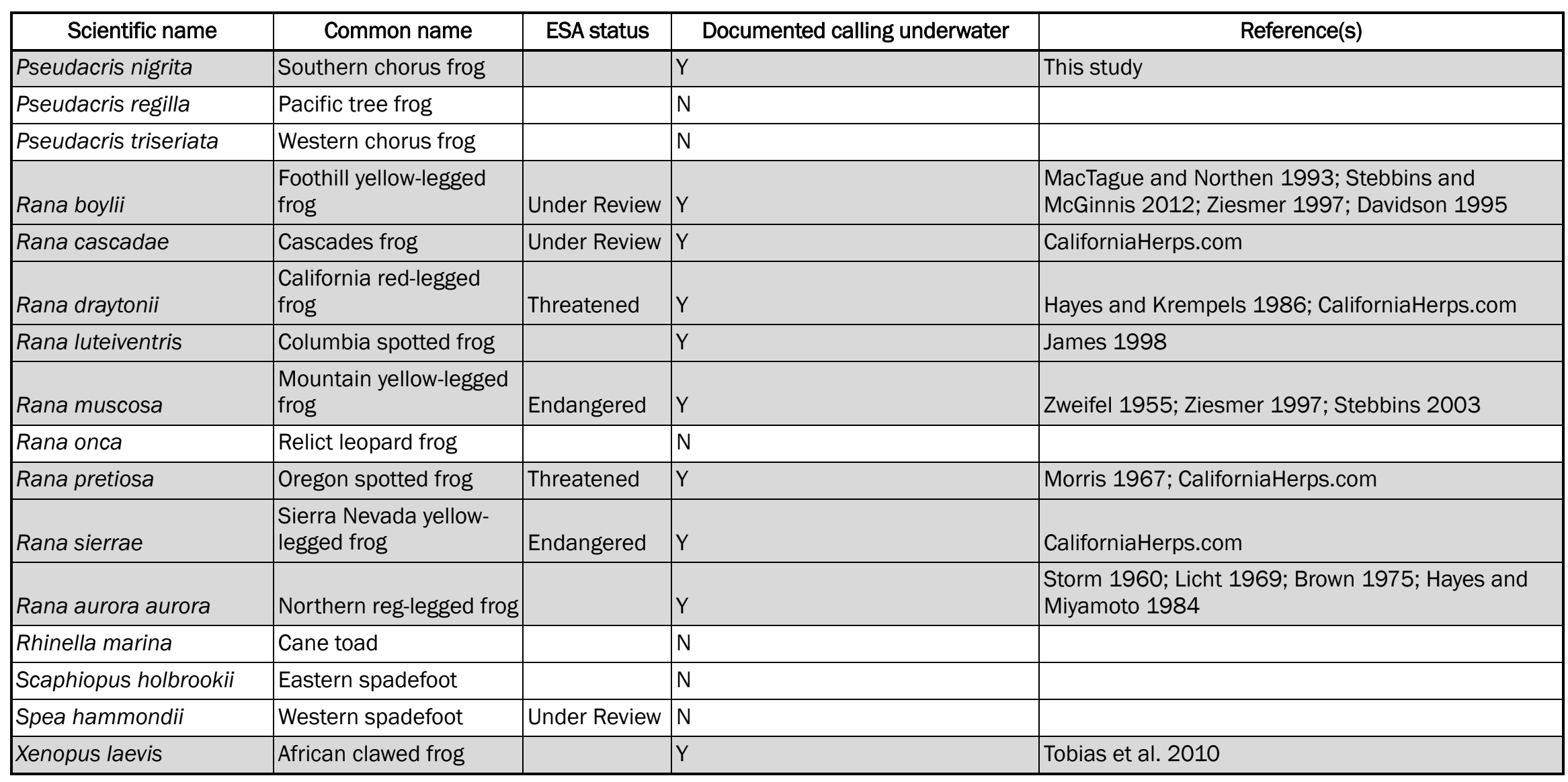




\section{REPORT DOCUMENTATION PAGE}

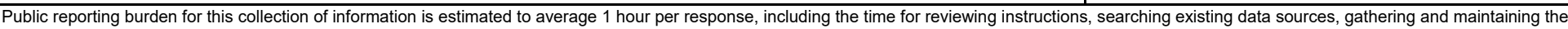

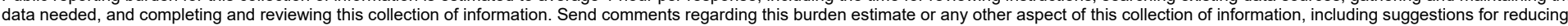

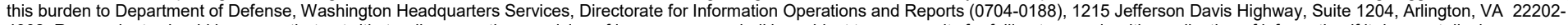

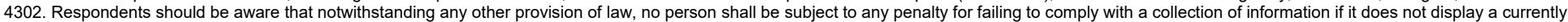
valid OMB control number. PLEASE DO NOT RETURN YOUR FORM TO THE ABOVE ADDRESS.
1. REPORT DATE (DD-MM-YYYY)
November 2021
2. REPORT TYPE
Final Technical Report (TR)
3. DATES COVERED (From - To)

\section{TITLE AND SUBTITLE}

Demonstration of Subsurface Passive Acoustic Monitoring (SPAM) to Survey for and Estimate Populations

of Imperiled Underwater-calling Frogs

5a. CONTRACT NUMBER

5b. GRANT NUMBER

5c. PROGRAM ELEMENT

6. AUTHOR(S)

Patrick J. Wolff, Brett A. DeGregorio, and Aaron N. Rice

5d. PROJECT NUMBER

5e. TASK NUMBER

5f. WORK UNIT NUMBER

\section{PERFORMING ORGANIZATION NAME(S) AND ADDRESS(ES)}

U.S. Army Engineer Research and Development Center (ERDC)

Construction Engineering Research Laboratory (CERL)

2902 Newmark Dr.

Champaign, IL 61822-9005

\section{SPONSORING / MONITORING AGENCY NAME(S) AND ADDRESS(ES)}

SERDP/ESTCP

480o Mark Center Drive, Suite 17Do8

Alexandria, VA 22350-3605

\section{DISTRIBUTION / AVAILABILITY STATEMENT}

Approved for public release; distribution is unlimited.

\section{SUPPLEMENTARY NOTES}

Funding provided by MIPRW74RDV93508403.

\section{ABSTRACT}

The management and recovery of threatened and endangered amphibians on Department of Defense (DoD) lands relies on an understanding of their distribution and abundance. Fortunately, most anuran species can be surveyed acoustically using vocalizations during the breeding season. This work demonstrated the use of subsurface passive acoustic monitoring (SPAM) to survey for rare underwater-calling, at-risk anuran species on DoD installations. We evaluated the performance of SPAM relative to traditional Passive acoustic monitoring (PAM) (microphone) and human manual calling survey (MCS) methods. Results showed that SPAM outperformed PAM and MCS in validation experiments where calls were generated underwater; SPAM was less successful than PAM and MCS in the field demonstration. Most leopard frog calls were apparently produced in air despite previous reports of extensive underwater-calling behavior. This project highlights how acoustic information can help address a data gap in the ecology of at-risk species, which can help refine future survey methodology and management efforts. Ultimately, the utility of SPAM for underwater-calling species will depend on the focal species, the landscape where it occurs, and technological considerations available to the surveyor. SPAM is more expensive than traditional methods but in some situations may be the only way to effectively detect species.

\section{SUBJECT TERMS}

Endangered species-Frogs, Animal population-Estimates, Environmental management, Wildlife conservation, Military bases, Passive acoustic monitoring, Bioacoustics, Detection probability

\begin{tabular}{|c|c|c|c|c|c|}
\hline 16. SECURITY C & IFICATION OF: & & $\begin{array}{l}\text { 17. LIMITATION } \\
\text { OF ABSTRACT }\end{array}$ & $\begin{array}{l}\text { 18. NUMBER } \\
\text { OF PAGES }\end{array}$ & 19a. NAME OF RESPONSIBLE PERSON \\
\hline $\begin{array}{l}\text { a. REPORT } \\
\text { Unclassified }\end{array}$ & $\begin{array}{l}\text { b. ABSTRACT } \\
\text { Unclassified }\end{array}$ & $\begin{array}{l}\text { c. THIS PAGE } \\
\text { Unclassified }\end{array}$ & SAR & 102 & $\begin{array}{c}\text { 19b. TELEPHONE NUMBER } \\
\text { (include area code) } \\
217-373-5847\end{array}$ \\
\hline
\end{tabular}

